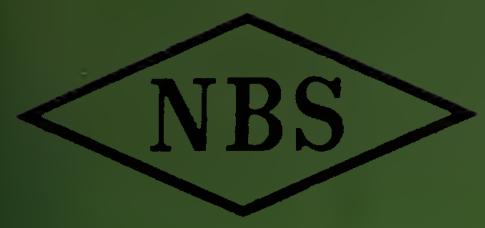

Eechnical Note No. 337

\title{
ADVANCES IN IONOSPHERIC MAPPING BY NUMERICAL METHODS
}

WILLIAM B. JONES, RONALD P. GRAHAM AND MARGO LEFTIN

U. S. DEPARTMENT OF COMMERCE

NATIONAL BUREAU OF STANDARDS 


\section{THE NATIONAL BUREAU OF STANDARDS}

The National Bureau of Standards is a principal focal point in the Federal Government for assuring maximum application of the physical and engineering sciences to the advancement of technology in industry and commerce. Its responsibilities include development and maintenance of the national stand. ards of measurement, and the provisions of means for making measurements consistent with those standards; determination of physical constants and properties of materials; development of methods for testing materials, mechanisms, and structures, and making such tests as may be necessary, particularly for government agencies; cooperation in the establishment of standard practices for incorporation in codes and specifications; advisory service to government agencies on scientific and technical problems; invention and development of devices to serve special needs of the Government; assistance to industry, business, and consumers in the development and acceptance of commercial standards and simplified trade practice recommendations; administration of programs in cooperation with United States business groups and standards organizations for the development of international standards of practice; and maintenance of a clearinghouse for the collection and dissemination of scientific, technical, and engineering information. The scope of the Bureau's activities is suggested in the following listing of its four Institutes and their organizational units.

Institute for Basic Standards. Electricity. Metrology. Heat. Radiation Physics. Mechanics. Applied Mathematics. Atomic Physics. Physical Chemistry. Laboratory Astrophysics.* Radio Standards Laboratory: Radio Standards Physics; Radio Standards Engineering. ** Office of Standard Reference Data.

Institute for Materials Research. Analytical Chemistry. Polymers. Metallurgy. Inorganic Materials. Reactor Radiations. Cryogenics. ${ }^{*}$ Office of Standard Reference Materials.

Central Radio Propagation Laboratory. * Ionosphere Research and Propagation. Troposphere and Space Telecommunications. Radio Systems. Upper Atmosphere and Space Physics.

Institute for Applied Technology. Textiles and Apparel Technology Center. Building Research. Industrial Equipment. Information Technology. Performance Test Development. Instrumentation. Transport Systems. Office of Technical Services. Office of Weights and Measures. Office of Engineering Standards. Office of Industrial Services.

* NBS Group, Joint Institute for Laboratory Astrophysics at the University of Colorado.

** Located at Boulder, Colorado. 


\title{
NATIONAL BUREAU OF STANDARDS Eechnical Note 337 ISSUED May 12, 1966
}

\author{
ADVANCES IN IONOSPHERIC MAPPING \\ BY NUMERICAL METHODS
}

\author{
William B. Jones, Ronald P. Graham and Margo Leftin \\ Institute for Telecommunication Sciences and Aeronomy* \\ Environmental Science Services Administration \\ Boulder, Colorado
}

\begin{abstract}
NBS Technical Notes are designed to supplement the Bureau's regular publications program. They provide a means for making available scientific data that are of transient or limited interest. Technical Notes may be listed or referred to in the open literature.
\end{abstract}

\footnotetext{
*Formerly the Central Radio Propagation Laboratory of the National Bureau of Standards. $C R P L$ was transferred to ESSA in October 1965 , but will temporarily use NBS publication series pending inauguration of their ESSA counterparts.
}

For sale by the Superintendent of Documents, U. S. Government Printing Office

Washington, D.C. 20402

Price: $45 \$$ 



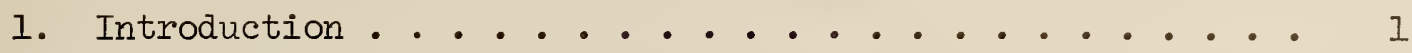

2. Screen Analysis ............... 4

3. Second Analysis .................. 16

3.1 Geographic Variation ........... 17

3.2 Diurnal Variation ............. 22

4. Comparison of Different Analyses . . . . . . . 28

5. Application of Numerical Maps .......... 31

5.I Simplified Expression of $\Omega(\lambda, \theta, T) \ldots . . . .3 I$

5.2 Calculation of Magnetic Dip I. . . . . . . 36

5.3 Fortran Program ................. 38

6. References .................... 44

Appendix A Fourier Coefficients for foF2 Monthly Median . . 47

Appendix B Contour Maps of Orthonormal Functions . . . . 57

Appendix C Diurnal Variation of Orthonormal Coefficients $d_{k} 63$

Appendix D SAMPLE Program Listing ......... 68 

ADVANCES IN IONOSPHERIC MAPPING BY NUMERICAL METHODS

by

William B. Jones, Ronald P. Graham and Margo Leftin

Paper describes recent progress made at ITSA (formerly CRPL) to improve numerical methods for mapping and predicting ionospheric characteristics used in telecommunication. Two major problems are considered: ( 1 ) tendency of maps to smooth out physical properties of the ionosphere, particularly at low latitudes and (2) ambiguous values at geographic poles and resulting distortions in immediate surroundings. The second problem is overcome by means of a universal time analysis. Significant improvement is made in the first problem by the use of a modified magnetic dip coordinate. A general description is given of the new procedures for forming numerical maps, including a number of illustrations. Also included are a discussion ot the use of numerical maps in the revised form and a Fortran Program for evaluating numerical maps of ionospheric characteristics and for calculating the $\mathrm{MUF}(\mathrm{ZERO}) \mathrm{F} 2$ and MUF( 4000$) \mathrm{F} 2$.

\section{Introduction}

In recent years the Institute for Telecommunication Sciences and Aeronomy (formerly the Central Radio Propagation Laboratory) has been engaged in the development of numerical methods and computer programs for mapping and predicting characteristics of the ionosphere used in telecommunication. Work along these lines was initiated prior to the International Geophysical Year, with the first descriptive publication appearing in the Telecommunication Journal [Jones and Gallet, 1960].

Since that time numerous technical papers have been written to describe the further advances in: (a) methods for data analysis and representation of ionospheric characteristics [Jones, 1962; Jones and Gallet, 1962a, 1965a, 1965b], (b) methods for applying numerical maps of ionospheric characteristics [Jones and Gallet, 1962b], and 
(c) development of computer programs associated with this work [Hinds and Jones, 1963]. The methods described in the preceding references have been used as the basis for a number of applications in ionospheric predictions: see for example [Haydon and Lucas, in publication; Lucas and Haydon, in publication; Davies, 1965]. In January 1963 the methods were adopted for producing Ionospheric Predictions [ITSA], issued monthly by the Institute for Telecommunication Sciences and Aeronomy (formerly CRPL) as an aid to determining the best sky wave frequencies over any transmission path, at any time of day, for average monthly conditions.

Although the previous work on ionospheric mapping (referred to above) has overcome many of the basic mapping problems and produced numerical representations and predictions of ionospheric characteristics which are useful and acceptable for many purposes, it was recognized [Jones and Gallet, 1962a, 1962b, 1965a] that there remained certain weaknesses in numerical methods of mapping which would eventually need further work. The present paper is concerned with recent efforts focused on two such problem areas: (1) a tendency of the maps to smooth out certain physical properties of the ionosphere, particularly at low latitudes, and (2) the presence of ambiguous values in the maps at geographic poles, resulting from a local mean time analysis. The second problem has been overcome by means of an analysis in universal time. Evidence of the first problem is found in residuals (between actual data and computed values) which are above the level of noise inherent in ionospheric measurements. Significant progress in this 
area has been achieved by taking into account more explicitly the relationship between ionospheric characteristics and the magnetic field. Previous studies ${ }^{1}$ have indicated the dependence of the ionosphere on the magnetic field, particularly at low latitudes.

The revised methods and programs described in this paper have been used to produce a provisional Atlas of Ionospheric Characteristics for consideration at the 12th Plenary Assembly of CCIR to be held at Oslo, Norway, June 1966. For this Atlas, two characteristics have been analyzed: monthly median of the F2 layer critical frequency (foF2) for all months of the five year period extending from 1954 through 1958, and monthly median of $\mathrm{M}(3000) \mathrm{F} 2$ for all months of 1954 and 1958. The revised method will also soon be used as the basis for ITSA Ionospheric Predictions.

The intention of the present paper is to give a general description of the new procedures for ionospheric mapping, with emphasis on illustrating various main steps by means of graphs, maps, and tables. Also included are: (1) a comparison of results from two different types of analyses, (2) a careful discussion of how to apply numerical maps of ionospheric characteristics in their present (revised) form and (3) a FORTRAN program for evaluating numerical maps of ionospheric characteristics and for calculating MUF(ZERO)F2 and MUF(4000)F2 (Appendix D). By way of illustration we have used only the characteristic, foF? median, since it is the most interesting and important for telecommunication.

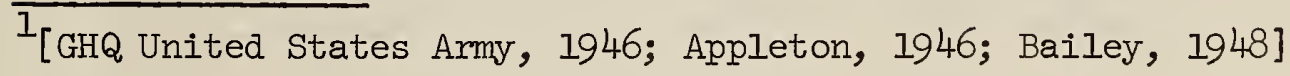




\section{Screen Analysis}

As in the previous paper by Jones and Gallet [1965a] the numerical mapping procedures described here involve two principal analyses of the data, both performed in one pass on the computer. First, a so-called "screen analysis" is made of available A- and B-data to produce approximate values of the ionospheric characteristic (called "C-data") at carefully chosen locations ("screen points") in large regions, such as oceans, where no stations are available. These regions will be called the critical areas. The C-data are then combined with the original Aand B-data in forming a second (and final) analysis. The purpose of C-data, discussed at length in the preceding reference, is to control instabilities in the maps, which tend to develop in the critical areas.

The screen analysis is started by Fourier analyzing the monthly medians of foF2 for each station for the 24 hours of the day. Thus the diumal variation at each place is decomposed into eleven harmonics

$$
a_{j} \cos j t+b_{j} \sin j t=c_{j} \cos \left(j t-\psi_{j}\right), 1 \leqq j \leqq 11,
$$

and a constant term $a_{0}$ which is the arithmetic mean of the 24 medians $^{2}$. Here $t$ denotes the local mean hour angle $\left(-180^{\circ} \leqq t \leqq 180^{\circ}, t=0^{\circ}\right.$ at noon LMT). Each harmonic is defined by an amplitude $c_{j}$ and phase $\psi_{j}$,

\footnotetext{
The terms A- and B-data are defined in the above references. In short, A-data refer to measurements at stations taken during the actual month in question. B-data refer to values of the characteristic obtained from interpolation or extrapolation in time at a station which did not report data for the specific month in question but was active for a period of time before or after. B-data are used to fill gaps where A-data are not available (Fig. 1).

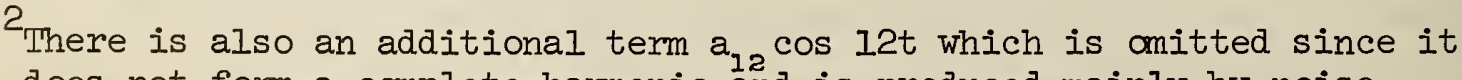
does not form a complete harmonic and is produced mainly by noise.
} 
Figure 1

MAP OF IONOSPHERIC STATIONS (MARCH 1958)

(SCREEN POINTS SELECTED FOR GEOGRAPHIC LATITUDE DISTRIBUTION)

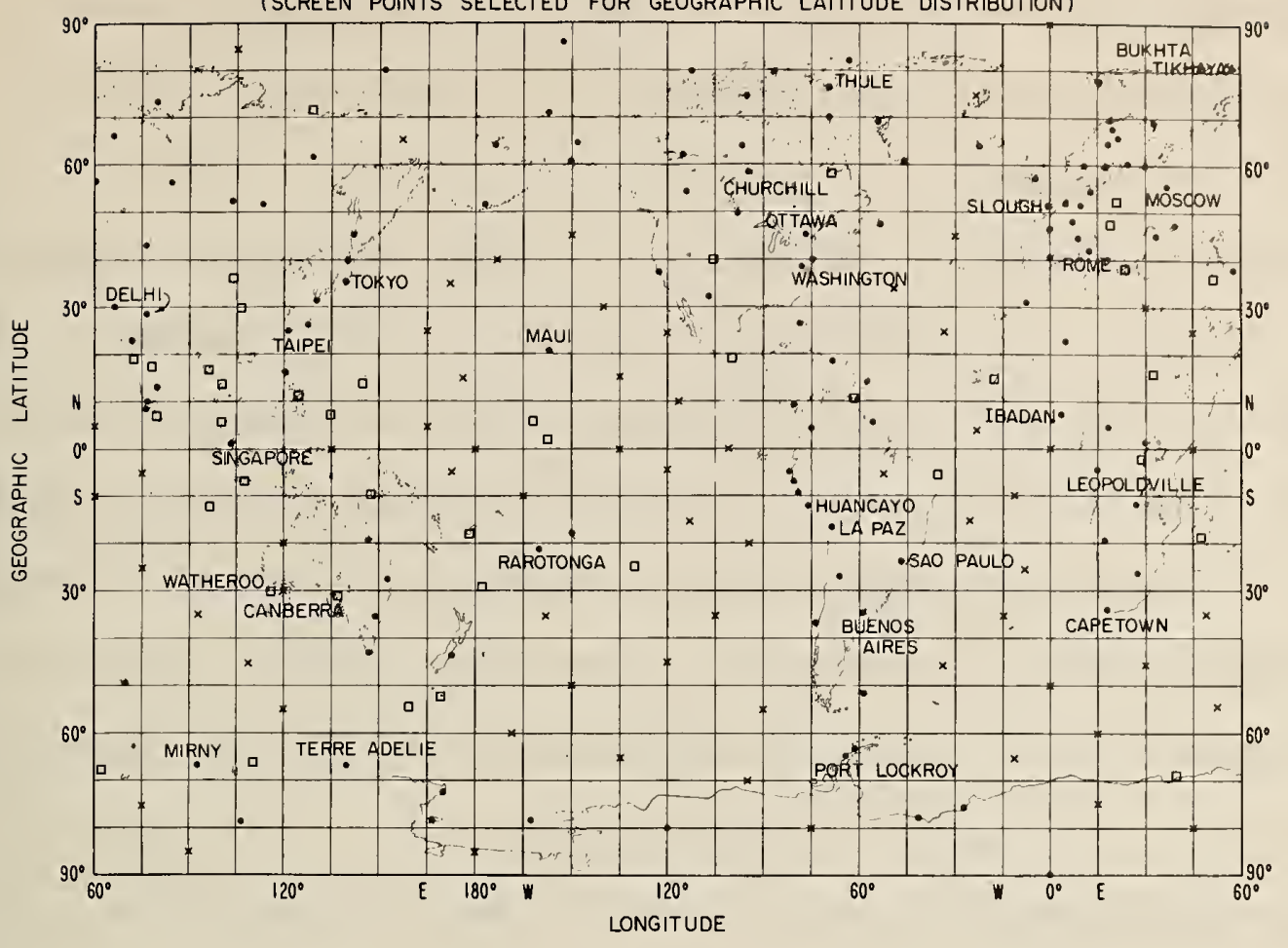

MAP OF IONOSPHERIC STATIONS (MARCH 1958)

(SCREEN POINTS SELECTED FOR MODIFIED DIP $X$ DISTRIBUTION)

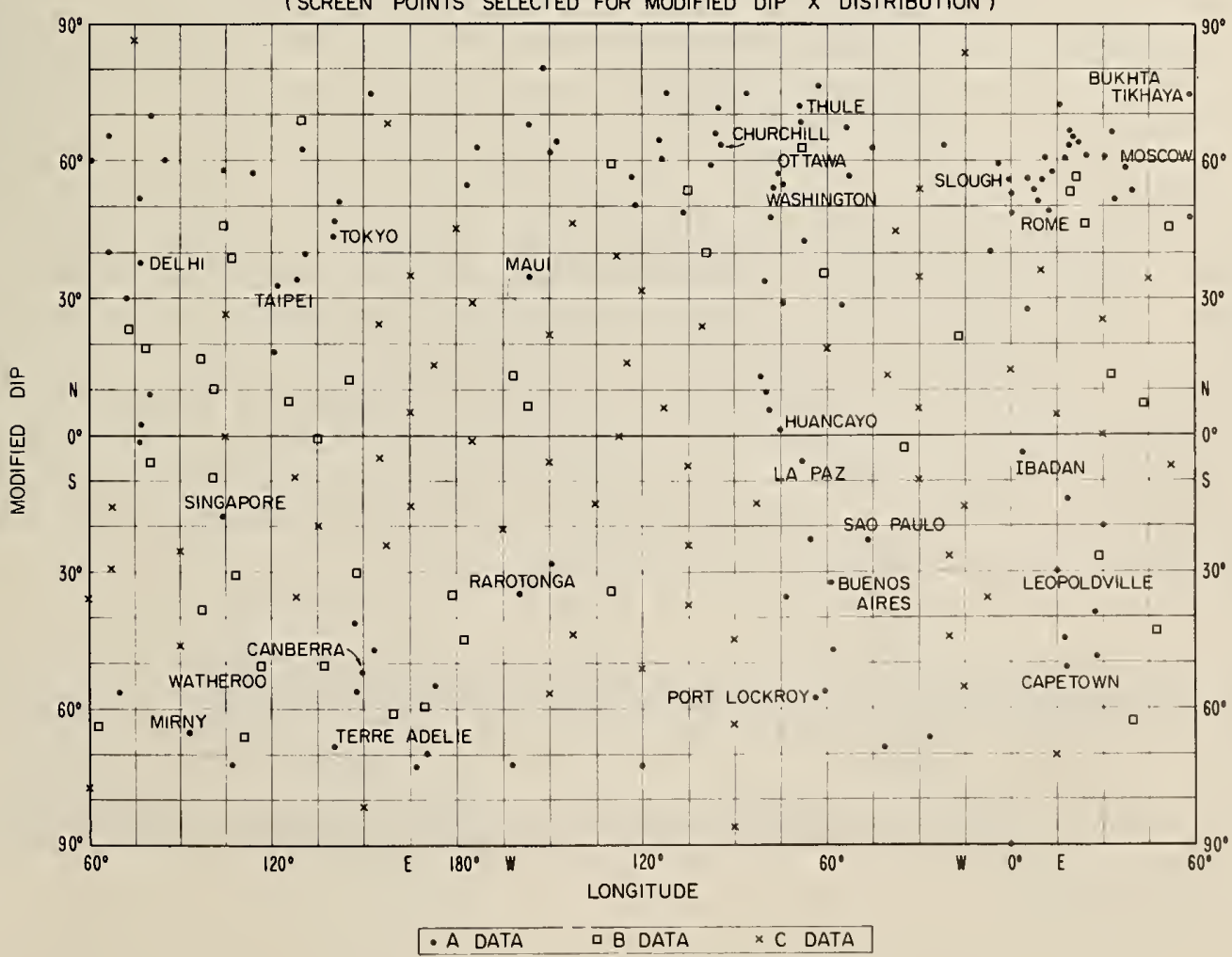


equivalently, by cosine and sine coefficients $a_{j}$ and $b_{j}$, respectively. Harmonics above the eighth order are dropped since they are produced more by noise than by real physical variation [ Jones, 1962; Jones and Gallet, 1962a and 1965b ].

Basically, the purpose of the screen analysis is to reduce the major part of the two-dimensional geographic variation of each Fourier coefficient $a_{j}$ and $b_{j}(j \leqq 8)$ to that of a single variable $x$, which in general may be a function of both geographic latitude $\lambda$ and Iongitude $\theta$. Since there will be no large gaps in the distribution of stations in the one dimension of $\mathrm{x}$, an approximate representation of the ionospheric characteristic can be obtained as a function of $\mathrm{x}$ without the danger of instability. Accordingly, the Fourier coefficients $a_{j}$ and $b_{j}$ are represented geographically (to a first approximation) by a series of the form

$$
\sum_{k=0}^{K} D_{k} G_{k}(x)
$$

where the functions $G_{k}(x)$ may be powers of $x$ or $\sin x$, or some other functions. The coefficients $D_{k}$ are determined by the method of least squares and the cutoff $K$ is made (by the computer) using a Student's $t$ test [Jones and Gallet, 1962a]. Thus the approximate representation of the ionospheric characteristic has the form

$$
\Gamma(x, t)=a_{0}(x)+\sum_{j=I}^{8}\left[a_{j}(x) \cos j t+b_{j}(x) \sin j t\right],
$$

where $a_{j}(x)$ and $b_{j}(x)$ represent the Fourier coefficients as functions of $x$ in the form (2). 
In previous work [Jones and Gallet, 1965a] the variable $\mathrm{x}$ was taken to be geographic latitude $\lambda$, and $\sin ^{k} \lambda$ was selected for the function $G_{k}(x)$. This choice of $G_{k}$ was justified by a study included in Jones and Gallet, [1962a]. Results from this method were reasonably good, since the Fourier coefficients $a_{j}$ and $b_{j}$ are adjusted to local mean time and hence their main geographic variation is latitudinal. The resulting errors in C-data were therefore due to neglected secondary effects of longitude and, to a lesser extent, noise inherent in the measurements. A quantity used to measure the error in C-data is the root mean square of residuals between A- and B-data and values computed by (3). Values of this quantity were given for a representative sample of months by Jones and Gallet [1965a].

One of the main aspects of the present study has centered around the question of finding a best (or at least better) choice of $\mathrm{x}$. Most of the work has been concentrated on variables related to the magnetic field, because of its strong effect on ionospheric characteristics. With geomagnetic latitude for the variable $\mathrm{x}$, no noticeable improvement was achieved. On the other hand, by taking $x$ to be the magnetic dip $I$, and certain simple modifications of I, significant reductions in residuals of the screen analysis have resulted ${ }^{1}$. This will be illustrated by comparing screen analyses of the same data using for $x$ the five variables: $\lambda$, $I$, and the following three modifications of I suggested by various workers ${ }^{2}$ :

\footnotetext{
$\overline{I_{\text {The functional }}}$ dependence of $I$ on $\lambda$ and $\theta$ will be defined in Section 5 , using results from the Jenson and Cain [1962] analysis of the magnetic field for epoch 1960.

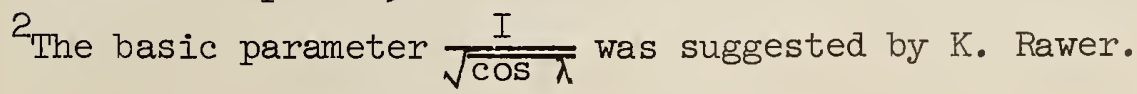




$$
\begin{aligned}
& x_{1}=\operatorname{Tan}^{-1}\left[\frac{I}{\sqrt{\cos \lambda}}\right], \\
& x_{2}=\operatorname{Tan}^{-1}\left[\frac{\tan I}{\sqrt{\cos \lambda}}\right], \\
& x_{3}=\operatorname{Tan}^{-1}\left[\frac{\tan I}{\sqrt{\cos (\lambda-\delta)}}\right],
\end{aligned}
$$

where $\delta$ denotes solar declination ${ }^{I}$. In each analysis $G_{k}(x)=\sin ^{k} x$ was used with a maximum possible value of 12 for the degree $\mathrm{K}$.

The root mean square (RMS) of residuals between foF' medians ( $A$ - and B-data) and values computed from (3) for all hours and all stations ${ }^{2}$ are given in Table 1, for four seasonal months of the high and low years of solar activity 1958 and 1954. From these results may be seen a strong improvement with the use of I compared with $\lambda$, for all months except June, at which time the difference is insignificant. In addition, the modified variables $x_{1}, x_{2}, x_{3}$ give some improvement over $I$, particularly during high solar activity (1958). Although the difference between values of the RMS residual obtained using $x_{1}, x_{2}$ and $x_{3}$ is small, the values for $x_{1}$ appear slightly smaller in most months. Hence $x_{1}$ was selected as the best geographic variable for the screen analysis.

${ }^{1}$ Here, as throughout the text, we use $\operatorname{Tan}^{-1}$ to denote the principal value $\mathrm{v}$ of the arctangent such that $-90^{\circ} \leqq \mathrm{v} \leqq 90^{\circ}$.

2 The approximate numbers of stations with $A$ - and B-data for each month are given in Table 6 . 
Table 1

RMS Residuals (Mc/s) from Screen Analyses

of foF2 Medians

\begin{tabular}{|c|c|c|c|c|c|c|c|c|}
\cline { 2 - 9 } \multicolumn{1}{c|}{} & \multicolumn{4}{c|}{1954} & \multicolumn{4}{c|}{1958} \\
\hline Variable $(\mathrm{x})$ & Mar. & June & Sept. & Dec. & Mar. & June & Sept. & Dec. \\
\hline$\lambda$ & .85 & .68 & .80 & .78 & 1.41 & 1.25 & 1.35 & 1.31 \\
\hline$I$ & .65 & .69 & .68 & .69 & 1.06 & 1.24 & 1.00 & 1.08 \\
\hline$x_{1}$ & .62 & .63 & .65 & .67 & .97 & 1.08 & .95 & 1.02 \\
\hline$x_{2}$ & .61 & .65 & .65 & .68 & .98 & 1.12 & .95 & 1.05 \\
\hline$x_{3}$ & .62 & .64 & .65 & .70 & .98 & 1.14 & .95 & 1.19 \\
\hline
\end{tabular}

( $\lambda$ = geographic latitude, $\quad I$ = magnetic dip,

$x_{1}, x_{2}$, and $x_{3}$ are modified forms of $I_{\text {.) }}$

In the sequel $x_{1}$ will be the only modified form of $I$ used; hence from this point on we shall drop the subscript and write $x_{1}$ as merely $x$. To help understand the difference between $\mathrm{x}$ and $\mathrm{I}$, contour maps of these two quantities are shown in figure 2. The main difference occurs in the higher latitudes. At low latitudes $x$ is quite similar to $I$, but at high latitudes it tends to behave more as geographic latitude $\lambda$. Thus, in a sense, $x$ combines certain characteristics of both $I$ and $\lambda$. Perhaps this accounts for the superiority of $\mathrm{x}$ over $\lambda$ and $I$ as the geographic variable.

A study of the distribution of Fourier coefficients $a_{j}$ and $b_{j}$, relative to the various geographic variables considered above, throws much light on the significance of Table 1 and helps explain the advantages of certain choices of the geographic variable over others. As an example, 
Figure 2

MAGNETIC DIP

EPOCH 1960 HEIGHT $300 \mathrm{~km}$

LONGITUDE

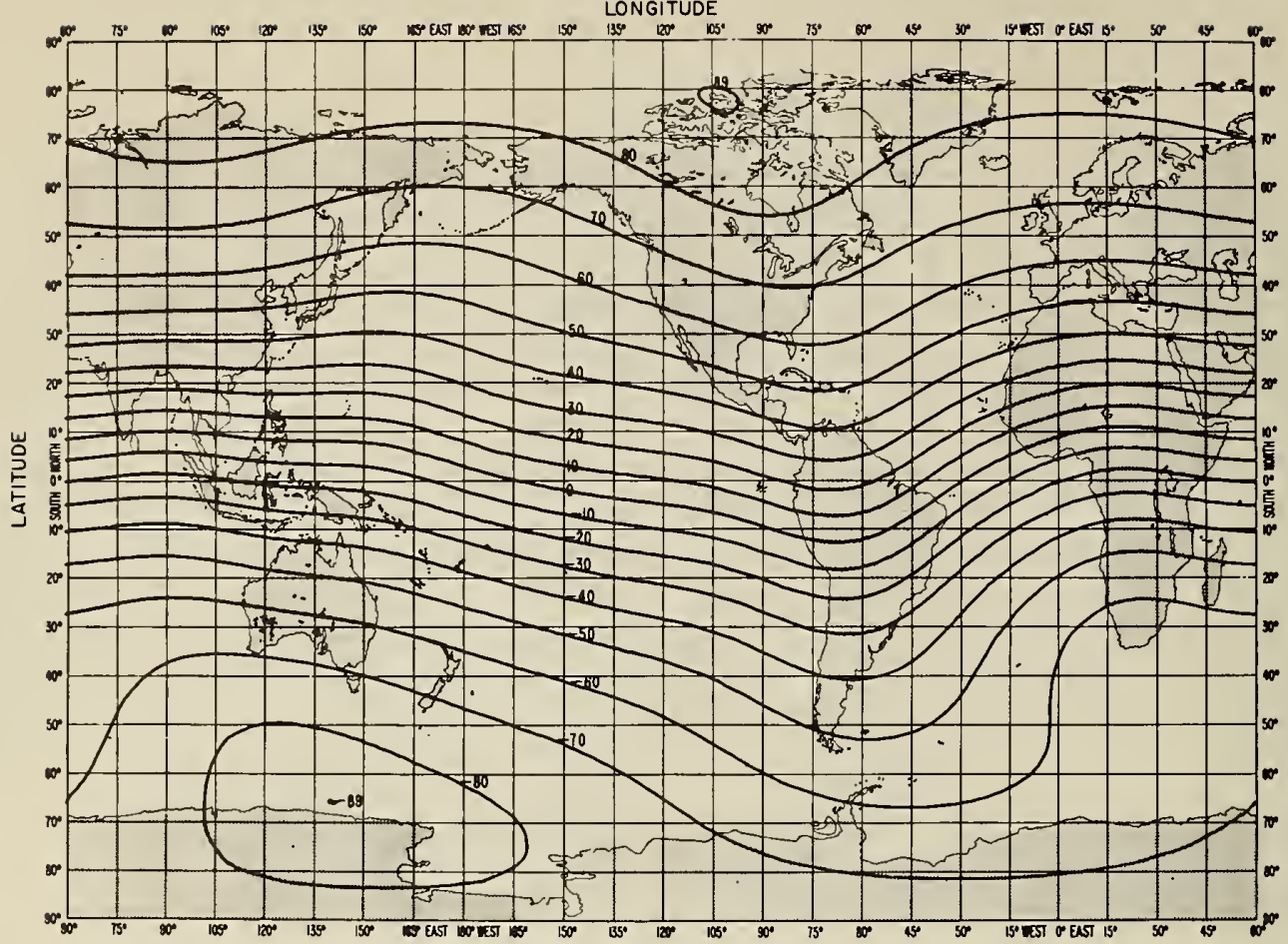

MODIFIED MAGNETIC DIP

EPOCH 1960 HEIGHT $300 \mathrm{~km}$

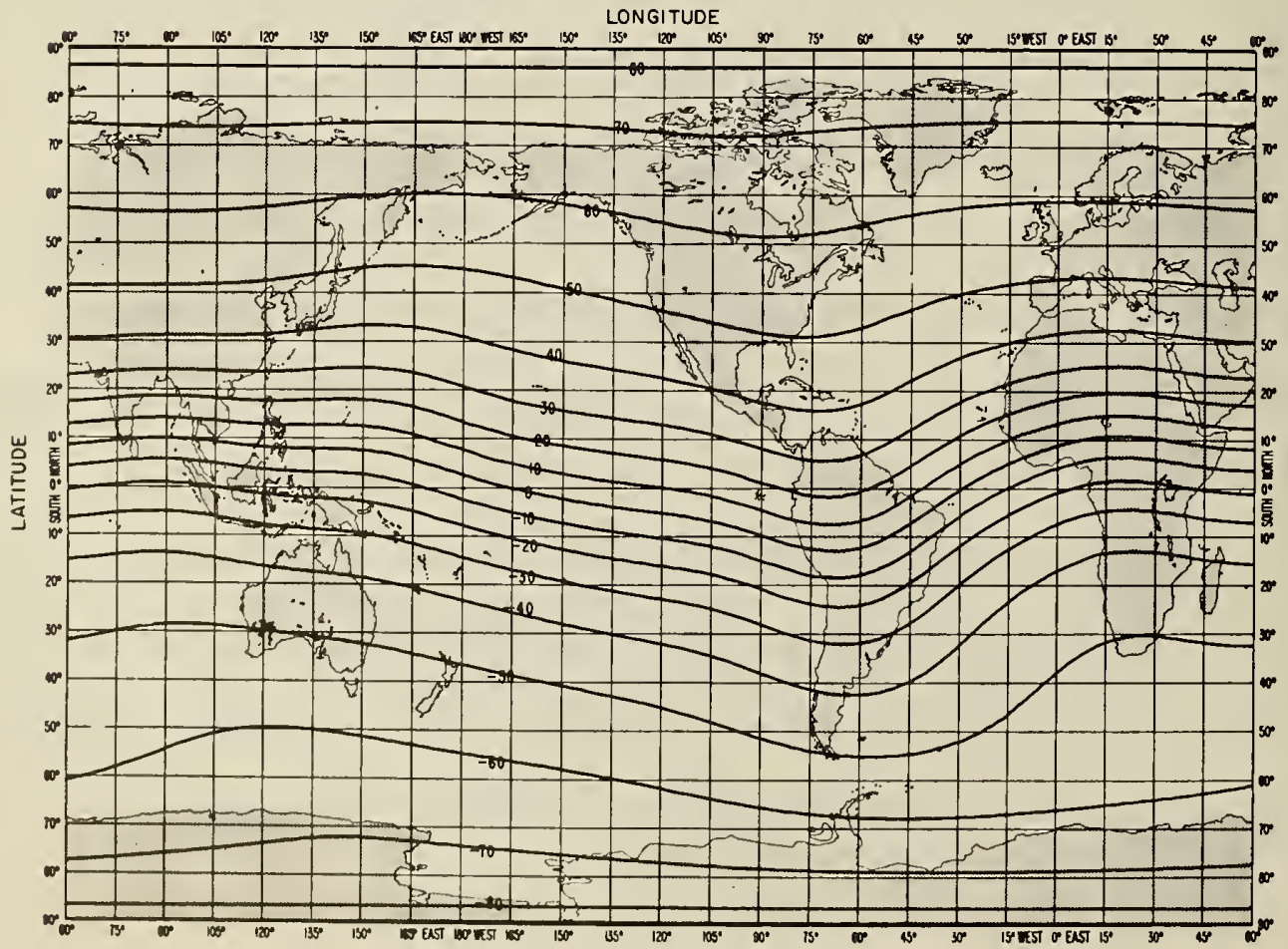


Figure 3 shows the distribution of $a_{0}$ (the arithmetic mean of the 24 hour medians of foF2) as a function of geographic latitude (top) and of the modified magnetic dip x (bottom) for March 1958. Here, as expected from previous studies, we find a remarkable simplification induced by the variable $x$. On each graph is shown the least square approximation of the form (2) discussed above. The graphs are made somewhat three-dimensional by the use of special plotting symbols to distinguish the approximate geographic longitudes of stations (see Longitudinal Code on each graph). From this it can be seen that the Fourier coefficients are not randomly dispersed about the least square curve; in certain intervals they are systematically grouped according to longitude. Similar illustrations for the coefficients $a_{j}$ and $b_{j}, j=1,2,3,4$, are contained in Appendix A. For the first two harmonics the advantage of $\mathrm{x}$ over $\lambda$ is seen to be comparable with that in the case of $a_{0}$. For higher harmonics the difference appears to be less noticeable.

From the standpoint of the screen analysis, the most important aspect of the distributions illustrated is the dispersion of the coefficients about the least square curves. Quantitatively, this dispersion is measured in terms of standard deviation of the residuals, an unbiased estimate of which is computed by

$$
e_{K}=\left[\frac{E_{K}}{N-K-1}\right]^{\frac{1}{2}}
$$

where $\mathrm{E}_{\mathrm{K}}$ denotes the sum of squares of the residuals, $\mathbb{N}$ is the number of stations with $A-$ or $B$-data, and $(N-K-I)$ is the number of degrees of freedom remaining after subtraction of 1 for each function in the series 
Figure 3

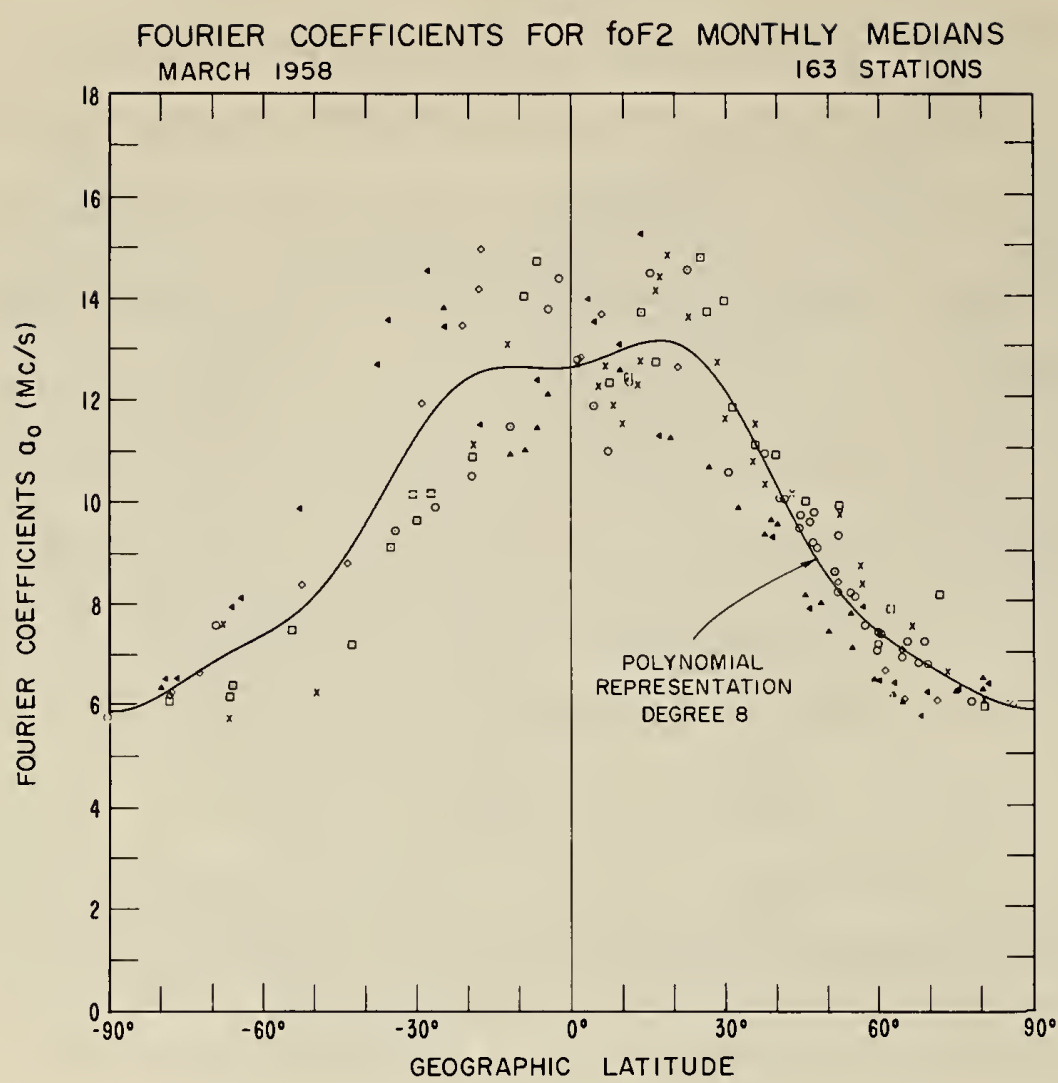

$a_{0}$

LONGITUDINAL CODE

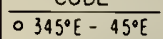

$\times 45^{\circ} \mathrm{E}-105^{\circ} \mathrm{E}$ - $105^{\circ} \mathrm{E}-165^{\circ} \mathrm{E}$

$\diamond 165^{\circ} \mathrm{E}-225^{\circ} \mathrm{E}$

$\triangle 225^{\circ} \mathrm{E}-285^{\circ} \mathrm{E}$

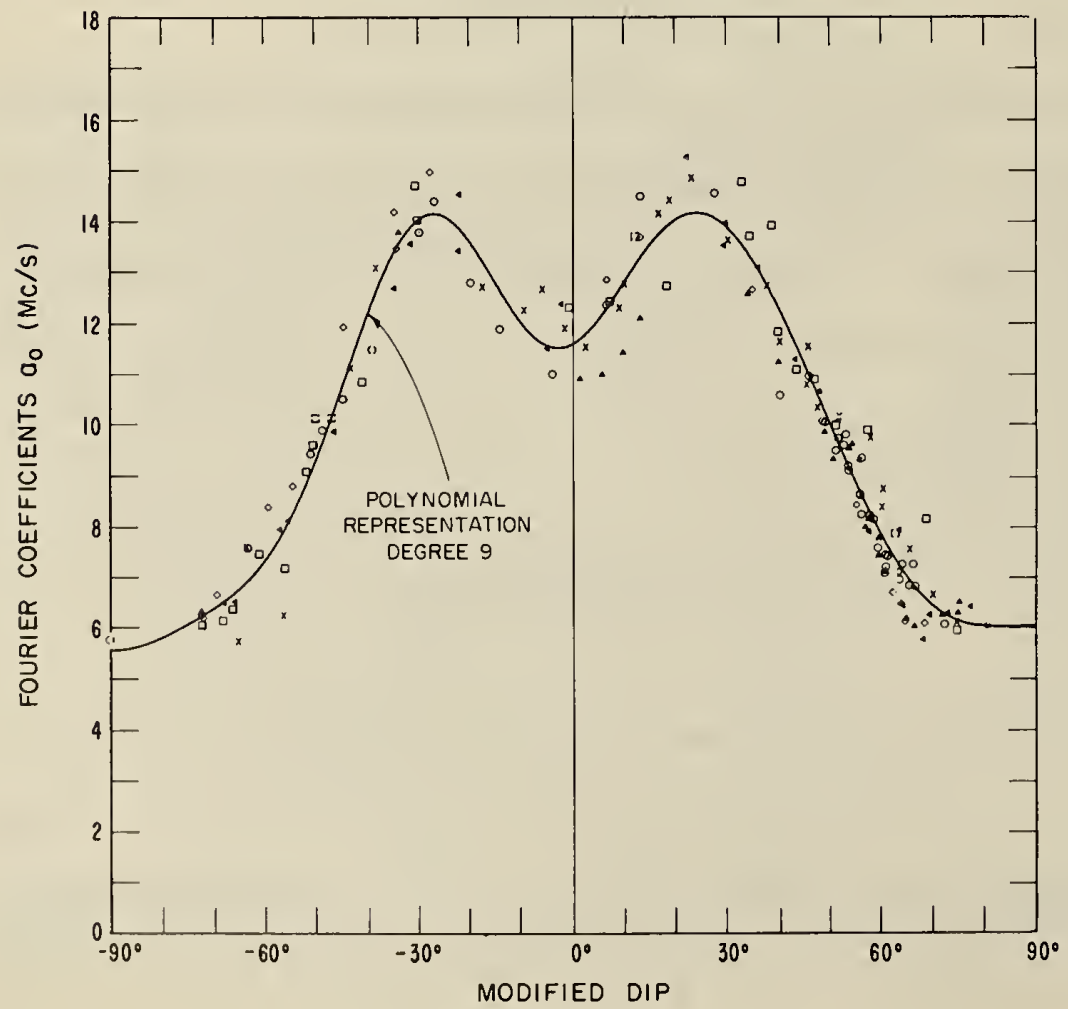

$\Delta 285^{\circ} \mathrm{E}-345^{\circ} \mathrm{E}$ 
(2). Values of $e_{K}$ are given in Table 2 for each Fourier coefficient through harmonic 4, March 1958, from analyses with $\lambda$ and with $\mathrm{x}$. The results shown in Table 2 are seen to agree with evidence brought out in the graphical illustrations: there is a great improvement from the use of $\mathrm{x}$ which lies mainly in the first two harmonics and the constant term $a_{0^{\circ}}$

Table 2

Standard Deviation of Residuals $e_{K}(\mathrm{Mc} / \mathrm{s})$ from Analyses of Fourier Coefficients for March 1958.

\begin{tabular}{|c|c|c|c|c|c|c|c|c|c|}
\hline Variable & $\mathrm{a}_{0}$ & $\mathrm{a}_{1}$ & $\mathrm{~b}_{1}$ & $\mathrm{a}_{2}$ & $\mathrm{~b}_{2}$ & $\mathrm{a}_{3}$ & $\mathrm{~b}_{3}$ & $\mathrm{a}_{4}$ & $\mathrm{~b}_{4}$ \\
\hline$\lambda$ & 1.09 & .75 & .74 & .42 & .43 & .23 & .23 & .13 & .13 \\
\hline $\mathrm{x}$ & .64 & .54 & .54 & .35 & .36 & .20 & .18 & .13 & .12 \\
\hline
\end{tabular}

( $\lambda$ = geographic latitude, $\mathrm{x}=$ modified magnetic dip)

As a final illustration of the screen analysis, figures 4 and 5 show maps of foF2 median for March 1958 computed from screen analysis representations of the form ( 3 ), using $\lambda$ (top) and $x$ (bottom) for the two hours U.T. = 06 and 18. As expected, the lower maps (from analysis with $\mathrm{x}$ ) give evidence of a strong connection with the magnetic field, whereas the upper maps (from analysis with $\lambda$ ) appear more symmetric with respect to the geographic equator. The lower maps represent a much greater degree of detail in the equatorial region. Attention is called to a further point illustrated by these maps: the presence of ambiguous values at the geographic poles. As an example, the lower map for U.T. = 18 has an 
Figure 4

MAPS OF fOF2 MEDIAN (MC/s) FROM SCREEN ANALYSIS
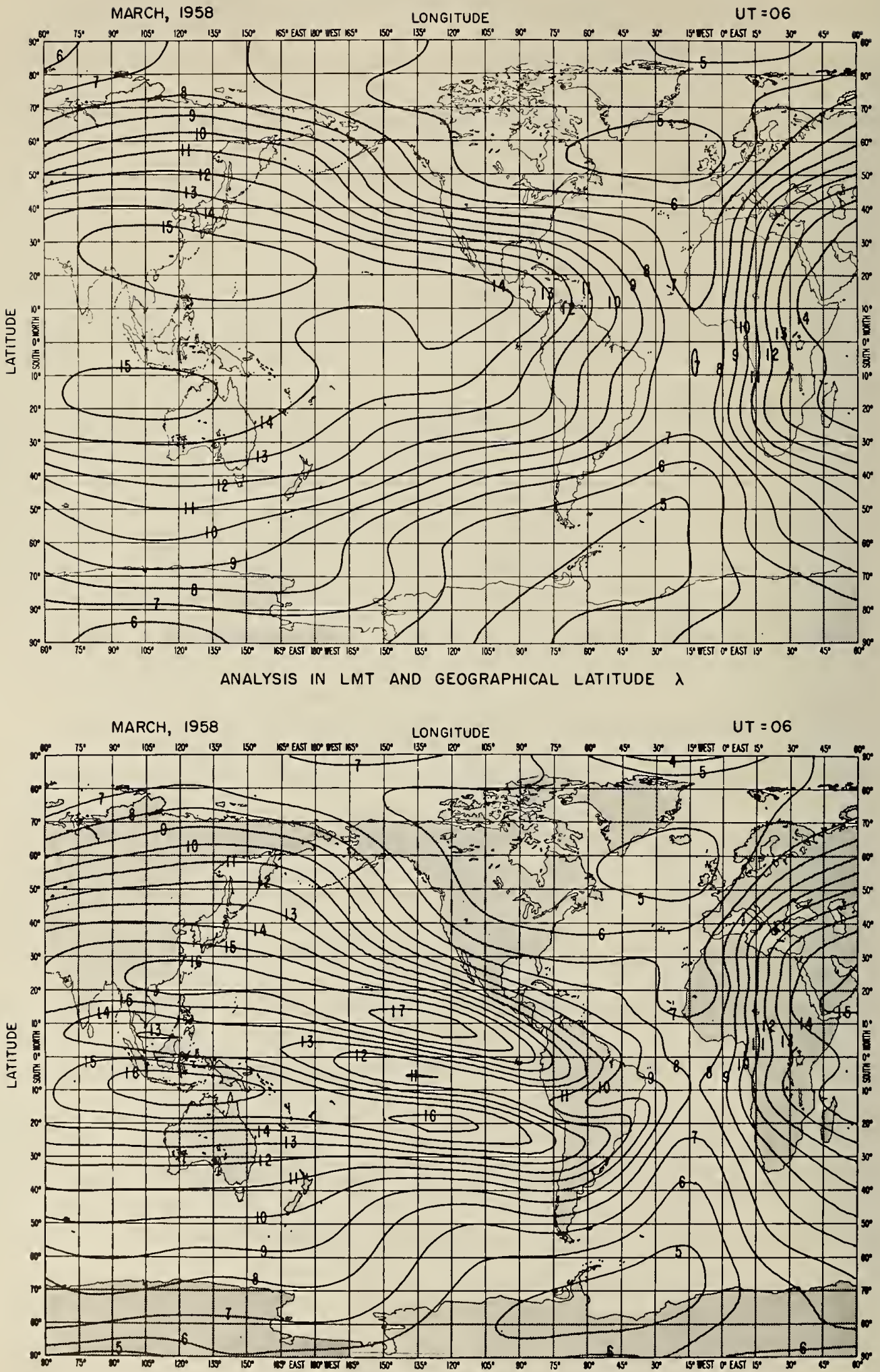

ANALYSIS IN LMT AND MODIFIED DIP $x$ 
Figure 5

MAPS OF FOF2 MEDIAN (MC/S) FROM SCREEN ANALYSIS

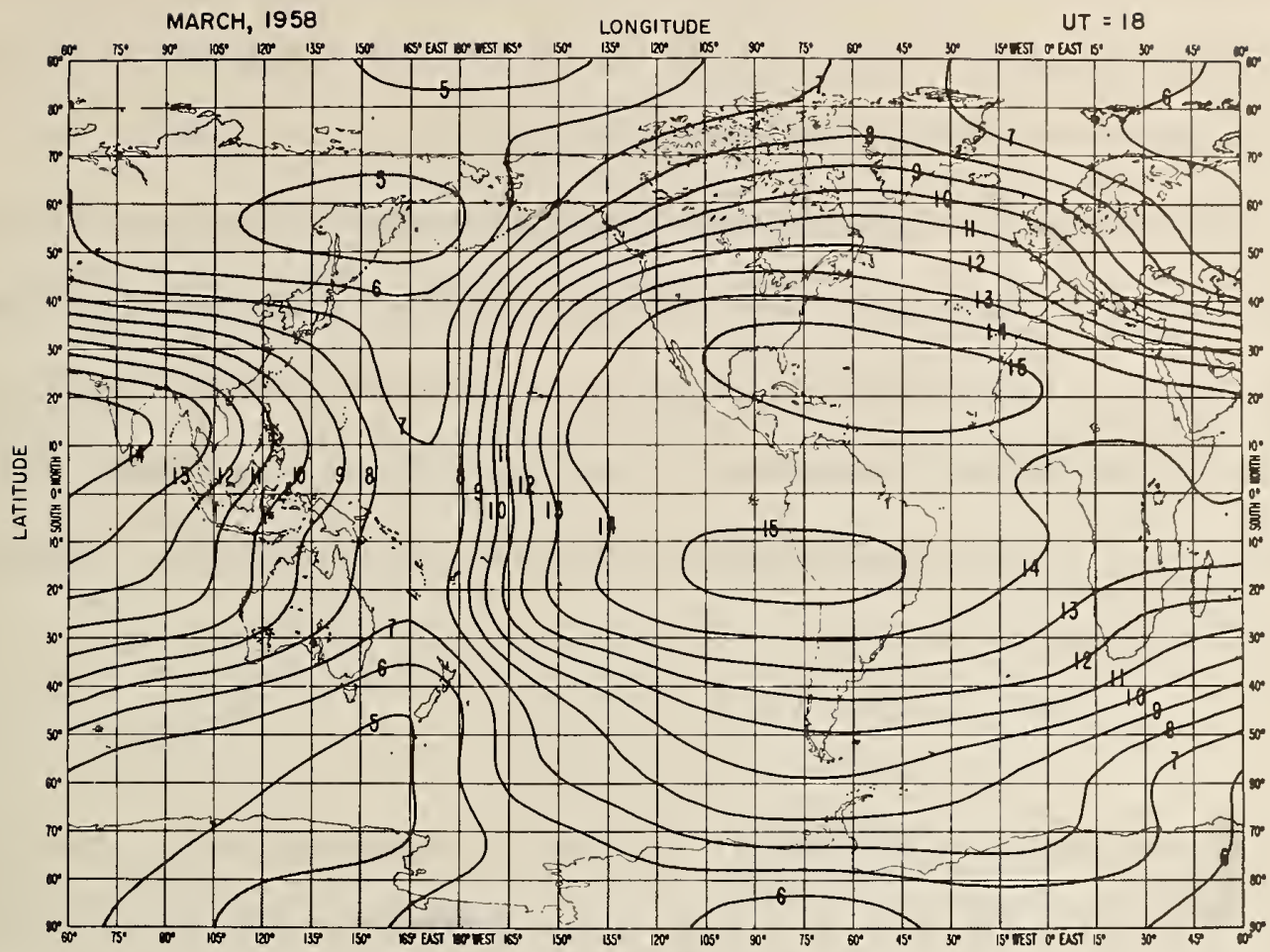

ANALYSIS IN LMT AND GEOGRAPHICAL LATITUDE $\lambda$

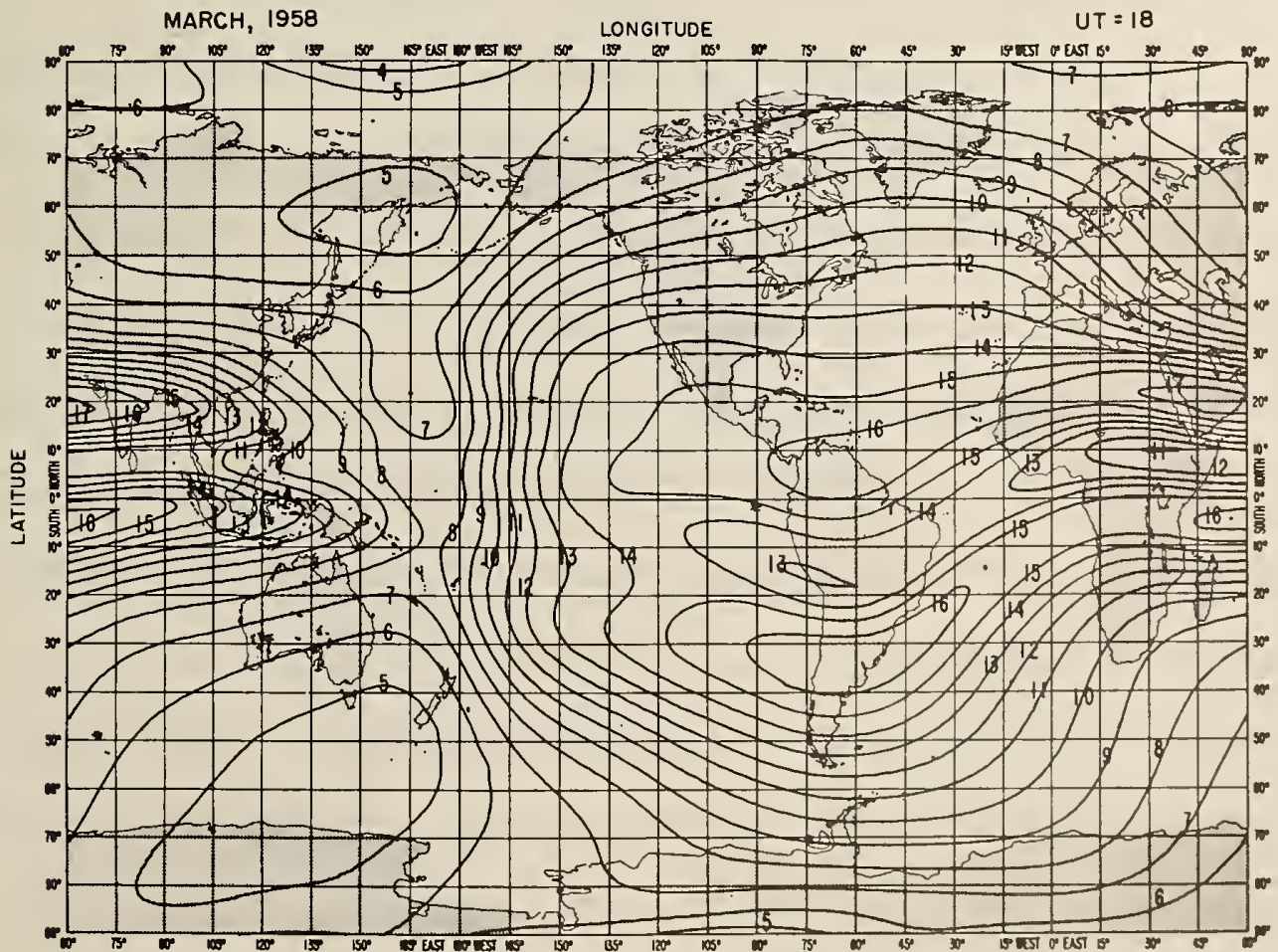

ANALYSIS IN LMT AND MODIFIED DIP $x$ 
interval of values from less than 4 to greater than $7 \mathrm{Mc} / \mathrm{s}$ at the North Pole. As mentioned in the introduction, the polar problem is a consequence of the analysis made in local mean time. It affects not only the poles but also produces distortion in small neighborhoods about them. The problem is not of great importance in the screen analysis, since the representation from the screen analysis is used only for defining C-data at screen points which are rarely needed in the close vicinity of the poles. The nature of the polar representation is important in the second analysis, however, and for that we have adopted the approach described in the following section.

\section{Second Analysis}

The second analysis is made of the combined set of A-, B-, and C-data. As a result, improvements in the screen analysis are carried over to the numerical map produced by the second analysis. The chief concern of this section is with basic differences in procedures for the second analysis described here and that described by Jones and Gallet [1965a]. The most important are the following: (I) reversal of the order of diurnal and geographic analyses, (2) geographic analyses of A-, B-, and C-data for fixed instants of universal time, (3) change in geographic functions to include explicit dependence on the modified magnetic dip $x$, as well as on $\lambda$ and $\theta$, and (4) diurnal analysis of orthonormal coefficients derived from the geographic analyses.

The use of modified magnetic dip $\mathrm{x}$ as a principal coordinate has resulted in a change in selecting screen points. As mentioned earlier, screen points are chosen to fill wide gaps in the distribution of stations 
where instabilities might develop. The use of $x$ and $\theta$ as principal coordinates (instead of $\lambda$ and $\theta$ ) has the effect of transforming the station distribution and hence of changing the shape and size of the gaps. Thus it is necessary to select different screen points from those used in previous analyses. As an illustration, the station distribution for March 1958 is shown in figure $l(a)$ in $(\lambda, \theta)$ coordinates and figure $l(b)$ in $(x, \theta)$ coordinates. The sets of screen points selected for the former distribution and for the transformed distributions are shown in the respective maps by the use of special plotting symbols (see captions). As in the previous case, the set of screen points changes very little from month to month.

\subsection{Geographic Variation}

The world-wide geographic variations of monthly median foF2 for each of 24 fixed hours of universal time (U.T. $=00,01, \ldots, 23$ ), are represented by series of the form

$$
\sum_{k=0}^{75} D_{k} G_{k}(\lambda, \theta),
$$

where the geographic functions $G_{k}(\lambda, \theta)$ are defined in Table 3. The coefficients $D_{k}$ are determined by the method of least squares using all available A-, B-, and C-data for the given hour. The modified magnetic $\operatorname{dip} x$ does not appear in the functional form $G_{k}(\lambda, \theta)$, since $x$ is itself a function of $\lambda$ and $\theta$ (see Section 5). The variable $\lambda$ has been retained in the weighting factors involving powers of $\cos \lambda$, in order to provide a continuous latitudinal variation of the weight factors and to annihilate 
Geographic Coordinate Functions $G_{k}(\lambda, \theta)$ for Analysis of foF2 Median ( $\lambda=$ geographic latitude, $\theta=$ geographic longitude, $x$ = modified magnetic dip)

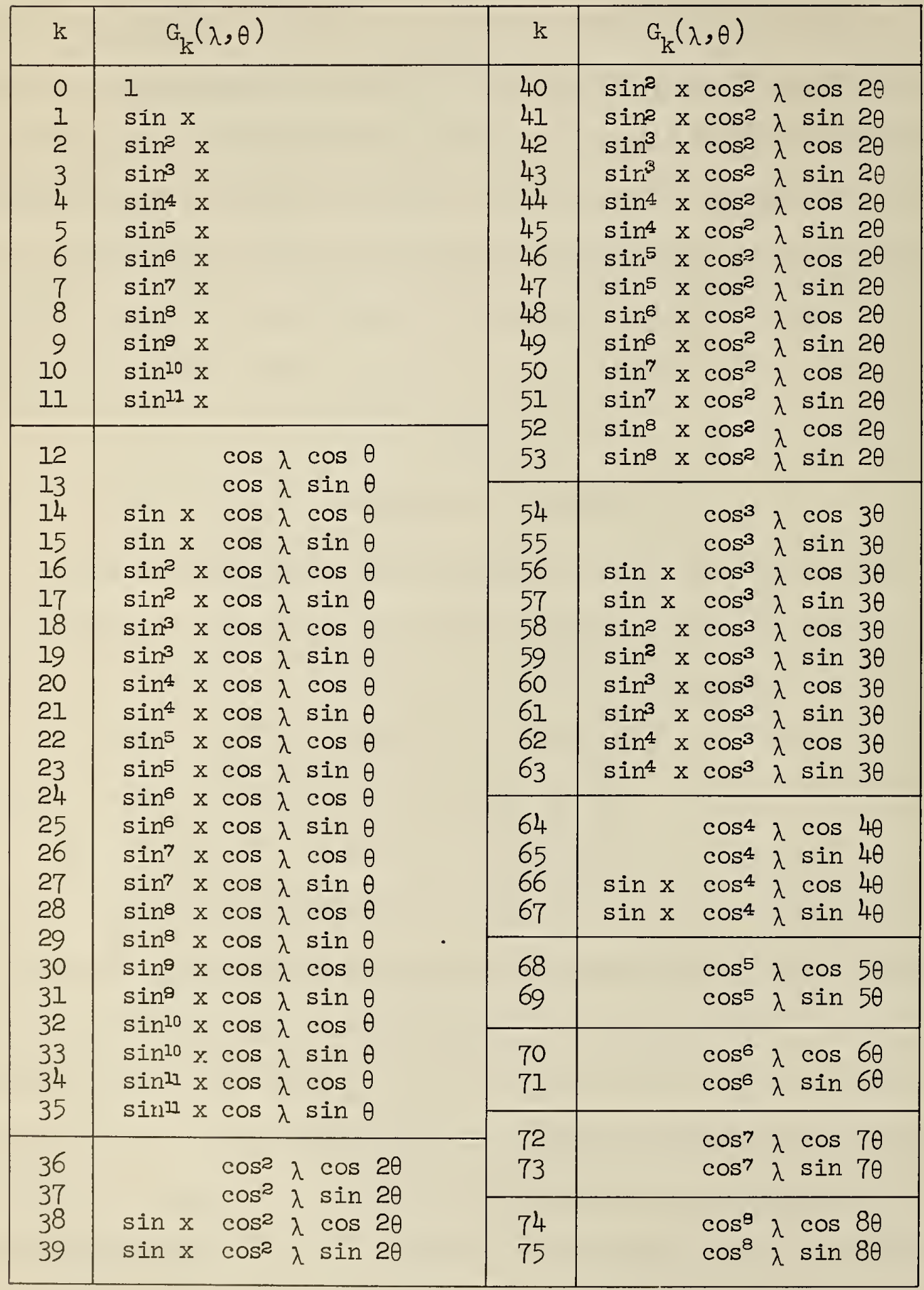


functions involving $\theta$, at the geographic poles. This prevents further ambiguous values at the poles. The variable $\mathrm{x}$ could also have been used in the weight factors, in place of $\lambda$, since $\cos x=0$, when $\lambda= \pm 90^{\circ}$. This change could be considered in future work, although its effect would perhaps be negligible.

In determining the least square approximations (8), a related set of orthonormal functions $\mathrm{F}_{\mathrm{k}}(\lambda, \theta)$ is formed as described by Jones and Gallet [1962a]. These functions are linear combinations of the $G_{k}(\lambda, \theta)$

$$
F_{k}(\lambda, \theta)=\sum_{j=1}^{k-1} a_{k j} F_{j}(\lambda, \theta)+d_{k k} G_{k}(\lambda, \theta),
$$

constructed so as to satisfy orthonormality conditions

$$
\sum_{i=1}^{\mathbb{N}} F_{k}\left(\lambda_{i}, \theta_{i}\right) F_{j}\left(\lambda_{i}, \theta_{i}\right)= \begin{cases}0 & k \neq j \\ 1 & k=j\end{cases}
$$

relative to the set of $\mathbb{N}$ positions $\left(\lambda_{i}, \theta_{i}\right)$ of ionospheric stations and screen points. Thus the least square approximations (8) are obtained by series of the form

$$
\sum_{k=0}^{75} a_{k} F_{k}(\lambda, \theta)
$$

in which the terms are mutually independent and can be tested individually for statistical significance. By an algebraic transformation, (II) can be converted to the form (8). The procedures for this transformation are described in the above reference, but in the present application our interest will be in the coefficient $d_{k}$. 
The choice of the highest degree in sin $x$ for each order of longitude $\theta$ shown in Table 3 has been made from studying tests of significance of the terms $a_{k} F_{k}(\lambda, \theta)$ in the series (11) for several typical hours in universal time from three seasonal months: March, June and December. For testing purposes, the powers of $\sin x$ (for each order of longitude $\theta$ ) were carried beyond those shown in Table 3, so that optimum cutoffs could be determined using the Student's t test [Jones and Gallet, 1962a], For example, in the case of zeroth order longitude, powers of $\sin x$ were carried out to degree 15, although degree 11 was the highest power used. Similar tests were made for the other orders of Iongitude. The studies showed that the optimum degree in $\sin x$ for a given order of longitude depends upon the hour of universal time, the month and the year. The highest degrees in sin $\mathrm{x}$ given by Table 3 are roughly the maxima of the optimum degrees for all hours and months tested. Thus, for a given hour and month, the series (II) may have terms which are not significant, and hence (1I) may not be as efficient as possible for that particular time. This situation has been brought about intentionally, however, in order to preserve uniformity in the representations. This procedure makes it possible to analyze the individual terms in (11) from hour to hour for the diurnal analysis. It is also useful for analyzing the individual terms of numerical maps from month to month for making long term predictions.

To gain insight into the nature of the approximations of the form (II) it is instructive to examine the graphs of the orthonormal functions $\mathrm{F}_{\mathrm{k}}(\lambda, \theta)$, given by contour maps. As an example, figure 6 shows the functions $F_{56}$ and $F_{57}$, whose leading terms $\left(G_{56}\right.$ and $\left.G_{57}\right)$ are the third 
Figure 6

CONTOUR MAP OF ORTHONORMAL FUNCTION $F_{56}(\lambda, \theta)$

(HIGHEST ORDER TERM $\sin x \cos ^{3} \lambda \cos 3 \theta$ )

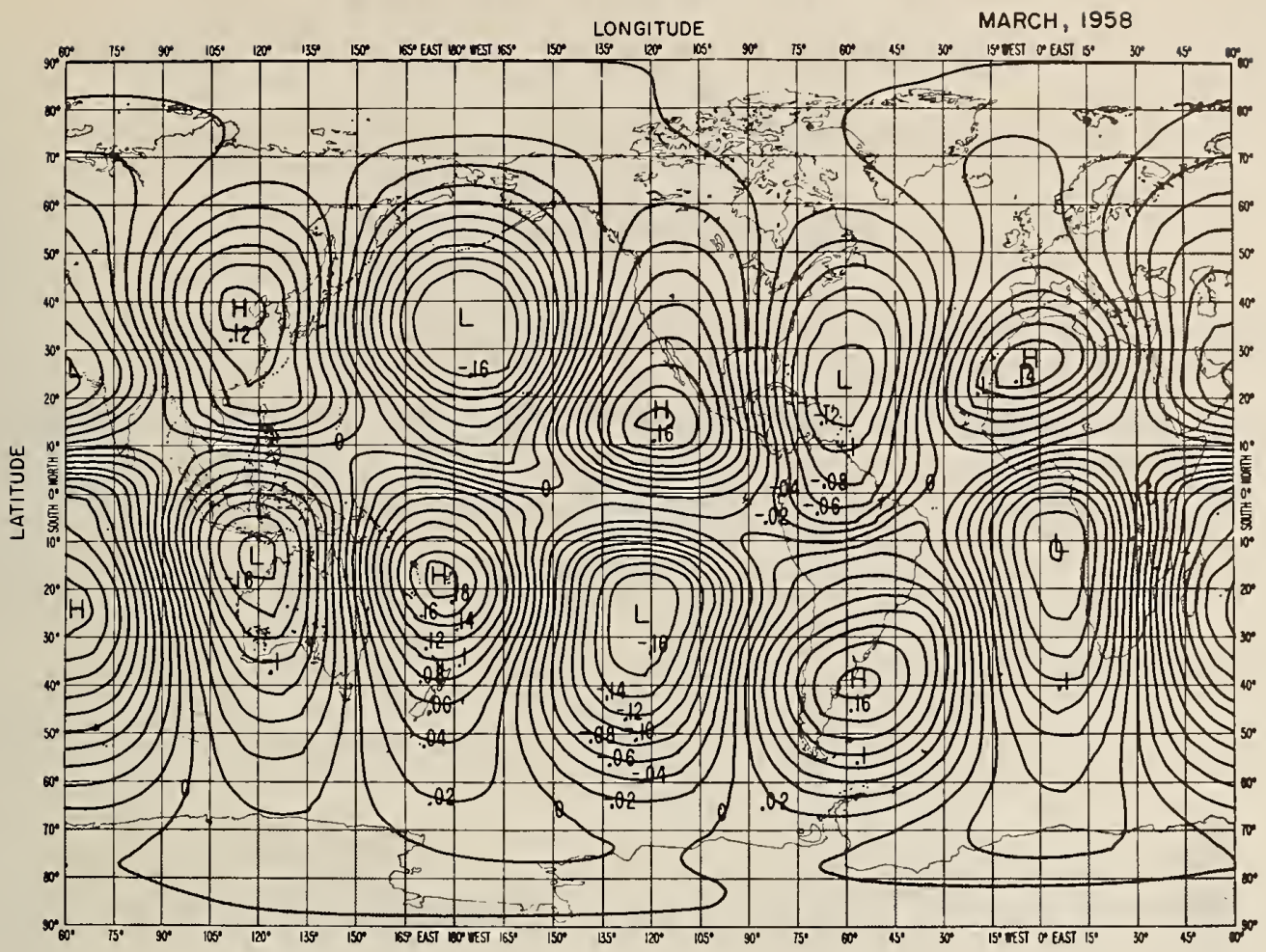

CONTOUR MAP OF ORTHONORMAL FUNCTION $F_{57}(\lambda, \theta)$

(HIGHEST ORDER TERM $\sin x \cos ^{3} \lambda \sin 3 \theta$ )

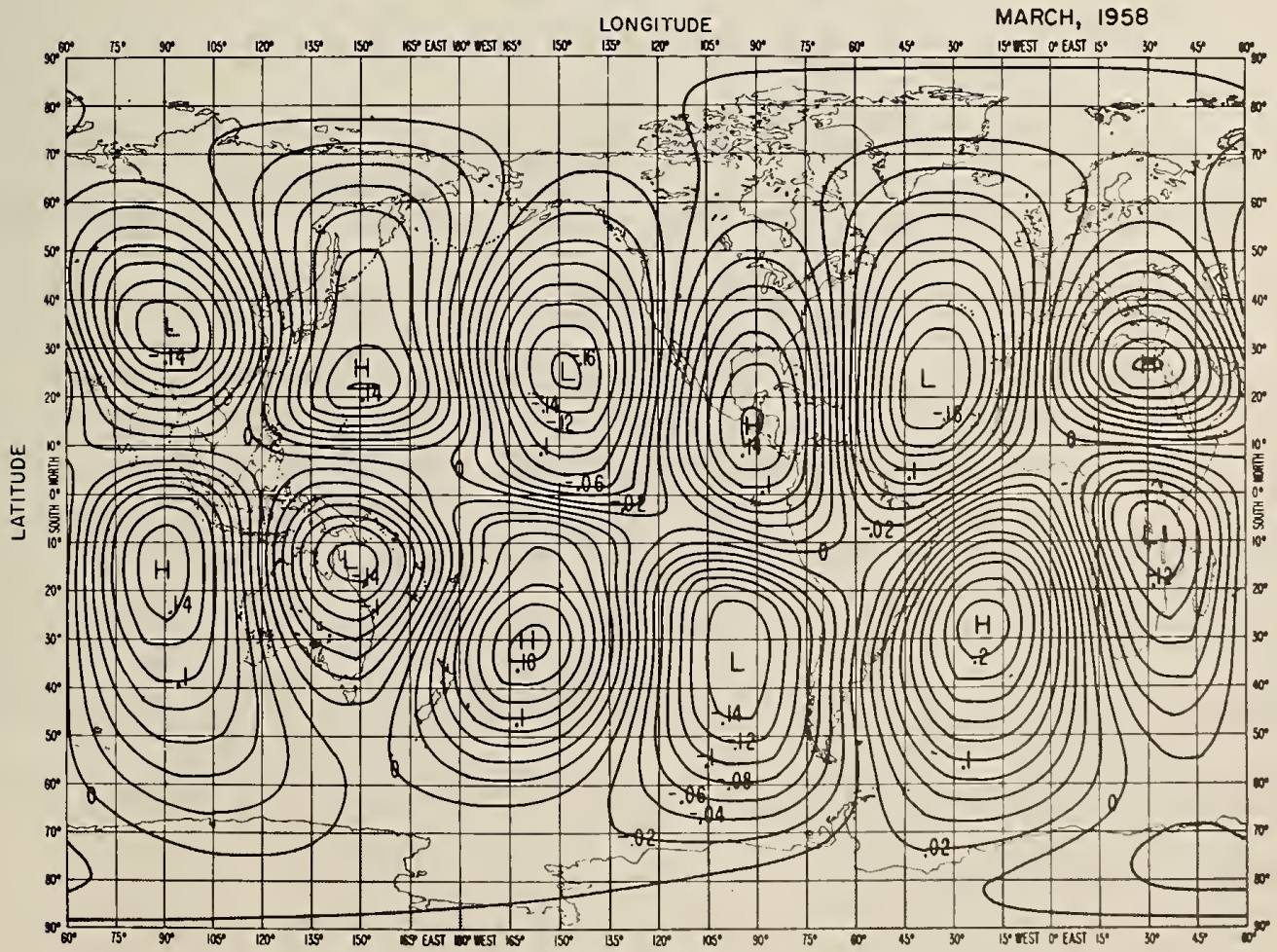


order longitude functions $\sin x \cos ^{3} \lambda \cos 3 \theta$ and $\sin x \cos ^{3} \lambda \sin 3 \theta$, respectively. Several additional examples are contained in Appendix B. Among the properties illustrated are the close relation to magnetic dip and the position of zeros and relative maximum and minimum points.

\subsection{Diurnal Variation}

A numerical map representing both the geographic, and diurnal variations of the ionospheric characteristic can now be formed by Fourier analyzing the orthonormal coefficients $d_{k}$ ( $k$ fixed) obtained from the geographic analyses for the 24 hours of universal time. Typical examples of these coefficients are shown in figure 7 for $k=0,1,2,3$ (March 1958). Also shown in these graphs are the Fourier representations of the form

$$
a_{k}(T)=a_{0}^{(k)}+\sum_{j=1}^{6}\left[a_{j}^{(k)} \cos j T+b_{j}^{(k)} \sin j T\right],
$$

where $\mathrm{T}$ denotes the universal time hour angle $\left(-180^{\circ} \leqq \mathrm{T} \leqq 180^{\circ}, \mathrm{T}=0^{\circ}\right.$ at 12 noon U.T.). Further examples of this type are given in Appendix C. Only six harmonics are used for this representation since it was known from previous work [Jones, 1962; Jones and Gallet, 1962a and 1965b] that at most eight harmonics are needed for the diurnal variation and since experiments made in this application showed that harmonics seven and eight gave no significant contribution. The $\mathrm{d}_{\mathrm{k}}$ have a remarkable degree of smoothness and continuity over a 24 hour period, in spite of the fact that the coefficients for each hour are obtained independently. Further studies have shown that the diurnal variations of the coefficients $D_{k}$ in (8) are not as smooth as for the $d_{k}$. 
Figure 7

DIURNAL VARIATION OF ORTHONORMAL COEFFICIENTS $d_{k}$
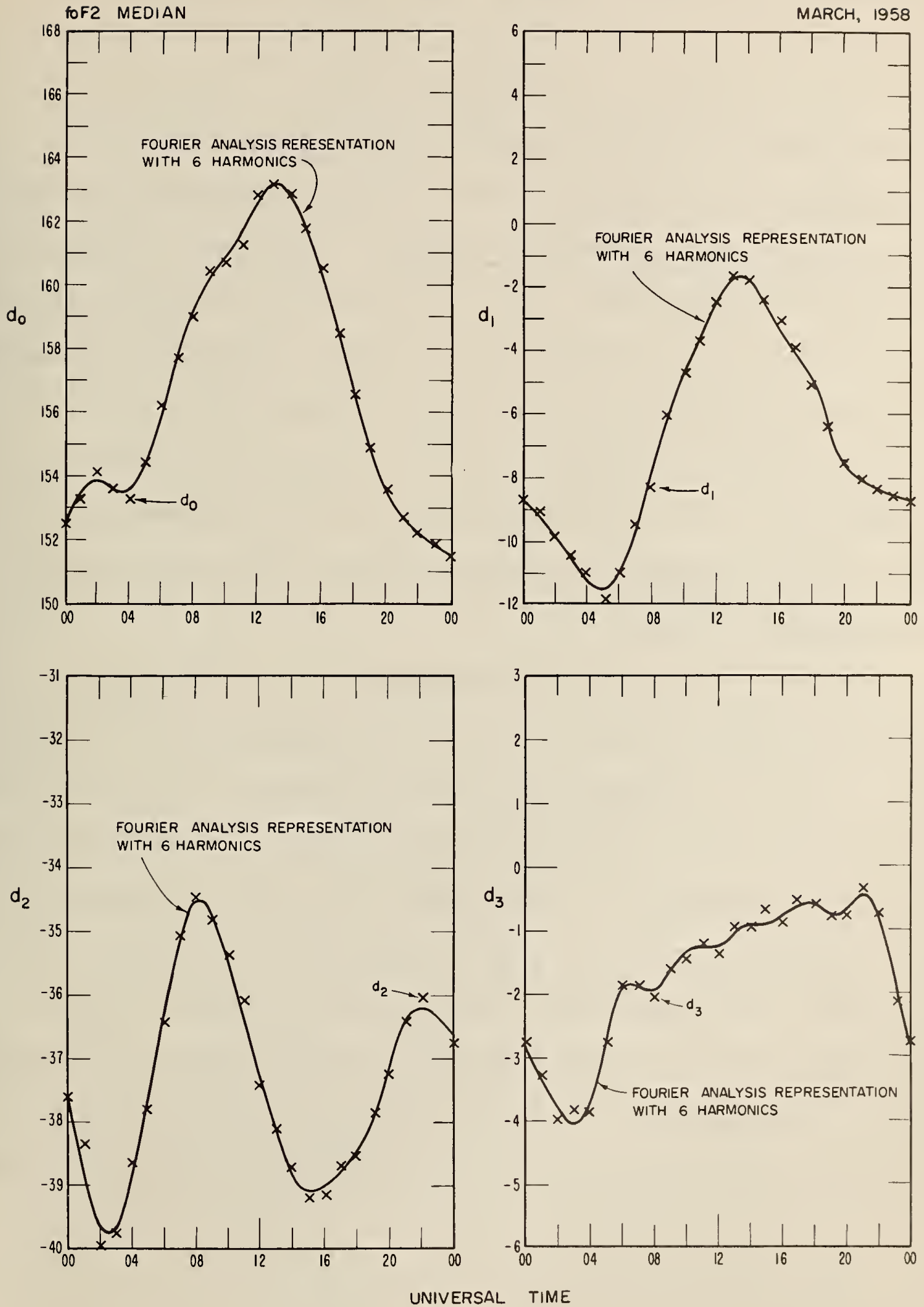
The numerical map of the ionospheric characteristic can now be written in the form

$$
\Omega(\lambda, \theta, T)=\sum_{k=0}^{75} d_{k}(T) F_{k}(\lambda, \theta),
$$

where the functions $a_{k}(T)$ have the form (12). For use in practical applications, $\Omega(\lambda, \theta, T)$ is expressed in terms of the simpler functions $G_{k}(\lambda, \theta)$ in Section 5. Examples of graphical contour maps of foF2 median for March 1958 computed from $\Omega(\lambda, \theta$, T) are shown in figures 8 and 9, for the hours U.T. $=00,06,12,18$. As can be seen, the problem of ambiguous polar values is no longer present. Also, by comparison with graphical contour maps from former analyses such as Jones and Gallet, [1965a], it is evident that the new maps represent more detail in the equatorial region. Further comparison of different analyses will be dealt with in the following section.

To conclude this section we shall mention a few of the strong connections between the various steps of the mapping procedures described above. The use of a universal time analysis eliminated polar ambiguities but, at the same time, created another difficulty: increased complication of geographic variations. To take account of that fact, it was necessary to use a larger number of geographic functions (including higher orders of longitude). This placed even more importance on C-data to control instability; hence more screen points had to be used. Since the geographic analysis is far more difficult than the diurnal, it was decided to analyze the geographic variations of the A-, B- and C- data for fixed hours of UT, 
rather than the Fourier coefficients from the diurnal analysis, adjusted to UT. The latter approach, though perhaps more desirable from the viewpoint of reducing the overall number of terms needed to define a numerical map, would be more complicated since the Fourier coefficients have extremely different types of variations from one coefficient to the next. Hence a careful study would be required for each (of approximately 17) Fourier coefficient. Perhaps this is an area worthy of further investigation. 
Figure 8

MAPS OF FOF2 MEDIAN (MC/S) COMPUTED FROM UT ANALYSIS
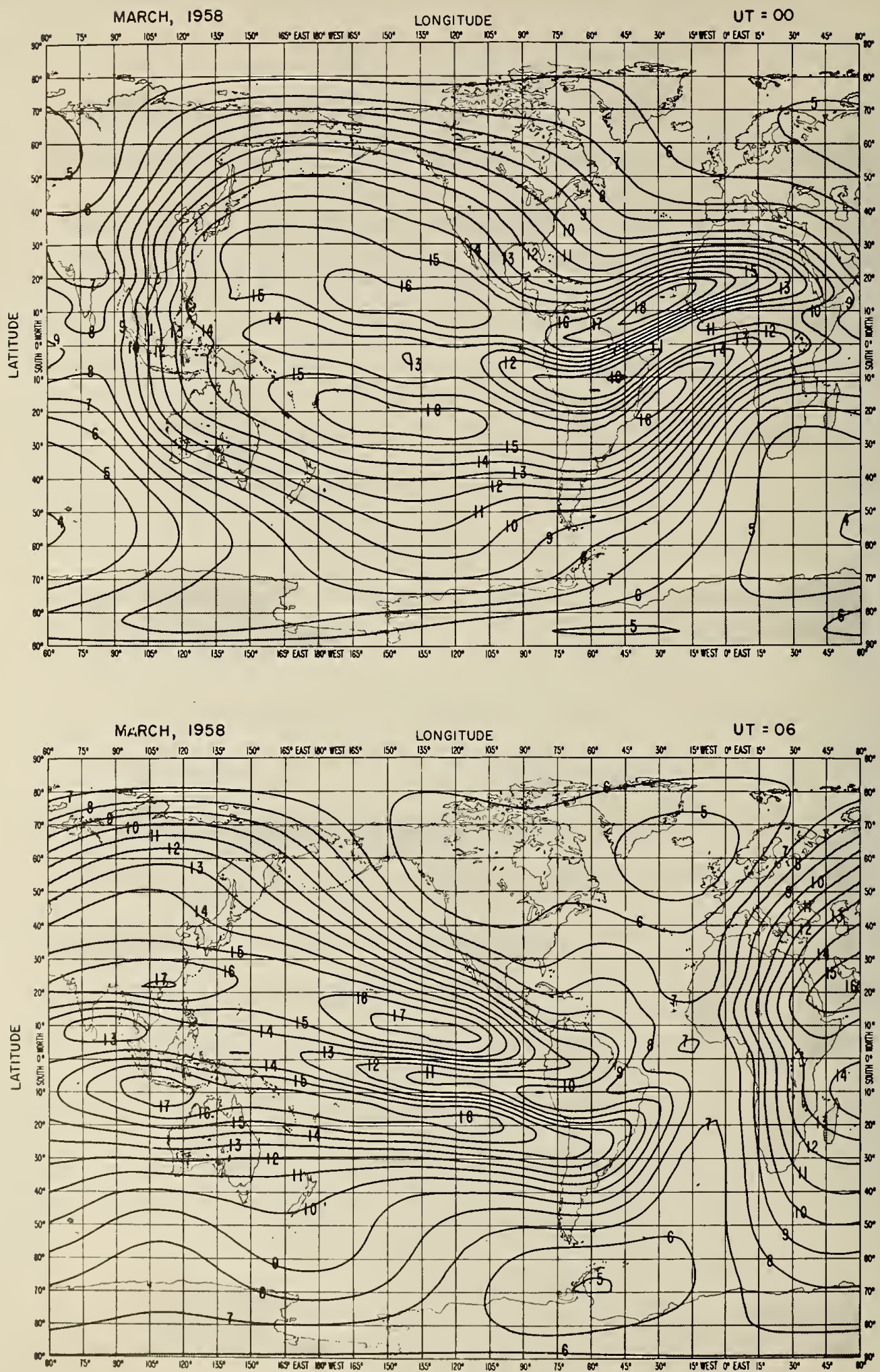
Figure 9

MAPS OF fOF2 MEDIAN (MC/s) COMPUTED FROM UT ANALYSIS
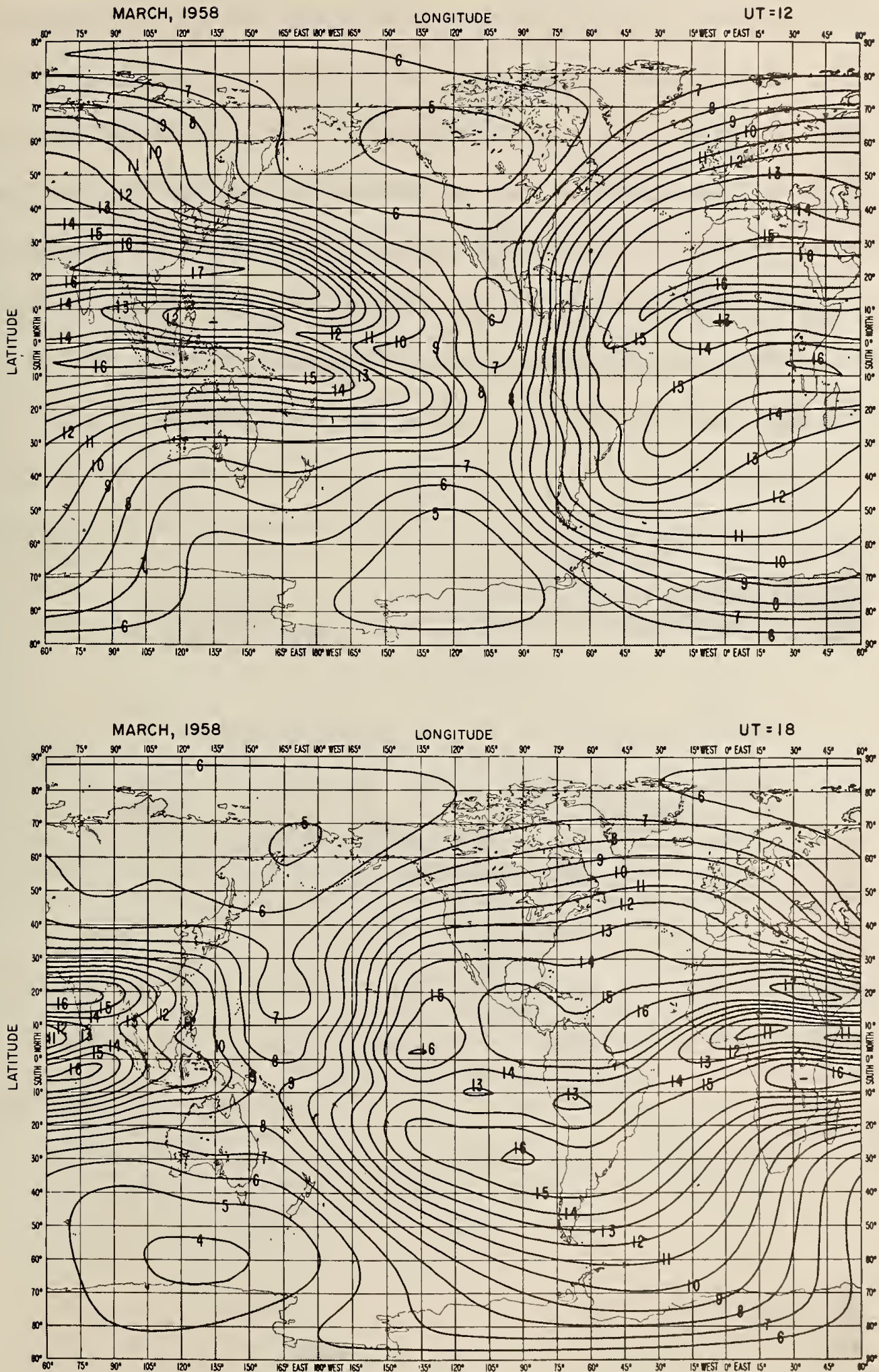


\section{Comparison of Different Analyses}

Results from two different types of analysis are compared in this section. Type $I$ is described by Jones and Gallet [1965a]. Iocal mean time is used for both the screen and second analyses. The geographic variable for the screen analysis is latitude $\lambda$. For the second analysis the geographic functions are similar to those given in Table 3, with a maximum of two orders of longitude $\theta$ and with the factor $\sin x$ replaced by $\sin \lambda$. Type II is described in the present paper (Sections 2 and 3 ). Local mean time is used in the screen analysis and universal time in the second analysis. The geographic variable for the screen analysis is the modified magnetic dip $x$, see (4), and the geographic functions for the second analysis are given in Table 3. Table 4 summarizes the main characteristics of the two types of analysis.

\section{Table 4}

Main Characteristics of Two Types of Analysis

\begin{tabular}{|c|c|l|c|c|}
\cline { 2 - 5 } \multicolumn{1}{c|}{} & \multicolumn{2}{c|}{ Screen Analysis } & \multicolumn{2}{l|}{ Second Analysis } \\
\cline { 2 - 5 } & Time & Geographic VariabIe & Time & Geographic Variables \\
\hline Type I & IMT & $\lambda=$ latitude & IMT & $\lambda$ and $\theta$ \\
\hline Type II & IMT & \begin{tabular}{c}
$\mathrm{x}=\begin{array}{l}\text { modified } \\
\text { magnetic dip }\end{array}$ \\
\hline
\end{tabular}
\end{tabular}

( $\theta=$ geographic longitude) 
For comparison, the two types of analysis have been applied to the same sets of A- and B-data for the characteristic foF2 median for four seasonal months of the high and low years of solar activity, 1958 and 1954. For each type analysis and each month, the root mean square (RMS) residual has been computed using residuals between A- and B-data and numerical map values for all stations and all 24 hours. The values of the RMS residual, which estimate the standard deviation of residuals, are given in Table 5. As can be seen, there is a major improvement in the representation of the given data. The reduction in the RMS residual for Type II ranges from 30 to 47 per cent. The values of the RMS residual

\section{Table 5}

RMS of Residuals of (Mc/s) of A- and B-data for Two Types of Analysis (A1I hours and all stations of foF2 medians)

\begin{tabular}{|l|c|c|c|c|c|c|c|c|}
\cline { 2 - 9 } \multicolumn{1}{c|}{} & \multicolumn{4}{c|}{1954} & \multicolumn{3}{c|}{1958} \\
\hline Analysis & Mar. & June & Sept. & Dec. & Mar. & June & Sept. & Dec. \\
\hline Type I & .72 & .58 & .69 & .66 & 1.10 & 1.06 & 1.09 & .98 \\
\hline Type II & .38 & .36 & .41 & .42 & .63 & .59 & .60 & .67 \\
\hline
\end{tabular}

in Table 5 for Type I are considerably higher than those reported in the previous paper [Jones and Gallet, 1965a]. This is due to the use of about 30 additional B-data stations. The number of stations with A- or B-data and the number of screen points for each month used in the present study are summarized in Table 6. 
Number of Stations $\left(\mathrm{N}_{\mathrm{A}}\right.$ and $\mathrm{N}_{\mathrm{B}}$ ) with $\mathrm{A}$ - and $\mathrm{B}$-data and Number of Screen Points $\left(N_{C}\right)$ used in Analysis of foF2 Median

\begin{tabular}{|c|c|c|c|c|c|c|c|c|}
\cline { 2 - 9 } \multicolumn{1}{c|}{} & \multicolumn{4}{c|}{1954} & \multicolumn{3}{c|}{1958} \\
\cline { 2 - 9 } \multicolumn{1}{c|}{} & Mar. & June & Sept. & Dec. & Mar. & June & Sept. & Dec. \\
\hline$N_{A}$ & 87 & 87 & 85 & 83 & 121 & 124 & 124 & 122 \\
\hline$N_{B}$ & 71 & 71 & 75 & 76 & 42 & 38 & 38 & 41 \\
\hline$N_{C}$ & 68 & 68 & 68 & 68 & 67 & 67 & 67 & 67 \\
\hline
\end{tabular}

By comparing the results of Table 5 for Type II analysis with estimates of the noise inherent in foF2 medians [Jones, 1962; Jones and Gallet, 1962a, 19650], it appears that the residuals in the numerical map representations are now close to the noise level. Although some additional geographic functions may be required to fully represent the physical variations in existing data, it is felt that a further extension of the series (11) could not be justified with the presently available distribution of ionospheric sounding stations. To summarize, the Type II analysis is superior to Type I on three major counts: (I) closer fitting of the given A- and B-data, (2) more accurate representation of the ionospheric characteristic in critical areas, a result of having improved C-data and (3) elimination of ambiguous values at the geographic poles. 


\section{Application of Numerical Maps}

5.I Simplified Expression of $\Omega(\lambda, \theta, T)$

As an aid to evaluating numerical maps, this section reduces the function $\Omega(\lambda, \theta, T)$ to a form expressed in terms of the geographic functions $G_{k}(\lambda, \theta)$. Also included in this section are the formulas necessary for calculating magnetic dip I. To obtain increased generality, so that the discussion will apply to numerical maps of any ionospheric characteristic, we introduce a set of geographic functions $G_{k}(\lambda, \theta)$ in Table 7 , of which Table 3 is a special case. Here the integer $q_{i}$, $i=0,1, \ldots, m$, denotes the highest power of $\sin x$ for the $i^{\text {th }}$ order harmonic in longitude, and $m$ denotes the highest order of longitude. The parameters $q_{i}$ and $m$ may change from one ionospheric characteristic to another. However, the general form of the numerical maps will remain fixed. For indexing purposes it is sometimes convenient to introduce the sequence $k_{i}, i=0,1, \ldots, m$, such that $G_{k_{i}}(\lambda, \theta)$ is the last of the geographic functions of $i^{\text {th }}$ order longitude:

$$
\begin{aligned}
& G_{k_{0}}(\lambda, \theta)=\sin ^{q} o_{x} \\
& G_{k_{i}}(\lambda, \theta)=\sin ^{q_{i}} x \cos ^{i} \lambda \sin i \theta, \quad i=1,2, \ldots, m .
\end{aligned}
$$

Thus

$$
q_{0}=k_{0} ; \quad q_{i}=\frac{k_{i}-k_{i-1}}{2}, \quad i=1,2, \ldots, m \text {, }
$$

and the total number of geographic functions in Table 7 is given by

$$
K+I=k_{m}+I
$$


For convenience in computing procedures we note that

$$
\sin x=\frac{I}{\sqrt{I^{2}+\cos \lambda}}
$$

which follows immediately from (4).

\section{Table 7}

\section{Geographic Coordinate Functions}

$G_{k}(\lambda, \theta)(x$ is a function of $\lambda, \theta), m$ is the maximum order in longitude.

\begin{tabular}{|c|c|c|c|c|c|c|c|c|}
\hline k & $\begin{array}{l}\text { Main Lat. } \\
\text { Variation }\end{array}$ & $\mathrm{k}$ & $\begin{array}{l}\text { First Order } \\
\text { Longitude } G_{k}\end{array}$ & $\mathrm{k}$ & $\begin{array}{l}\text { Second Order } \\
\text { Longitude } G_{k}\end{array}$ & ... & $\mathrm{k}$ & mth Order Longitude \\
\hline 0 & 1 & $\mathrm{k}_{0}+1$ & $\cos \lambda \cos \theta$ & $\mathrm{k}_{2}+1$ & $\cos ^{2} \lambda \cos 2 \theta$ & $\cdots$ & $\mathrm{k}_{\mathrm{m}-1}+1$ & $\cos ^{m} \lambda \cos m \theta$ \\
\hline 1 & $\sin x$ & $\mathrm{k}_{0}+2$ & $\cos \lambda \sin \theta$ & $k_{1}+2$ & $\cos ^{2} \lambda \sin 2 \theta$ & $\cdots$ & $\mathrm{k}_{\mathrm{m}-1}+2$ & $\cos ^{\mathrm{m}} \lambda \sin \mathrm{m} \theta$ \\
\hline 2 & $\sin ^{2} x$ & $\mathrm{k}_{0}+3$ & $\sin x \cos \lambda \cos \theta$ & $\mathrm{k}_{1}+3$ & $\sin \times \cos ^{2} \lambda \cos 2 \theta$ & $\cdots$ & $\mathrm{k}_{\mathrm{m}-1}+3$ & $\sin x \cos ^{m} \lambda \cos m \theta$ \\
\hline - & & $\mathrm{k}_{0}+4$ & $\sin x \cos \lambda \sin \theta$ & $\mathrm{k}_{1}+4$ & $\sin x \cos ^{2} \lambda \sin 2 \theta$ & $\cdots$ & $\mathrm{k}_{\mathrm{m}-\mathrm{I}}+4$ & $\sin x \cos ^{\mathrm{m}} \lambda \sin \mathrm{m} \theta$ \\
\hline$k_{0}$ & $\sin ^{9} x$ & 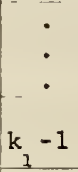 & $\sin ^{\mathrm{q}} 1 \times \cos \lambda \cos \theta$ & $\begin{array}{c}\dot{\cdot} \\
\mathrm{k}_{2}-1\end{array}$ & $\sin ^{2} \times \cos ^{2} \lambda \cos 2 \theta$ & 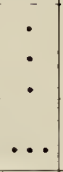 & $\begin{array}{c}\cdot \\
\dot{-} \\
\mathrm{k}_{\mathrm{m}}\end{array}$ & $\sin ^{\mathrm{q}_{\mathrm{m}}} \times \cos ^{\mathrm{m}} \lambda \cos \mathrm{m} \theta$ \\
\hline & & $k_{1}$ & $\sin ^{4} \times \cos \lambda \sin \theta$ & $k_{2}$ & $\sin ^{2} x \cos ^{2} \lambda \sin 2 \theta$ & $\cdots$ & $\mathrm{k}_{\mathrm{m}}$ & $\sin ^{m} x \cos ^{m} \lambda \sin m \theta$ \\
\hline
\end{tabular}

A numerical map, as described in Section 3, may then be written in the general form

$$
\Omega(\lambda, \theta, T)=\sum_{k=0}^{K} d_{k}(T) F_{k}(\lambda, \theta),
$$

where

$$
a_{k}(T)=a_{0}^{(k)}+\sum_{j=1}^{H}\left[a_{j}^{(k)} \cos j T+b_{j}^{(k)} \sin j T\right] \text {, }
$$

where $\mathrm{H}$ is the number of harmonics retained for representing the diumal variation of the orthonormal coefficients $a_{k}$. Here $F_{k}(\lambda, \theta)$ denotes the 
orthonormal functions, discussed in Section 3 , which are linear combinations of the $G_{k}(\lambda, \theta)$ in the form (9). In most applications it is convenient to express $\Omega(\lambda, \theta, T)$ explicitly in terms of the $G_{k}(\lambda, \theta)$. If (18) is substituted in (17) and the order of summation interchanged, we obtain

$$
\Omega(\lambda, \theta, T)=a_{0}(\lambda, \theta)+\sum_{j=1}^{H}\left[a_{j}(\lambda, \theta) \cos j T^{\circ}+b_{j}(\lambda, \theta) \sin j T\right],
$$

where

$$
\begin{aligned}
& a_{j}(\lambda, \theta)=\sum_{k=0}^{K} a_{j}^{(k)} F_{k}(\lambda, \theta), \\
& b_{j}(\lambda, \theta)=\sum_{k=0}^{K} b_{j}^{(k)} F_{k}(\lambda, \theta) .
\end{aligned}
$$

Now the procedure described by Jones and Gallet [1962a, Section 2.2] may be used to obtain the coefficients $U_{s, k}$ for defining the $a_{j}(\lambda, \theta)$ and $b_{j}(\lambda, \theta)$ in the form

$$
\begin{aligned}
& a_{j}(\lambda, \theta)=\sum_{k=0}^{K} U_{2 j, k} G_{k}(\lambda, \theta), \quad j=0,1, \ldots, H, \\
& b_{j}(\lambda, \theta)=\sum_{k=0}^{K} U_{2 j-1, k} G_{k}(\lambda, \theta), \quad j=1,2, \ldots, H .
\end{aligned}
$$

Thus a numerical map $\Omega(\lambda, \theta, T)$ is defined by specifying the integers $q_{0}, q_{i}, \ldots, q_{m}, H$, and the coefficients $U_{s, k}$ in (2I) and (22). As an example, for the numerical map of foF2 median for March 1958 obtained from the Type II analysis in Section 3 , we have $H=6, q_{0}=\frac{q}{3}=11, q_{2}=8$, $q_{3}=4, q_{4}=1, q_{5}=q_{6}=q_{y}=q_{8}=0$. The coefficients $U_{s, k}$ are given in Table 8. 
Table 8

TIME VARIATION

\begin{tabular}{|c|c|c|c|c|c|c|c|c|}
\hline \multicolumn{2}{|c|}{ Hormonic } & \multirow{2}{*}{$\frac{0}{0}$} & \multicolumn{2}{|c|}{ I } & \multicolumn{2}{|c|}{2} & \multicolumn{2}{|c|}{3} \\
\hline & 5 & & 1 & 2 & 3 & 4 & 5 & 6 \\
\hline I & $\begin{array}{r}0 \\
1 \\
2 \\
3 \\
4 \\
5 \\
6 \\
7 \\
8 \\
9 \\
10 \\
11\end{array}$ & 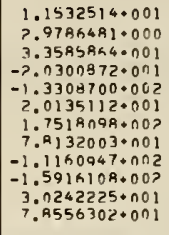 & 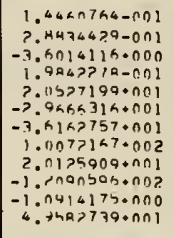 & 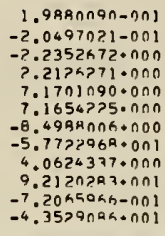 & 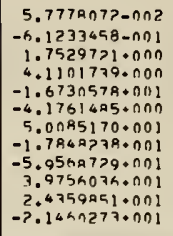 & $\begin{array}{r}2.7750279-00 ? \\
-3.7527066-001 \\
1.4446157+000 \\
8.6310942+000 \\
-1.7928747+001 \\
-3.3259921+001 \\
3.6457752+001 \\
4.97081 \times 5+001 \\
-4.2344146+001 \\
-2.9651677+011 \\
1.6721863+001 \\
4.96865490000\end{array}$ & 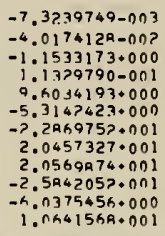 & 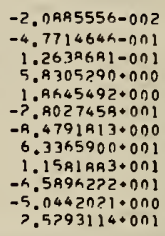 \\
\hline II & $\begin{array}{l}17 \\
13 \\
14 \\
15 \\
16 \\
17 \\
17 \\
19 \\
20 \\
21 \\
22 \\
23 \\
24 \\
25 \\
26 \\
27 \\
29 \\
29 \\
30 \\
31 \\
32 \\
33 \\
34 \\
35\end{array}$ & 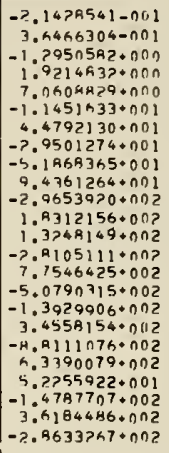 & 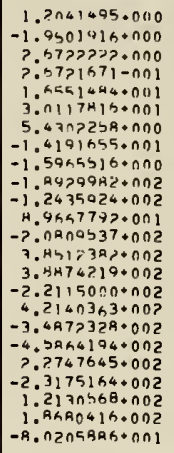 & 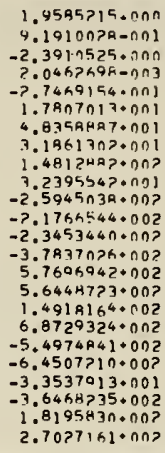 & 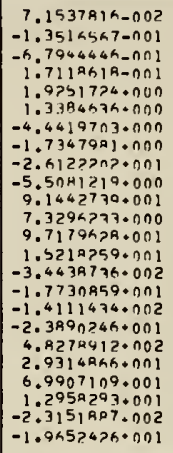 & 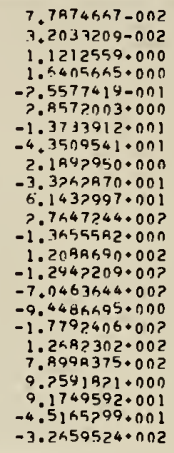 & 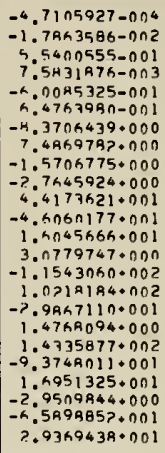 & 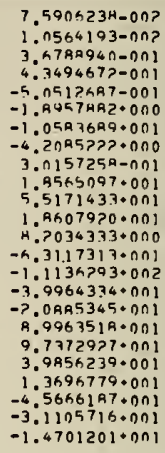 \\
\hline III & $\begin{array}{l}36 \\
37 \\
38 \\
39 \\
40 \\
41 \\
4 ? \\
43 \\
44 \\
45 \\
46 \\
47 \\
48 \\
49 \\
50 \\
51 \\
5 ? \\
53\end{array}$ & 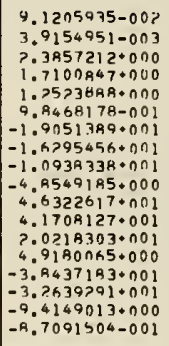 & 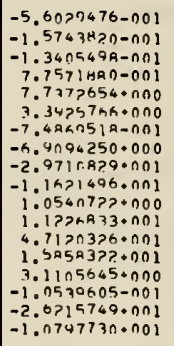 & 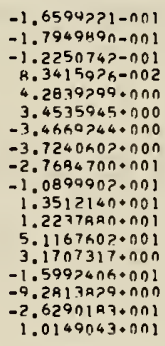 & 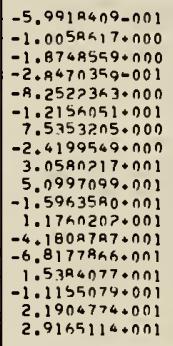 & 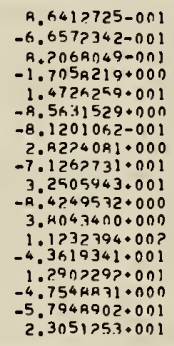 & 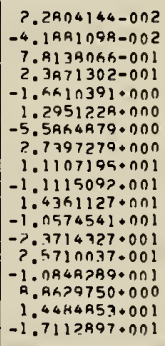 & 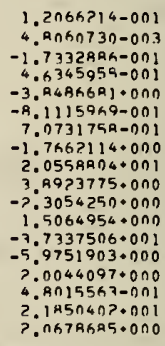 \\
\hline DV & $\begin{array}{l}54 \\
55 \\
56 \\
57 \\
58 \\
59 \\
60 \\
61 \\
62 \\
63\end{array}$ & $\begin{array}{r}-1.3451>52-002 \\
-9.5454513-002 \\
3.34927297-001 \\
2.6545483-0112 \\
-5.3508100-100 ? \\
-1.4929667+000 \\
-7.3424476-001 \\
? .3003949-001 \\
7.7094395-001 \\
? .6313893+000\end{array}$ & 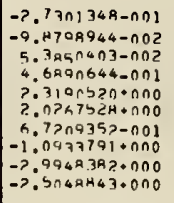 & 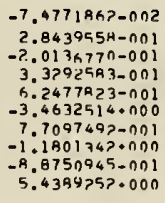 & 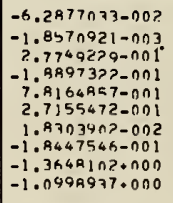 & 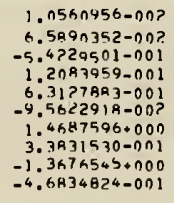 & 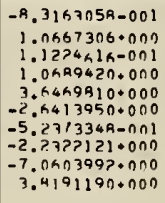 & 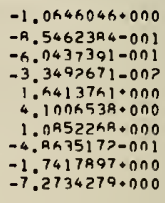 \\
\hline Z & $\begin{array}{l}64 \\
65 \\
66 \\
67\end{array}$ & $\begin{array}{r}-4.8641141-102 \\
-1.8283584-00 ? \\
-5.6522250-002 \\
1.3026795-001\end{array}$ & $\begin{array}{r}1.1 n>7507-n n 2 \\
1.7741635-n \cap ? \\
-5 . n 9 A n 132-n n ? \\
7.4 n 73767-n 03\end{array}$ & $\begin{array}{l}1.0706939-003 \\
1.015 n 305-001 \\
4.2654397-002 \\
8.8747593-002\end{array}$ & $\begin{array}{r}1.507767 k-n n 2 \\
4.475>752-002 \\
2.1228492-001 \\
-2.4434419-003\end{array}$ & $\begin{array}{r}2.7543323-002 \\
-2.7675717-00 ? \\
1.4846456-001 \\
5.91898 \times 3-00 ?\end{array}$ & 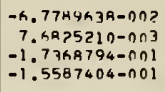 & $\begin{array}{r}1.13 .34173-003 \\
-9.2616111-003 \\
1.85 ? 270 H-001 \\
-1.1237079-001\end{array}$ \\
\hline VII & $\begin{array}{l}64 \\
69\end{array}$ & $\begin{array}{r}-1.44472 ., 10-001 \\
4.7078782-002\end{array}$ & $\begin{array}{l}1.5 n \cap 99097-n 02 \\
8.4 n 9 R 659-n 02\end{array}$ & $\begin{array}{r}-5.1823611-\cap n ? \\
4.0754018-\cap 02\end{array}$ & $\begin{array}{l}\text { h. } 9669 A 76-00 ? \\
2.7354 \cap 46-0 \cap 2\end{array}$ & $\begin{array}{r}3.095>397-002 \\
-1.20111939-002\end{array}$ & $\begin{array}{r}-1.417>224-100 ? \\
3.4773954=003\end{array}$ & $\begin{array}{l}5.3143309-003 \\
5.4143005-0 n 2\end{array}$ \\
\hline VIII & $\begin{array}{l}70 \\
71\end{array}$ & $\begin{array}{l}1.6313974-00.3 \\
1.4541404-002\end{array}$ & $\begin{array}{r}-1.15>3154=0 n 1 \\
\text { R. } 3410301-003\end{array}$ & $\begin{array}{l}-4.0930545=00 ? \\
-5.0261 A 67-007\end{array}$ & $\begin{array}{r}6.0305991-n \cap 2 \\
-1.87519 נ 1-n n 2\end{array}$ & $\begin{array}{r}2.3175386-002 \\
-6.5 ? 9>043-003\end{array}$ & $\begin{array}{l}4.551>107-n \cap ? \\
? .374 n 425-002\end{array}$ & $\begin{array}{r}2.9363960-00 ? \\
-3.0 R A 7 ? 45-00 ?\end{array}$ \\
\hline VIIII & $\begin{array}{l}72 \\
73\end{array}$ & $\begin{array}{l}-4.7592458 \ldots 17 ? \\
-6.1512262-00 ?\end{array}$ & 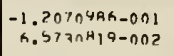 & $\begin{array}{l}2.623375 A-n 0 ? \\
1.9004476-00.3\end{array}$ & $\begin{array}{r}5.605 k 1>7-n n 2 \\
-9.2109477-0 n 2\end{array}$ & $\begin{array}{l}-4.5053592-00 ? \\
-3.1465009-002\end{array}$ & $\begin{array}{l}3.6549207-0 n 2 \\
3.1294>57=0 n 3\end{array}$ & $\begin{array}{l}-7.169925 n=0 n 2 \\
-4.527 n 331-0 n 2\end{array}$ \\
\hline IX & $\begin{array}{l}74 \\
75\end{array}$ & $\begin{array}{r}-4.27511179-00 ? \\
1.4220117-00 ?\end{array}$ & $\begin{array}{r}7.914 \times 919-002 \\
-1.2444254-0 \cap 2\end{array}$ & $\begin{array}{r}1.2444798-001 \\
-1.850>32.7-002\end{array}$ & $\begin{array}{r}-9.0615177-003 \\
4.11 ? \geqslant 7 \cap 5-\cap 02\end{array}$ & $\begin{array}{r}-9.7783027-00 ? \\
1.187148 ?-001\end{array}$ & $\begin{array}{l}-9.3049374-002 \\
-4.6537463-003\end{array}$ & $\begin{array}{l}? .15763 R 4=002 \\
9.3644797-0033\end{array}$ \\
\hline
\end{tabular}

I - Man latifudinal varıtion. Mixed latitudinal and langitudinal voriation; प - First order in langitude;

III - Secand arder, in langitude. ..... IX - Eighth order in langitude.

Notoltan: For each entry the number given by the first eight digits and sign is multiplied by the pawer of

ten defined by the last three digits and sign.

COEFFICIENTS $U_{S K}$ DEFINING THE FUNCTION $\Omega(\lambda, \theta, T)$ FOR

MONTHLY MEDIAN fOF2 (MC/s)

MARCH 1958 
Table 8 (contd.)

TIME VARIATION

\begin{tabular}{|c|c|c|c|c|c|c|c|}
\hline \multicolumn{2}{|c|}{ Harmonic } & \multicolumn{2}{|c|}{4} & \multicolumn{2}{|c|}{5} & \multicolumn{2}{|c|}{6} \\
\hline & $\mathrm{K}^{5}$ & 7 & 8 & 9 & 10 & 11 & 12 \\
\hline I & $\begin{array}{r}0 \\
1 \\
2 \\
3 \\
4 \\
5 \\
6 \\
7 \\
8 \\
9 \\
10 \\
11\end{array}$ & 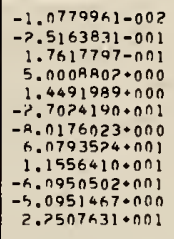 & 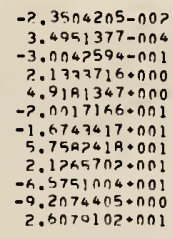 & 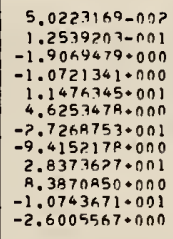 & 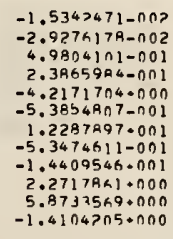 & $\begin{array}{r}-8.1190315-003 \\
.5182227-0002 \\
1.2314179-0001 \\
-2.8400371=001 \\
-1.1915910=001 \\
1.3510171+000 \\
-8.880934-001 \\
-4.0530746 .000 \\
1.9977740+000 \\
5.4099207+1000 \\
-1.1181373+1000 \\
-2.4713309+000\end{array}$ & 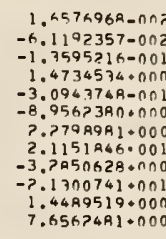 \\
\hline प & $\begin{array}{l}17 \\
13 \\
14 \\
15 \\
16 \\
17 \\
18 \\
19 \\
20 \\
21 \\
22 \\
23 \\
24 \\
25 \\
26 \\
27 \\
24 \\
29 \\
30 \\
31 \\
32 \\
33 \\
34 \\
35\end{array}$ & 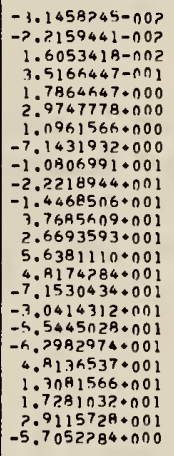 & 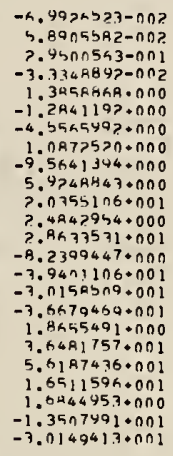 & 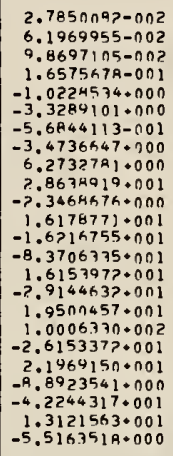 & 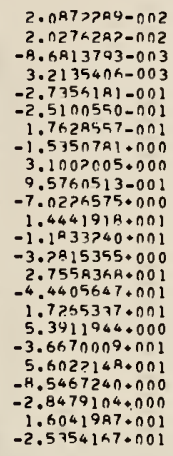 & 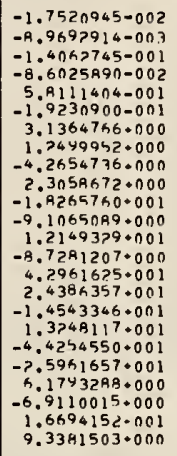 & 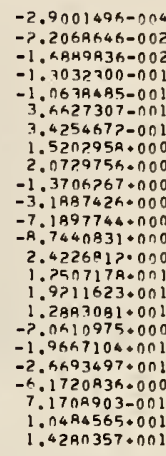 \\
\hline III & $\begin{array}{l}36 \\
37 \\
38 \\
39 \\
40 \\
41 \\
42 \\
43 \\
44 \\
45 \\
46 \\
47 \\
44 \\
49 \\
50 \\
51 \\
52 \\
53\end{array}$ & 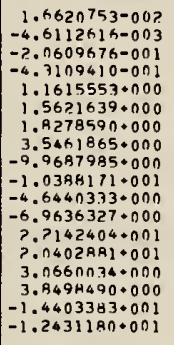 & 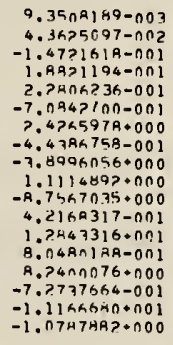 & $\begin{array}{r}-1.7836453-002 \\
1.9616151-002 \\
-6.4175022-002 \\
1.2855997-001 \\
3.8100805-001 \\
-1.4162618+000 \\
3.9497903-001 \\
-1.4466337+000 \\
-7.8534835-001 \\
9.54993550000 \\
-7.8604977-001 \\
2.9414559+000 \\
-6.6582155-001 \\
-2.1219091+001 \\
7.3676757-001 \\
-1.714031+000 \\
1.482 .3537+000 \\
1.44601 ? 4+001\end{array}$ & 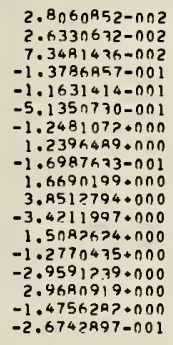 & $\begin{array}{r}3.8016123-00 ? \\
-2.1 A 6 R 669-003 \\
-1.5399902-001 \\
-7.695992-002 \\
-9.2070603-001 \\
2.0306040-001 \\
1.2200315+000 \\
-3.8335868-00 ? \\
5.0403690+100 \\
-6.0166055-001 \\
-2.6309910+000 \\
6.4303710-001 \\
-9.3487013+000 \\
5.119 A 332-001 \\
1.61 A 3555+000 \\
-4.8090416-001 \\
5.4644740+000 \\
-2.2700363-001\end{array}$ & 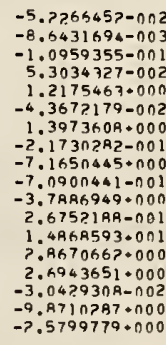 \\
\hline DV & $\begin{array}{l}54 \\
55 \\
54 \\
57 \\
58 \\
50 \\
60 \\
61 \\
62 \\
63\end{array}$ & $\begin{array}{r}7.2832114-002 \\
1.5239718-007 \\
4.4816403-002 \\
-2.7603405-001 \\
-4.4921730-001 \\
3.5216262-002 \\
-4.8451815-003 \\
4.9907794-001 \\
5.7205307-001 \\
-2.5665734-001\end{array}$ & 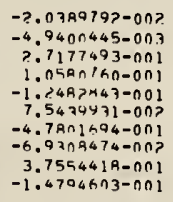 & $\begin{array}{r}7.8774426-003 \\
-1.6769639-002 \\
1.7797075-002 \\
3.0096395-102 \\
7.9967947-002 \\
-6.9711364-007 \\
-5.0020724-00 ? \\
-8.11737447-00 ? \\
-6.16347 .32-002 \\
3.1409744-061\end{array}$ & $\begin{array}{r}2.8 \cap 61195-002 \\
-9.268 n 243-003 \\
-5.0444740-002 \\
8.5955596-003 \\
-5.3480474-002 \\
2.0900151-001 \\
2.4527609-001 \\
8.0430120-002 \\
-6.8014707-002 \\
-4.3419296-001\end{array}$ & $\begin{array}{r}2.0920550-002 \\
9.7618165-0003 \\
9.2971316-002 \\
-6.0280165-002 \\
-1.8945459-0001 \\
3.1421447-002 \\
-2.7050890-001 \\
-3.6565761-002 \\
3.2620970-001 \\
-6.2514650-002\end{array}$ & $\begin{array}{r}-4.4 n 55183-n 02 \\
5.1498 A 40-003 \\
-2.2825522-002 \\
4.7255015-002 \\
4.5860038-001 \\
-2.3092020-001 \\
7.8751864-002 \\
-4.3459351=00 ? \\
-4.6174797=001 \\
1.8238921=001\end{array}$ \\
\hline Z & $\begin{array}{l}64 \\
65 \\
66 \\
67\end{array}$ & $\begin{array}{l}2.9461028-001 \\
7.5799998-001 \\
1.3543195-001 \\
1.1650050=001\end{array}$ & $\begin{array}{r}-7.9644147-001 \\
2.6751476-001 \\
-1.6547476-001 \\
1.1874679-001\end{array}$ & $\begin{array}{r}? .015757 A-002 \\
-3.0073797-002 \\
-1.1847 n G A-001 \\
-2.555244 A-n \cap ?\end{array}$ & $\begin{array}{r}2.8399051-n \cap 3 \\
-6.7519533-n 03 \\
7.7147367-0 \cap 2 \\
-2.871 \text { A } 101-002\end{array}$ & $\begin{array}{r}-1.1443148-003 \\
9.7485471=003 \\
1.9120149-003 \\
2.0003978-003\end{array}$ & $\begin{array}{r}-H .0223370-003 \\
-6.7844802-003 \\
3.2158505-002 \\
1.5974910=002\end{array}$ \\
\hline VI & $\begin{array}{l}68 \\
69\end{array}$ & $\begin{array}{l}-4.2422449-002 \\
-3.495+211-003\end{array}$ & $\begin{array}{r}-7 . y 7>2>59-002 \\
4.7>445 ? 9-003\end{array}$ & $\begin{array}{r}2.9134 \text { A? } 3-001 \\
-1.4252193-001\end{array}$ & $\begin{array}{l}1.66490690-001 \\
3.61413233-001\end{array}$ & $\begin{array}{l}-9.4621915-004 \\
-9.31383>4-003\end{array}$ & $\begin{array}{r}-C . H 111944-n 03 \\
2.020745 ?-002\end{array}$ \\
\hline VII & $\begin{array}{l}70 \\
71\end{array}$ & $\begin{array}{r}-4.1576>>0-002 \\
6.5759298-00.7\end{array}$ & $\begin{array}{l}-A .4>\triangle A R A K D=003 \\
-7.244 R H 54=003\end{array}$ & $\begin{array}{r}1.87795>9-n 0 ? \\
-9.1919>65-004\end{array}$ & $\begin{array}{l}1.07 .1497 R-102 \\
R .07914 K G-103\end{array}$ & $\begin{array}{l}-1.085 ? 350-001 \\
-1 . \text { A3ARO006-001 }\end{array}$ & $\begin{array}{r}1.5656747-n n 1 \\
-7.3074362-n n 2\end{array}$ \\
\hline VIIII & $\begin{array}{l}72 \\
73\end{array}$ & $\begin{array}{r}-1.4174 n G 4-018 ? \\
6.2887233=0 n .3\end{array}$ & $\begin{array}{r}-6 . \cap 74 \cap 4 ? R-0 \cap 7 \\
3.4170007-003\end{array}$ & $\begin{array}{l}5.6854444-\cap 0.3 \\
5.0504747-\cap 04\end{array}$ & 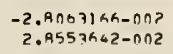 & $\begin{array}{l}-2.4771362-0 n 3 \\
-7.4174 n n 2-0 n ?\end{array}$ & $\begin{array}{l}6.4377171=003 \\
1.1032996-003\end{array}$ \\
\hline IX & $\begin{array}{l}74 \\
75\end{array}$ & $\begin{array}{l}4.6182573-002 \\
4.7004174-002\end{array}$ & $\begin{array}{r}1.5734645-n 0> \\
-2.2405 n 15-00 ?\end{array}$ & $\begin{array}{r}3.1559 R 9 A-\cap 0 ? \\
-1.4974 \cap 33-\cap 02\end{array}$ & $\begin{array}{r}-3.21674 K 9-\cap n ? \\
1 . K 2 ? 45 \cap n-n \cap ?\end{array}$ & $\begin{array}{r}2.1 A 57576-00 ? \\
-1.6 \geqslant\{R 146-002\end{array}$ & $\begin{array}{r}1.034558 n-002 \\
-2.0737849-003\end{array}$ \\
\hline
\end{tabular}

I - Main latifudinal voriation. Mixed latifudinal and longifudinal variatian; I - First order in langilude;

III - Secund order in longifude. ..... IX - Eighth order in langitude.

Notation: Far eoch entry the number given by the first eight digits and sign is mulfiplied by the power of ten defined by the last three digits and sign.

COEFFICIENTS $U_{S K}$ DEFINING THE FUNCTION $\Omega(\lambda, \theta, T)$ FOR MONTHLY MEDIAN foF2 ( $\mathrm{MC} / \mathrm{S})$

MARCH 1958 


\subsection{Calculation of Magnetic Dip I}

To evaluate the geographic functions $G_{k}(\lambda, \theta)$ in Table 7 for given values of $\lambda$ and $\theta$, it is necessary to calculate magnetic dip I, from which we may obtain the modified magnetic dip $x$ defined by (4). We include here for completeness the necessary formulas. Introduce the notation for colatitude, $\varphi=90^{\circ}-\lambda$, and

$$
R=\frac{a}{a+h}
$$

where $a=6371.2 \mathrm{~km}$ is the radius of the earth and $\mathrm{h}$ is height above sea level in kilometers. For F2 layer characteristics the value $\mathrm{h}=300 \mathrm{~km}$ has been used. Thus we compute

$$
I=\operatorname{Tan}^{-1}\left[\frac{-Z}{\sqrt{X^{2}+Y^{2}}}\right]
$$

where $X, Y$, and $Z$ are, respectively, the north, east, and vertical (down)

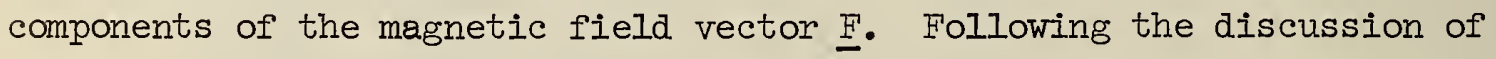
spherical harmonic analysis of the magnetic field by Chapman and Bartels [1962], we have

$$
\begin{aligned}
& X=\sum_{n=1}^{6} \sum_{m=0}^{n} x_{n}^{m}\left[g_{n}^{m} \cos m \theta+h_{n}^{m} \sin m\right] R^{n+2}, \\
& Y=\sum_{n=1}^{6} \sum_{m=0}^{n} y_{n}^{m}\left[g_{n}^{m} \sin m-h_{n}^{m} \cos m \theta R^{n+2},\right. \\
& Z=\sum_{n=1}^{6} \sum_{m=0}^{n} z_{n}^{m}\left[g_{n}^{m} \cos m \theta+h_{n}^{m} \sin m\right] R^{n+2},
\end{aligned}
$$


where

$$
\begin{aligned}
x_{n}^{m} & =\frac{d}{d \varphi} P_{n, m}(\cos \varphi), \\
y_{n}^{m} & =\frac{m P_{n, m}(\cos \varphi)}{\sin \varphi} \\
z_{n}^{m} & =-(n+I) P_{n, m}(\cos \varphi) .
\end{aligned}
$$

Here the function $P_{n, m}(\cos \varphi)$ is a multiple of the associated Iegendre function and is defined by

$$
\begin{gathered}
P_{n, m}(\cos \varphi)=\sin ^{m} \varphi\left[\cos ^{n-m} \varphi-\frac{(n-m)(n-m-1)}{2(2 n-1)} \cos ^{n-m-2} \varphi\right. \\
\left.\quad+\frac{(n-m)(n-m-1)(n-m-3)}{(2)(4)(2 n-1)(2 n-3)} \cos ^{n-m-4} \varphi-\ldots\right]
\end{gathered}
$$

The coefficients $g_{n}^{m}$ and $h_{n}^{m}$ used in the present work are those given by Jensen and Cain [1962] from the analysis of the magnetic field for Epoch 1960. 


\subsection{Fortran Program}

Appendix D contains a FORTRAN program which may be used to evaluate a numerical map $\Omega(\lambda, \theta, T)$ of an ionospheric characteristic such as foF2 median, or to calculate the F2 layer maximum usable frequencies for zero and 4000 kilometers [MUF( $\mathrm{ZERO}) \mathrm{F}_{2}$ and $\mathrm{MUF}(4000) \mathrm{F} 2$ ]. We introduce the following notation:

$$
\begin{array}{ll}
\text { (1) } \lambda \text { geographic latitude, } & -90^{\circ} \leqq \lambda \leqq 90^{\circ}, \\
\text { (2) } \theta=\text { east geographic longitude } & 0^{\circ} \leqq \theta \leqq 360^{\circ}, \\
\text { (3) } h_{l}=\text { hours in local mean time (IMT) } & 0 \leqq h_{l} \leqq 24, \\
\text { (4) } h_{u}=\text { hours in universal time (UT) } & 0 \leqq h_{u} \leqq 24, \\
\text { (5) } T=\text { universal time hour angle, }-180^{\circ} \leqq T \leqq 180^{\circ}, \\
T=15 h_{u}-180=15 h_{l}+180-\theta \\
\text { (6) } \mathrm{B}=\text { intensity of magnetic field, } \\
\text { (7) } \mathrm{f}_{\mathrm{H}}=\text { gyrofrequency }
\end{array}
$$

The following three examples are given for the use of the FORTRAN program.

Example I. Compute foF2 median (or any other ionospheric characteristic) for a fixed instant $h_{u}$ of universal time at several geographic points $(\lambda, \theta)$. 1

(a) Compute $\mathrm{T}_{0}=15 \mathrm{~h}_{\mathrm{u}}-180$.

(b) Evaluate cos $j T_{0}$ and $\sin j T_{0}, j=1,2, \ldots, H$.

(c) Compute $D_{k}\left(T_{0}\right)=U_{0, k}+\sum_{j=1}^{H}\left[U_{2 j, k} \cos j T_{0}+U_{2 j-1, k} \sin j T_{0}\right]$, $\mathrm{k}=0, \mathrm{l}, \ldots, \mathrm{K}$, (where the $\mathrm{U}_{\mathrm{s}, \mathrm{k}}$ are given either by a table such as Table 8 or on cards or tape.

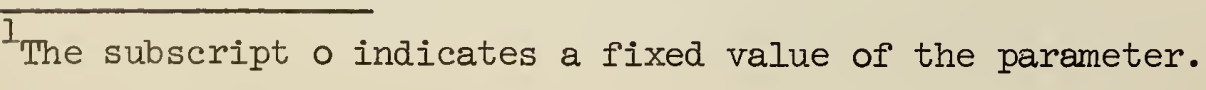


(d) Compute magnetic field components $X, Y, Z$ for the given point $(\lambda, \theta)$ and height $=300 \mathrm{~km}$

(Use Subroutine MAGFIN in program SAMPLE.),

$$
\begin{aligned}
& I=\operatorname{Tan}^{-I}\left(-Z / \sqrt{X^{2}+Y^{2}}\right), \\
& \sin x=I / \sqrt{I^{2}+\cos \lambda} \cdot
\end{aligned}
$$

(e) Evaluate $G_{k}(\lambda, \theta) \quad k=0, I, \ldots, K$.

(f) Compute $\Omega_{f}\left(\lambda, \theta, T_{0}\right)=\sum_{k=0}^{K} D_{k}\left(T_{0}\right) G_{k}(\lambda, \theta)$.

Repeat steps $d$, e, $f$ for each given point $(\lambda, \theta)$; steps $a, b, c$ need not be repeated if $T_{0}$ remains fixed. Here $\Omega_{f}$ is used to denote the numerical map value of foF2 median (Mc/s). Similarly $\Omega_{m}$ will be used later to denote the map value of the characteristic $M(3000) F 2$ median.

Example II. Compute MUF(ZERO)F2 at a fixed geographic point $\left(\lambda_{0}, \theta_{0}\right)$ for several instants $h_{u}$ of universal time.

(a) Compute $X, Y, Z, I$ and $\sin x$ for the fixed point $\left(\lambda_{0}, \theta_{0}\right)$ and height $=300 \mathrm{~km}$ as in Example I, step (d).

(b) Compute $B=\sqrt{X^{2}+Y^{2}+Z^{2}}$ and $f_{H}=2.8 B$.

(c) Evaluate $G_{k}\left(\lambda_{0}, \theta_{0}\right), k=0, I, \ldots, K$ (for map of foF2 median).

(d) Compute $a_{j}\left(\lambda_{0}, \theta_{0}\right)=\sum_{k=0}^{K} U_{2 j, k} G_{k}\left(\lambda_{\circ}, \theta_{0}\right), j=0,1, \ldots, H$,

$$
b_{j}\left(\lambda_{0}, \theta_{0}\right)=\sum U_{2 j-I, k} G_{k}\left(\lambda_{0}, \theta_{0}\right), j=1,2, \ldots, H,
$$
using coefficients $U_{s, k}$ for map of foF2 median. 
(e) Compute $T=15 h_{u}-180$.

(f) Evaluate cos $j T$ and $\sin j T, \quad j=1,2, \ldots, H$.

(g) Compute $\Omega_{f}\left(\lambda_{o}, \theta_{0}, T\right)=a_{o}\left(\lambda_{o}, \theta_{0}\right)+\sum_{j=1}^{H}\left[a_{j}\left(\lambda_{o}, \theta_{0}\right) \cos j T\right.$ $\left.+b_{j}\left(\lambda_{0}, \theta_{0}\right) \sin j T\right]$.

(h) $\operatorname{MUF}\left(\right.$ ZERO)F2 $=\Omega_{\mathrm{f}}+f_{\mathrm{H}} / 2$.

For each $\mathrm{T}$ repeat steps $\mathrm{e}-\mathrm{h}$; steps a - d need not be repeated if $\left(\lambda_{0}, \theta_{0}\right)$ remains fixed.

Example III. Compute MUF( 4000$)$ F2 for a given point $\left(\lambda_{0}, \theta_{0}\right)$ for several instants $h_{\ell}$ of local mean time.

(a) Compute $X, Y, Z, I$ and $\sin x$ for the fixed point $\left(\lambda_{0}, \theta_{0}\right)$ and height $=300 \mathrm{~km}$ as in Example I, step (d).

(b) 1. Evaluate $G_{k}\left(\lambda_{0}, \theta_{0}\right), a_{j}\left(\lambda_{0}, \theta_{0}\right), b_{j}\left(\lambda_{0}, \theta_{0}\right)$ as in Example II, steps (c) and (d) for map of foF2 median.

2. Evaluate $G_{k}\left(\lambda_{0}, \theta_{0}\right), a_{j}\left(\lambda_{0}, \theta_{0}\right), b_{j}\left(\lambda_{0}, \theta_{0}\right)$ as in Example II, steps (c) and (d) for map of $M(3000) F 2$ median.

(c) Compute $\mathrm{T}=15 \mathrm{~h} l+180-\theta_{0}$.

(d) Evaluate cos $j \mathrm{~T}$ and $\sin j \mathrm{~T}, j=1,2, \ldots, \mathrm{H}$,

where $\mathrm{H}$ is the maximum number of harmonics used for either of the characteristics foF2 and $M(3000) F 2$ median.

(e) Compute $\Omega_{f}\left(\lambda_{o}, \theta_{o}, T\right)$ and $\Omega_{m}\left(\lambda_{o}, \theta_{o}, T\right)$ as in Example II, $\operatorname{step}(g)$.

(f) $\mathrm{MUF}(4000) \mathrm{F2}=1.1 \Omega_{\mathrm{f}} \Omega_{\mathrm{m}}$.

Repeat steps (c) - ( $f$ ) for each instant of local mean time $h_{l}$; steps (a) and $(b)$ need not be repeated if $\lambda_{0}, \theta_{0}$ remain fixed. 
Sample Program

A sample program has been reproduced here to illustrate the examples of the previous section. This program was written in "Fortran 3600" for the CDC 3600. Program "SAMPLE" illustrates only a few of the possible applications of numerical maps.

The card deck set-up is pictured in Figure 10. Header card 1 is designed to give the following options:

Card Column

Purpose

$1=0$ prints diurnal curve of desired characteristic for each geographic point (example 2, 3)

f O fixed time, compute desired characteristic for each geographic point.

2 = I variable characteristic is computed (for example, if the coefficients read in represent foF2, foF2 is printed out)

$=2 \mathrm{MUF}(\mathrm{ZERO}) \mathrm{F} 2$ is computed

$=3 \mathrm{MUF}(4000) \mathrm{F} 2$ is computed

$3=0$ in Universal time (in hours)

$\neq 0$ Local mean time (in hours)

$4-6=$ number of geographic points punched in header cards $2,3, \ldots$

$7,8=$ number of fixed times (if ce $1 \neq 0$ )

$9-11$ = fixed time in format XX.X (if cc $8=1$ )

$12-14=$ fixed time in format XX.X (if cc $8=2$ )

$78-80=$ fixed time in format XX.X (if cc $7,8=24$ ) 


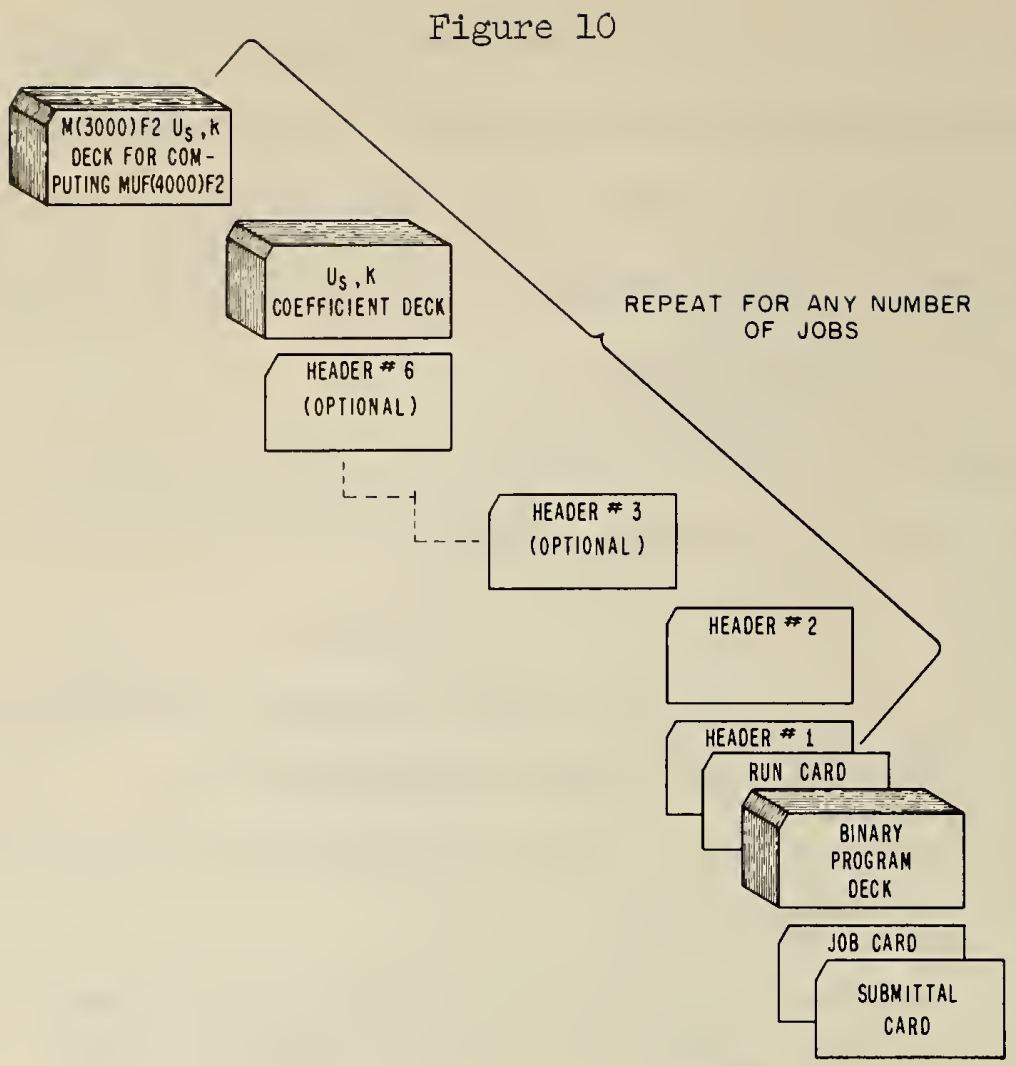

Header card number 2 is as follows:

Card Column

Purpose

$1-4$ geographic latitude of first point in format $\pm \mathrm{XX} . \mathrm{X}$

$5-8$ east geographic longitude of first point in format XXX.X

$11-14$ latitude of 2nd point

$15-18 \quad$ longitude of 2nd point

$73-76 \quad$ latitude of 20th point

77 - 80 longitude of 20 th point

If more than 20 points, punch header card number 3, 4, etc. in the same manner. 
A sample printout, corresponding to Example II, is shown in Table 9. Coefficients used were shown in Table 8.

\section{Table 9}

Sample Computer Printout of MUF(ZERO)F2

\begin{tabular}{|c|c|c|c|c|c|c|c|c|c|}
\hline CARD & COLUMNS & $1 \cdot 2 \cdot 3=$ & ? & DA $-1-3-1$ & TE $580: 3$ & CHARA & :RISTI & & 501 \\
\hline$U_{0} T_{\bullet}=$ & 0.0 & LATITUJDE & 86.4 & EAST & LONG I TUDE & 296.6 & OMEGA & $=$ & 6.6 \\
\hline$U_{0} T_{0}=$ & 0.0 & LATITUDE & 76.6 & EAST & LONG I TUDE & 291.3 & OMEGA & $=$ & 6.9 \\
\hline & 0.0 & LAT I TUUDE & 41.8 & EAST & LONG I TUDE & 12.5 & OMEGA & $=$ & 7.6 \\
\hline & 0.0 & LAT I TUDE - & & EAST & LONG I TUDE & 301.5 & OMEGA & - & 15.5 \\
\hline & 6.0 & LATI I TUDE & 86.4 & EAST & LONG I TUDE & 296.6 & OMEGA & $=$ & 7.0 \\
\hline & 6.0 & LATI IUDE & 76.6 & EAST & LONG I TUDE & 291.3 & OMEGA & 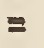 & 6.7 \\
\hline & 6.0 & LATITUDE & 41.8 & EAST & LONGI TUDE & 12.5 & OMEGA & & 8.8 \\
\hline & 6.0 & LAT I TUDDE- & -34.5 & FAST & LONG I TUDE & 301 & OMEGA & $=$ & 12.4 \\
\hline & $1 ? .0$ & LAT I TUDE & 86.4 & EAST & LONG I TUDE & 296.6 & OMEGA & & 7.2 \\
\hline & 12.0 & LATITUDE & 76.6 & EAST & LONG I TIJDE & 291.3 & OMEGA & $=$ & 6.9 \\
\hline & $1 ? .0$ & LAT I TUJDE & 41.8 & FAST & LONG I TIJDE & 12.5 & OMEGA & & 14.6 \\
\hline & 12.0 & LATITUDE- & $-34 . t$ & EAST & LONG I TUDE & 301. & OMEGA & & 13.0 \\
\hline & 18.0 & LATITIJDE & 86.4 & EAST & LONG I TUDDE & 296.6 & OMEGA & $=$ & 6.8 \\
\hline & 18.0 & LATITUUE & 76.6 & EAST & LONG I TUDE & 291.3 & OMEGA & & 7.2 \\
\hline & & $10 T T T O D F$ & & & LONG I TUDDE & & & & \\
\hline & & $m+1+1$ & & EAST & LONG I TUDE & 301.5 & OMEGA & & \\
\hline
\end{tabular}


Appleton, E.V. (1946), Nature, vol. 157, p. 691.

Bailey, D.K. (1948), Terr. Mag. and Atmos. Elect., vol 53, No. 1, 35-39. Chapman, S. and Bartels, J., (1962), Geomagnetism, vol II, oxford at the Clarendon Press.

Davies, K. (1965), "Ionospheric radio Propagation," National Bureau of Standards Monograph 80 (Chap. 7).

GHQ United States Army Forces, Office of the Chief Signal Officer, Pacific, Tokyo (May 1946), "Report on Japanese research on radio wave propagation."

Haydon, G.W. and Iucas, D.I., "Theoretical considerations in the selection of optimum frequencies for high frequency sky-wave communication services," (to be published).

Hinds, M. and Jones, W.B. (July 1963), "Computer program for ionospheric mapping by numerical methods, "NBS Tech. Note 181.

ITSA Ionospheric Predictions, issued monthly 3 months in advance, U.S. Government Printing Office, Washington, D.C., 20402.

Jensen, D.C. and Cain, J.C. (August 1962), "Interim geomagnetic field," J. Geoph. Res., No. 9, 3568-3569.

Jones, W.B. (April 1962), "Atlas of Fourier coefficients of diumal variations of foF2," NBS Tech Note 142.

Jones, W.B. and Gallet, R.M. (Dec. 1960), "Ionospheric Mapping by numerical methods," IIU Telecomm. Journal No. 12, 260-264.

Jones, W.B. and Gallet, R.M. (May 1962a), "Representation of diurnal and geographic variations of ionospheric data by numerical methods," IIU Telecomm. Journal 29, No. 5, 129-149; also published (JulyAugust 1962) Journal of Research NBS 66D (Radio Propagation), No. 4, 419-438.

Jones, W.B. and Gallet, R.M. (Nov.-Dec. 1962b), "Methods for applying numerical maps of ionospheric characteristics, "Journal of Research NBS 66D (Radio Propagation), No. 6, 649-662.

Jones, W.B. and Gallet, R.M. (Jan. 1965a), "Representation of diumal and geographic variations of ionospheric data by numerical methods, II. Control of instability," IIU Telecorm. Journal 32, No. 1, 18-28. 
Jones, W.B. and Gallet, R.M. (Feb. 1965b), "Atlas of Fourier coefficients of diumal variation of foF2. Part II. Distribution of amplitude and phase," NBS Tech Note 305.

Lucas, D.I., Haydon, G.W., et al, "Predicting statistical performance indexes for high frequency ionospheric telecommunication systems," (to be published). 
Appendix A

Fourier Coefficients

for

foF2 Monthly Median 
Figure A - I

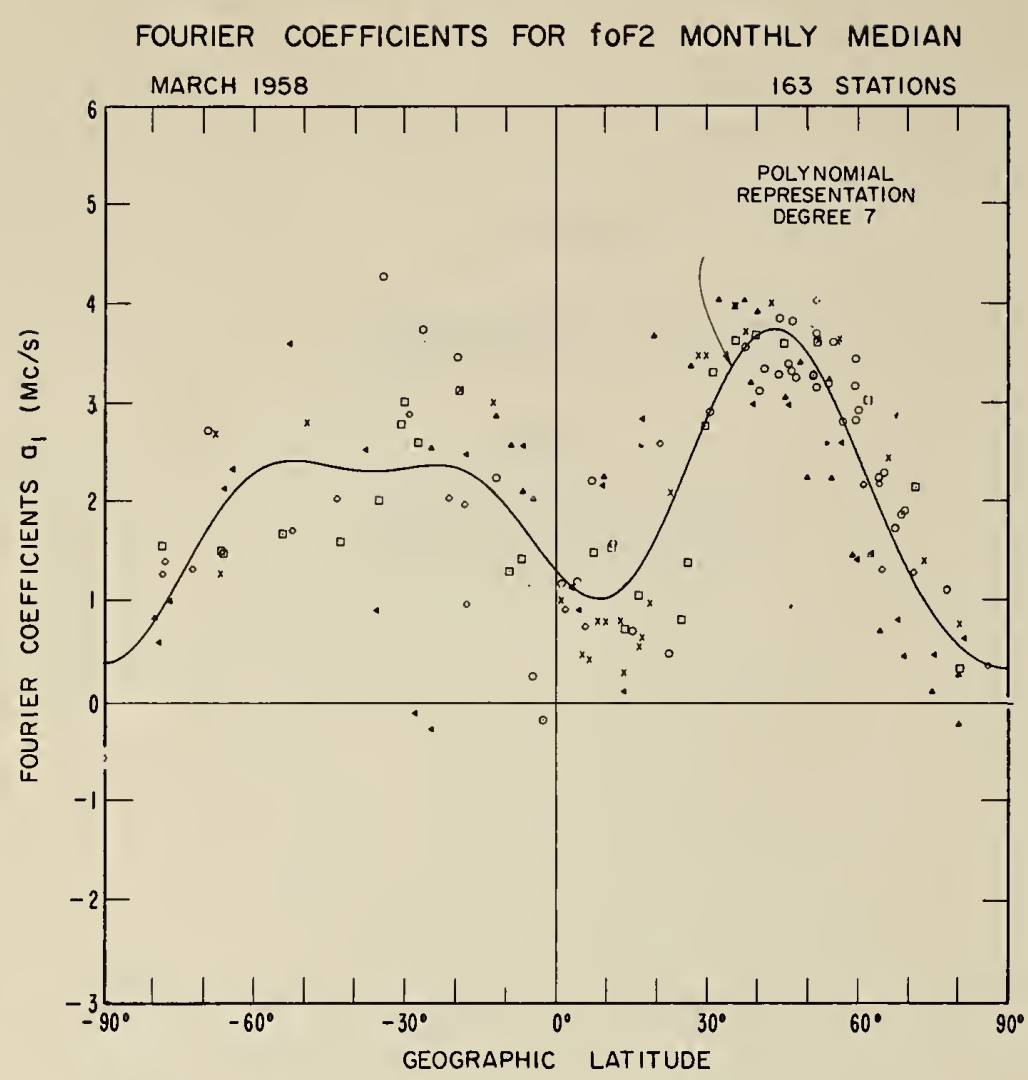

$a_{1}$

LONGITUDINAL CODE $0345^{\circ} E-45^{\circ} E$

$\times 45^{\circ} \mathrm{E}-105^{\circ} \mathrm{E}$

- $105^{\circ} \mathrm{E}-165^{\circ} \mathrm{E}$

- 165० E-225 E

$\triangle 225^{\circ} \mathrm{E}-285^{\circ} \mathrm{E}$

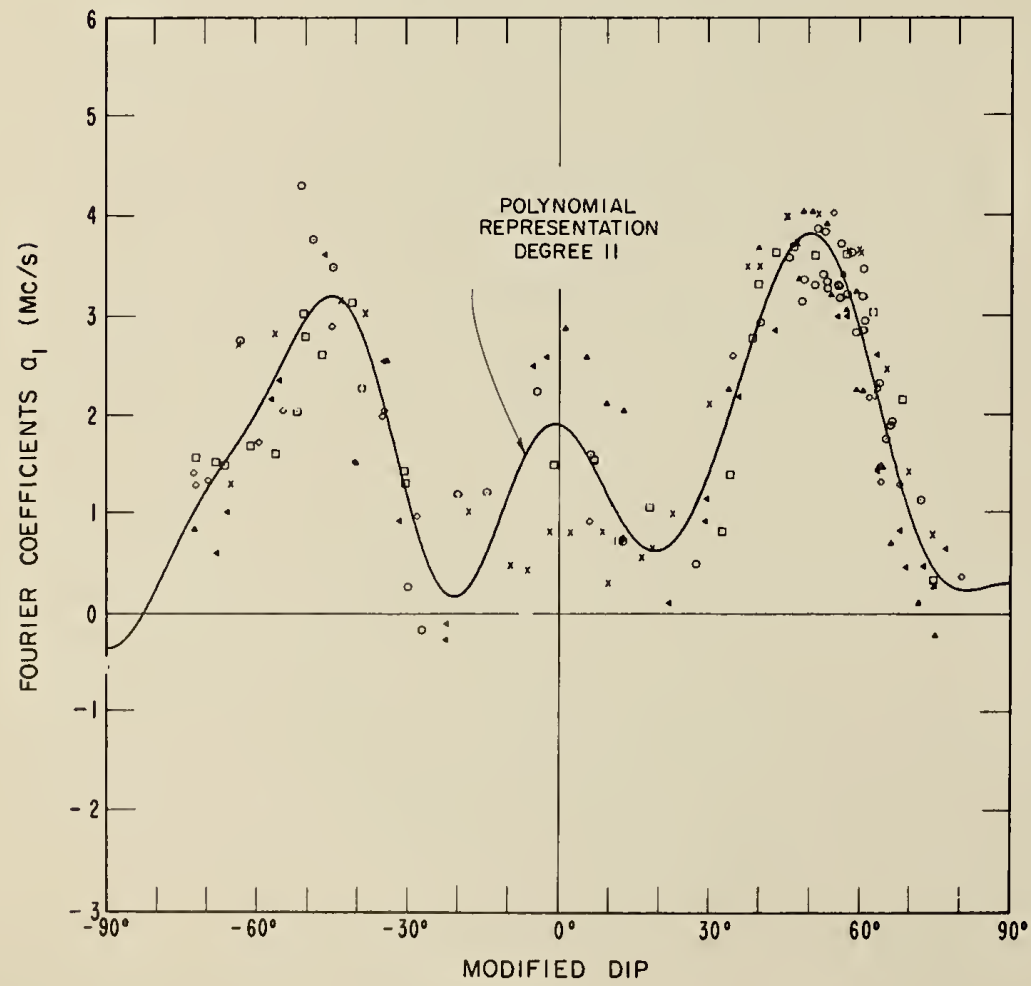

$\triangle 285^{\circ} \mathrm{E}-345^{\circ} \mathrm{E}$ 
Figure A - 2

FOURIER COEFFICIENTS FOR fOF2 MONTHLY MEDIANS

$b_{1}$

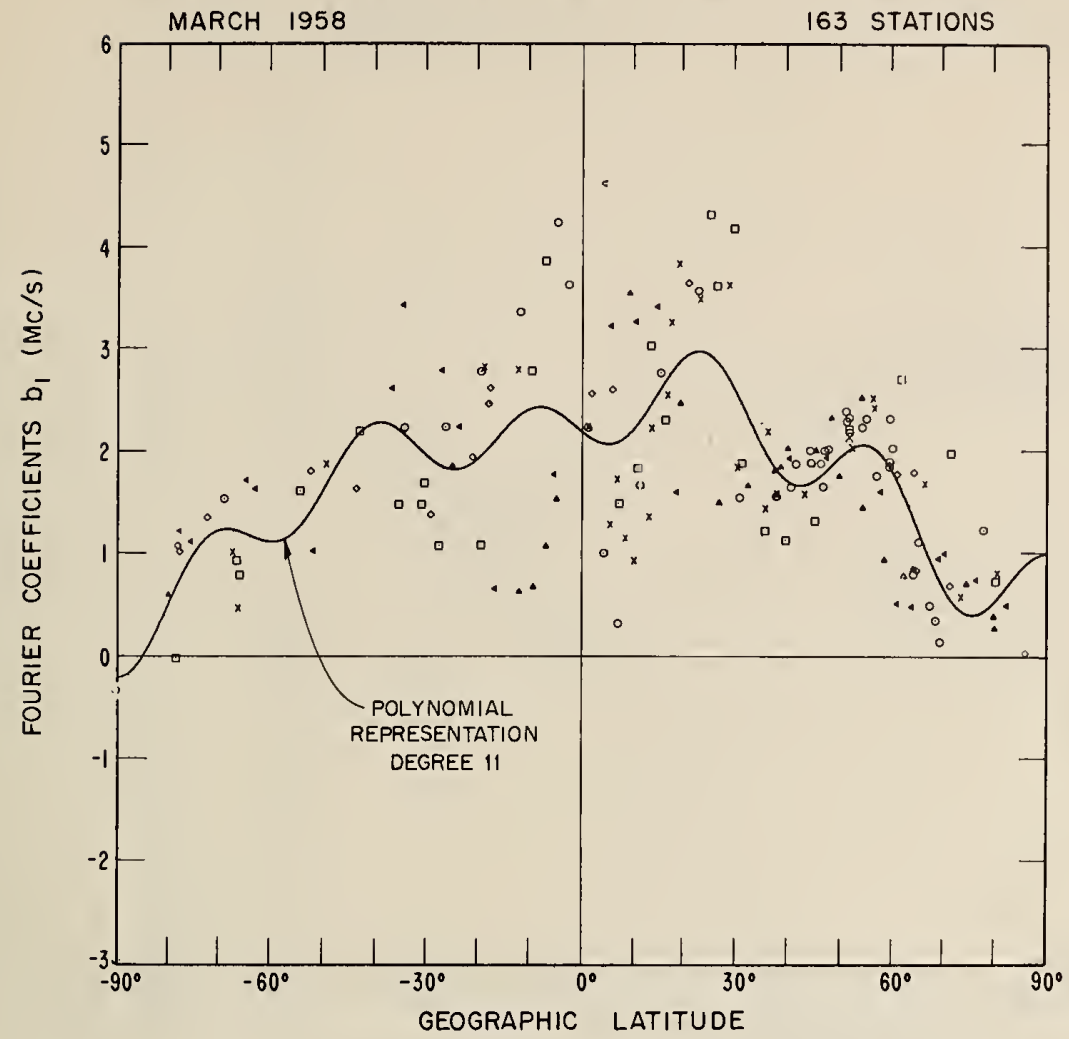

LONGITUDINAL CODE

- $345^{\circ} E-45^{\circ} E$

×. $45^{\circ} \mathrm{E}-105^{\circ} \mathrm{E}$

- $105^{\circ} \mathrm{E}-165^{\circ} \mathrm{E}$

$\circ 165^{\circ} \mathrm{E}-225^{\circ} \mathrm{E}$

$\triangle 225^{\circ} \mathrm{E}-285^{\circ} \mathrm{E}$

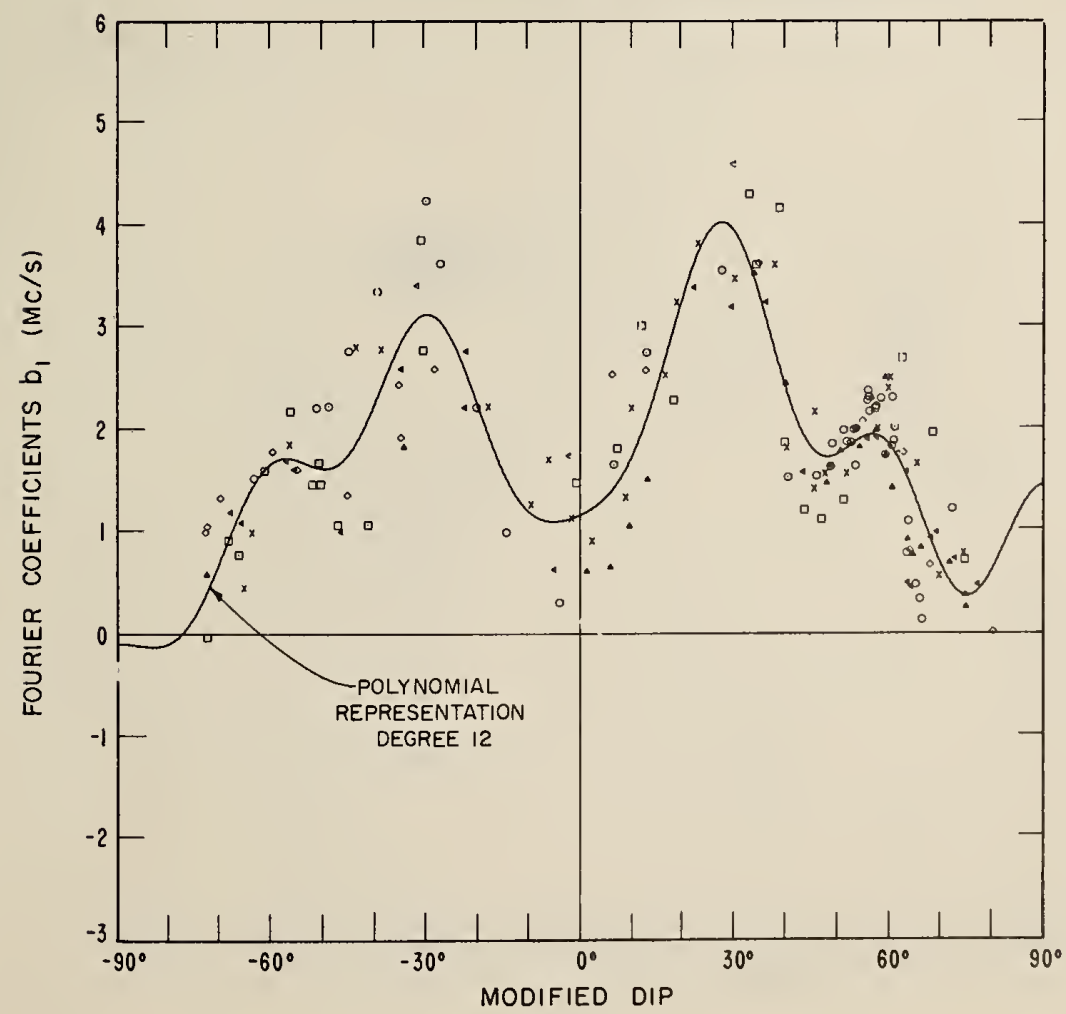

$\triangle 285^{\circ} \mathrm{E}-345^{\circ} \mathrm{E}$ 
Figure A - 3

FOURIER COEFFICIENTS FOR FOF2 MONTHLY MEDIANS MARCH 1958

163 STATIONS
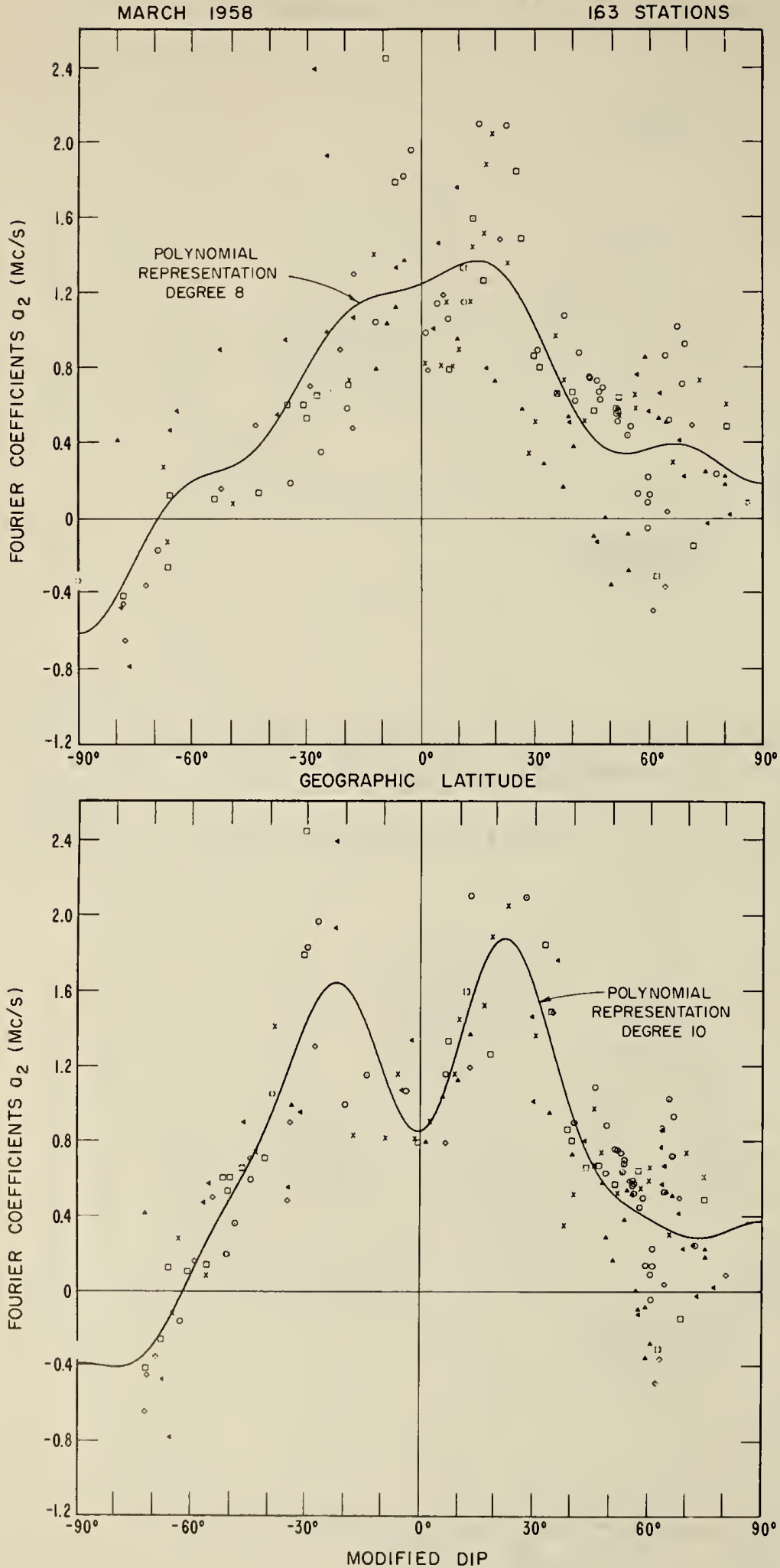

LONGITUDINAL 
Figure A - 4

FOURIER COEFFICIENTS FOR fOF2 MONTHLY MEDIANS
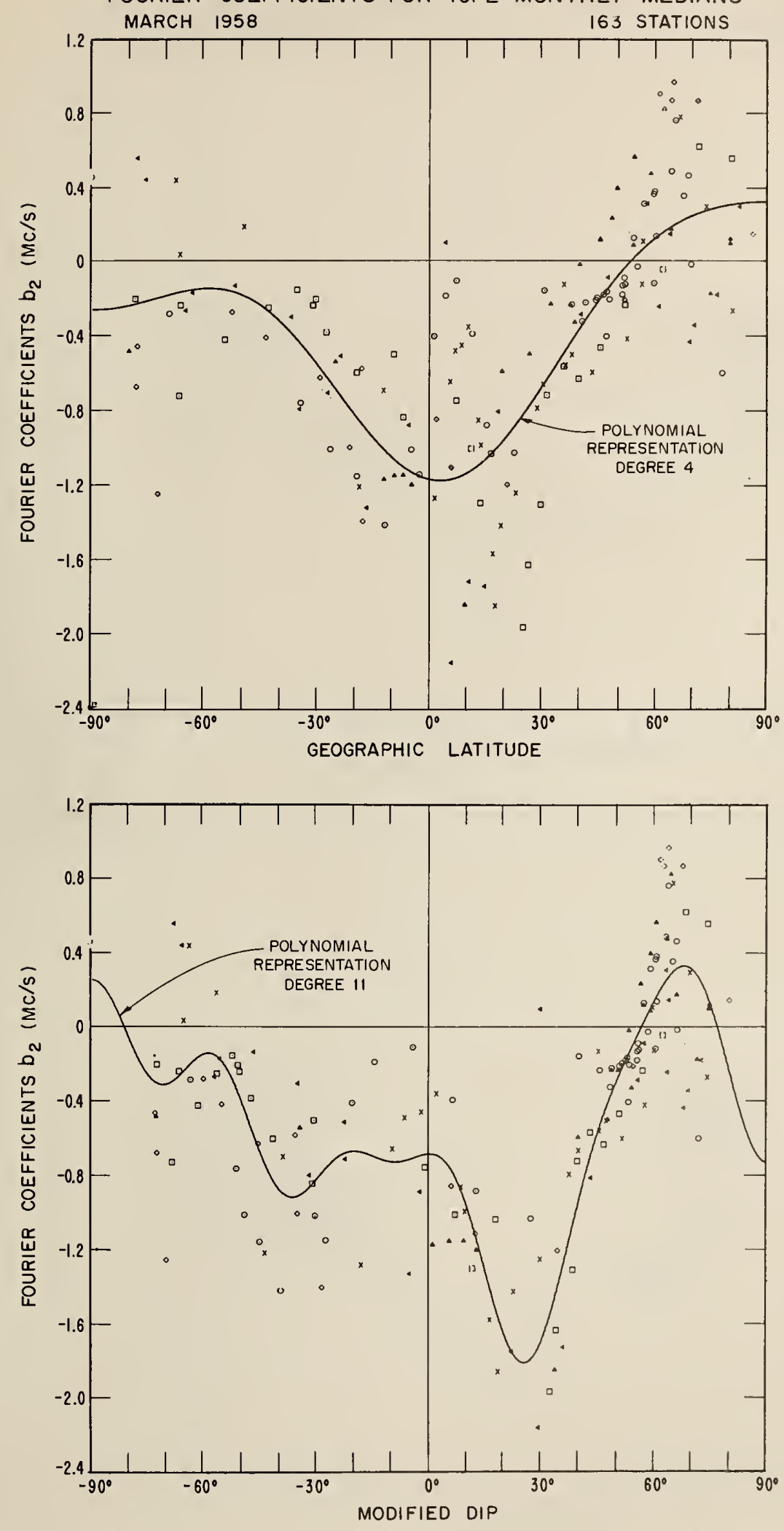

$\mathrm{b}_{2}$

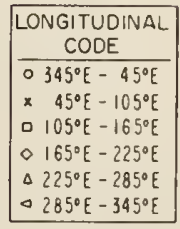


Figure A - 5

FOURIER COEFFICIENTS FOR FOF2 MONTHLY MEDIANS

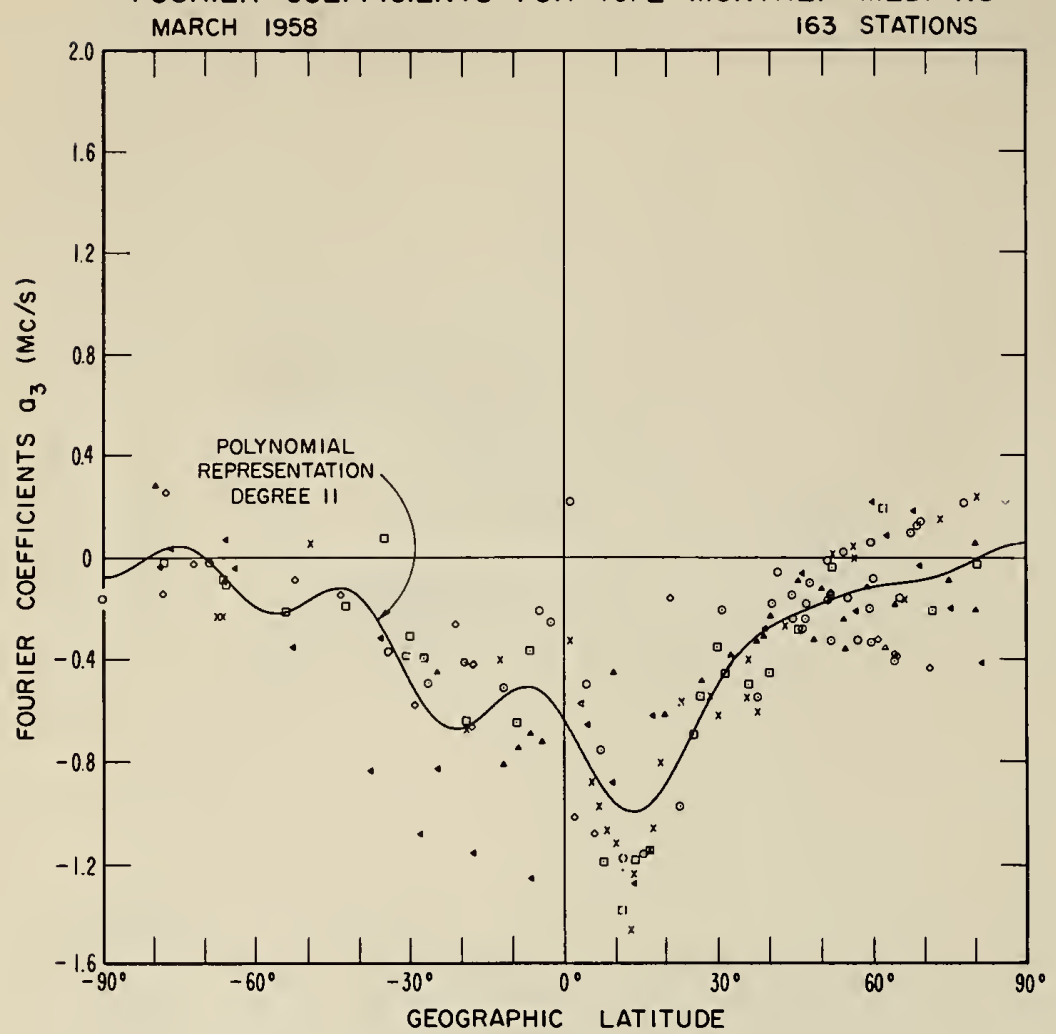

LONGITUDINAL

CODE

- $345^{\circ} \mathrm{E}-45^{\circ} \mathrm{E}$

$\times \quad 45^{\circ} \mathrm{E}-105^{\circ} \mathrm{E}$

- $105^{\circ} \mathrm{E}-165^{\circ} \mathrm{E}$

- $165^{\circ} \mathrm{E}-225^{\circ} \mathrm{E}$
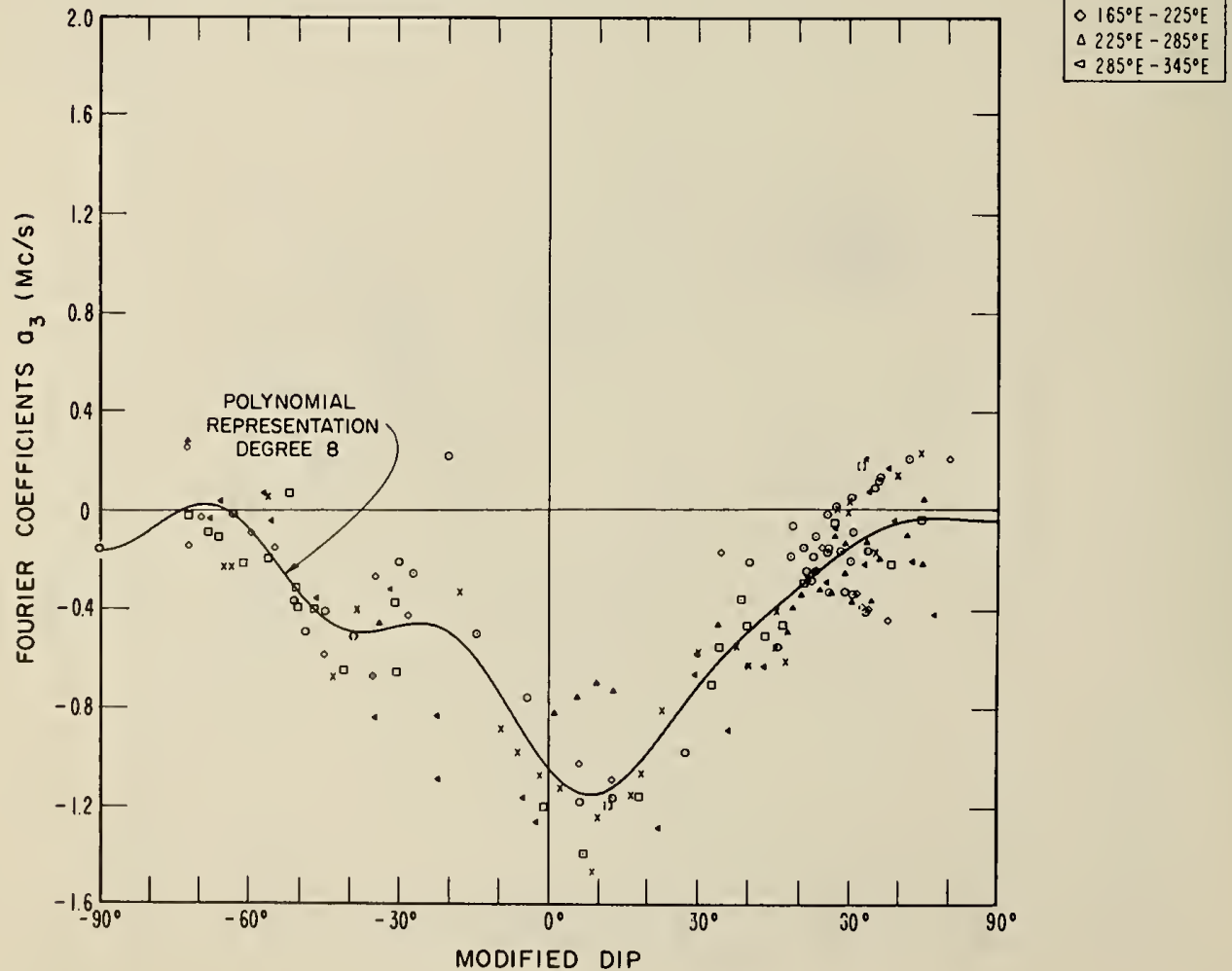
Figure A - 6

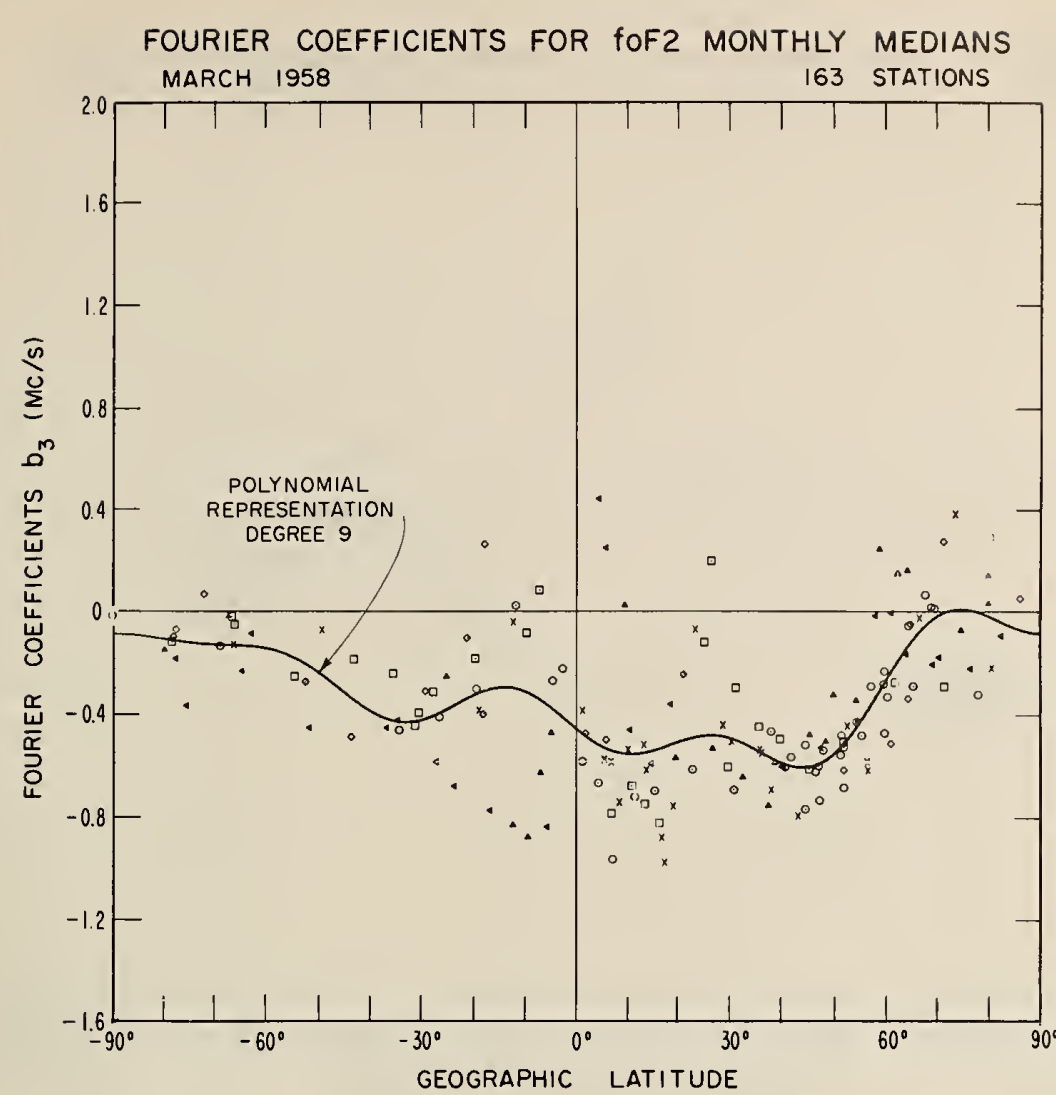

$b_{3}$

LONGI TUDINAL CODE

- $345^{\circ} E-45^{\circ} \mathrm{E}$

$\times 45^{\circ} \mathrm{E}-105^{\circ} \mathrm{E}$

- $105^{\circ} \mathrm{E}-165^{\circ} \mathrm{E}$

- $165^{\circ} \mathrm{E}-225^{\circ} \mathrm{E}$

$\triangle 225^{\circ} \mathrm{E}-285^{\circ} \mathrm{E}$

- $285^{\circ} \mathrm{E}-345^{\circ} \mathrm{E}$

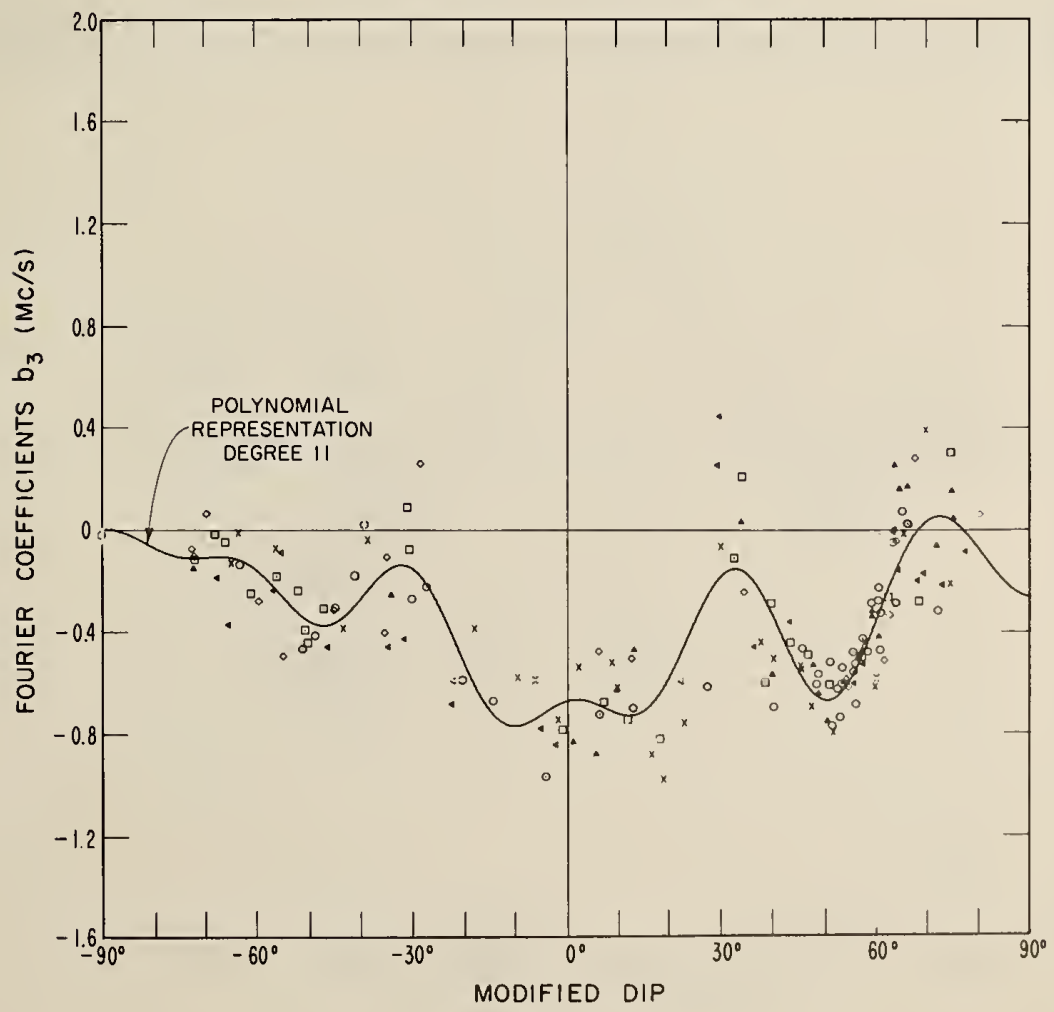


Figure A - 7

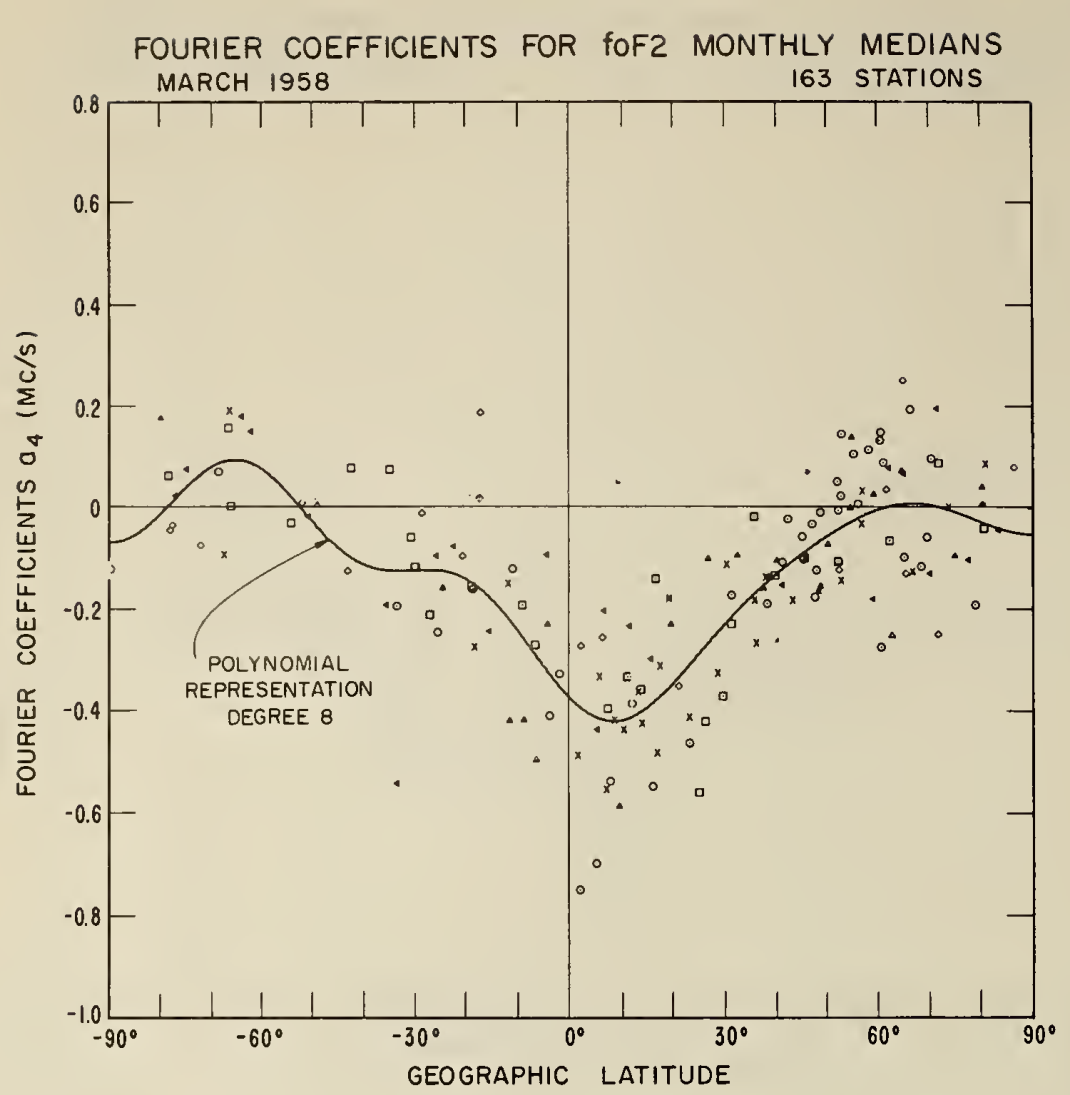

$a_{4}$

LONGITUDINAL

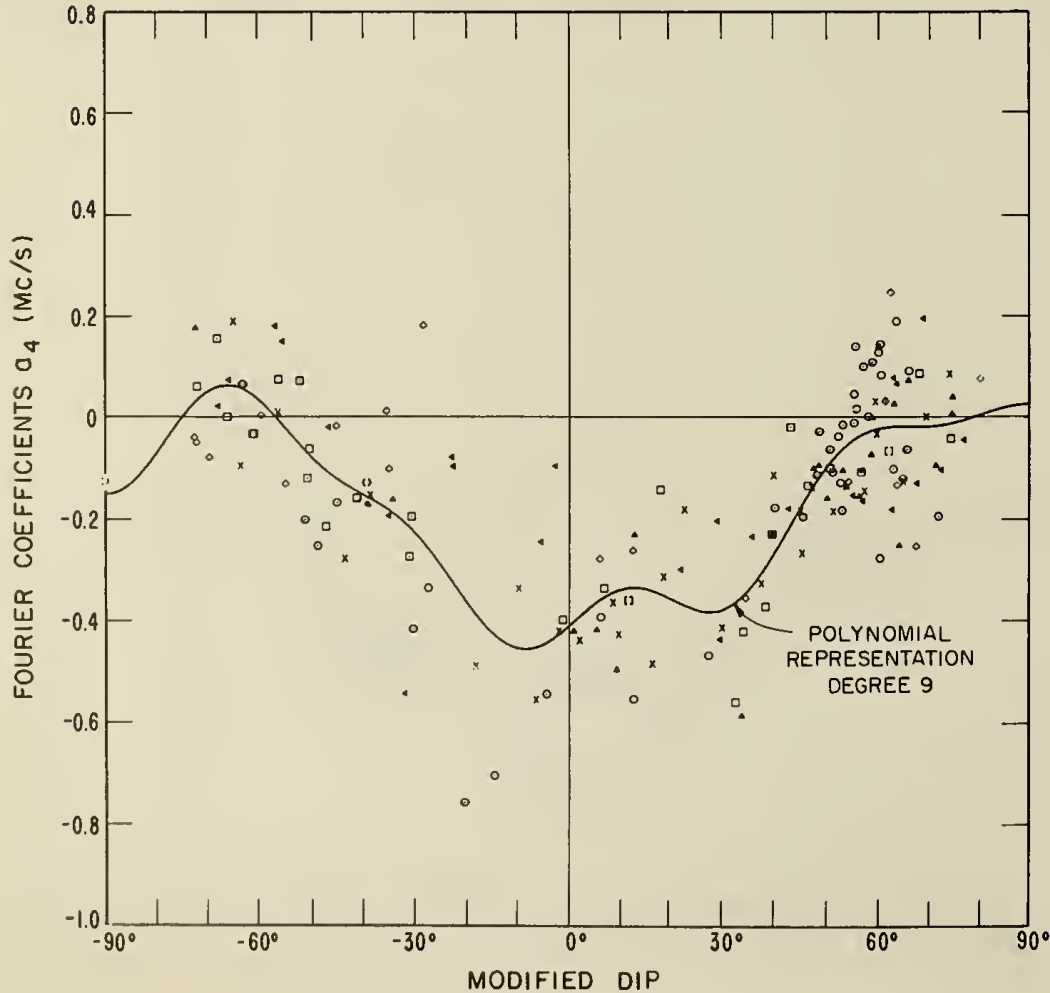

- $285^{\circ} \mathrm{E}-345^{\circ} \mathrm{E}$ 
Figure A - 8
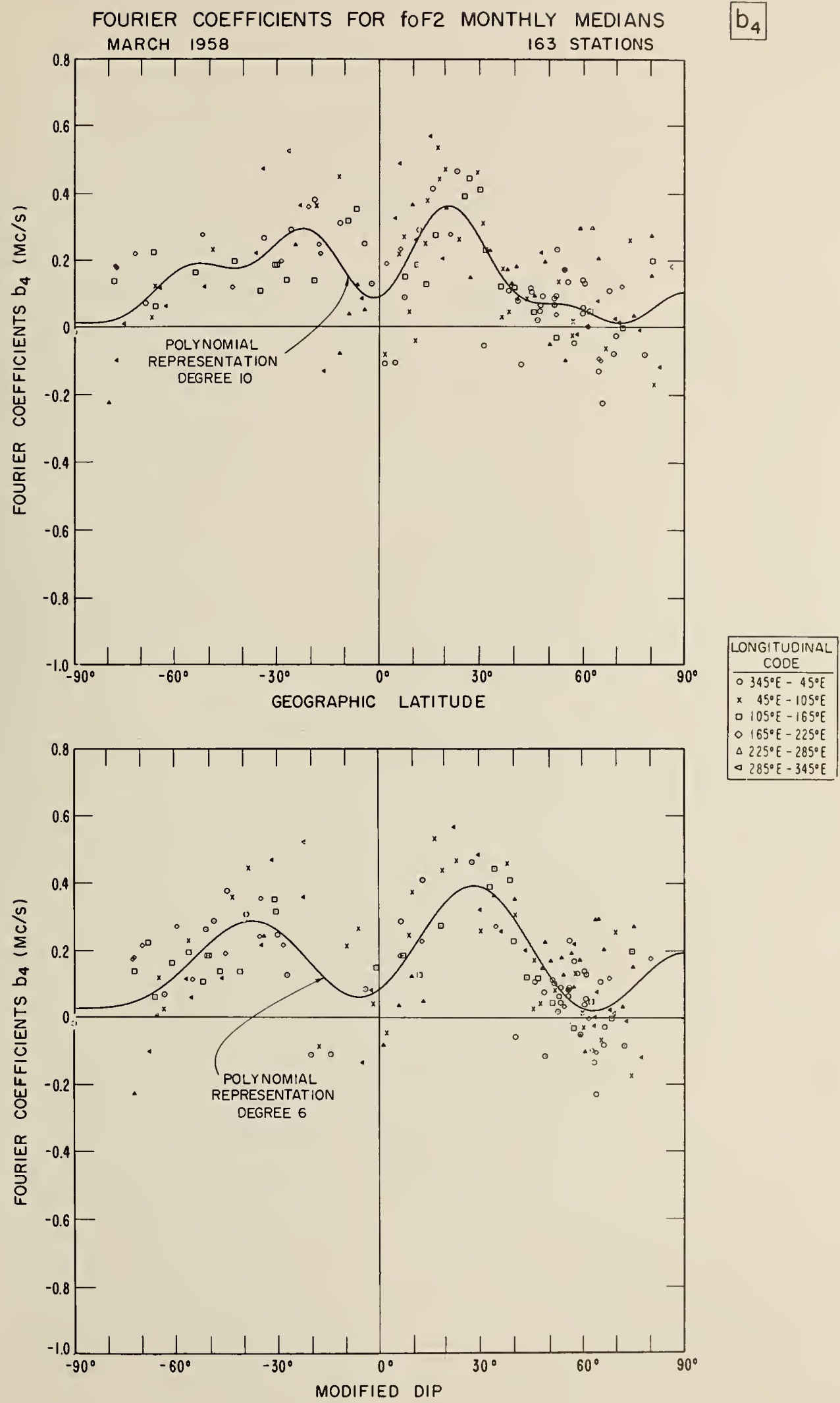

Appendix $B$

Contour Maps

of

Orthonormal Functions

$-57-$ 
Figure B - 1

CONTOUR MAP OF ORTHONORMAL FUNCTION $F_{1}(\lambda, \theta)$

(HIGHEST ORDER TERM $\sin x$ )

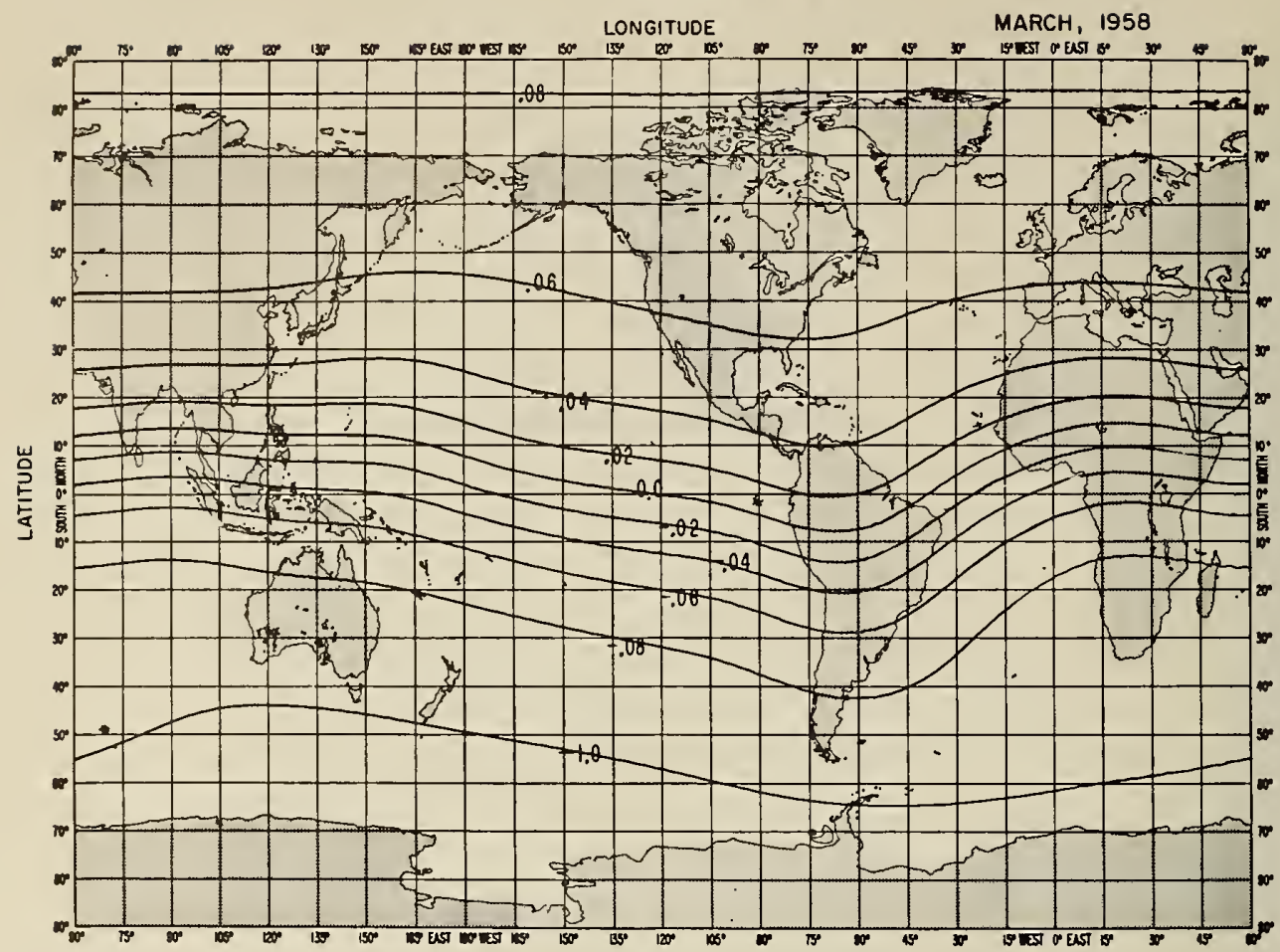

CONTOUR MAP OF ORTHONORMAL FUNCTION $F_{2}(\lambda, \theta)$

(HIGHEST ORDER TERM $\sin ^{2} x$ )

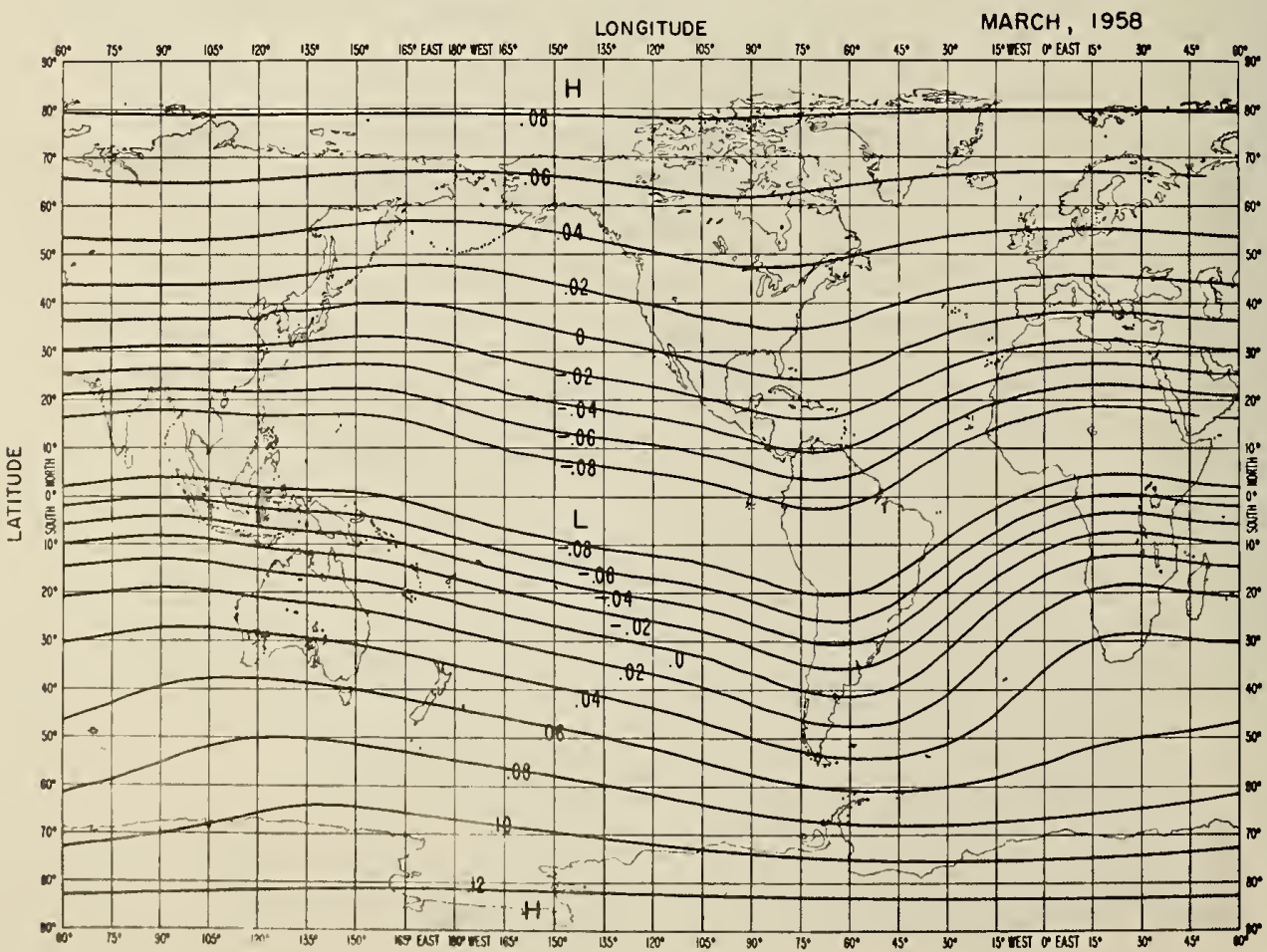


Figure B - 2

CONTOUR MAP OF ORTHONORMAL FUNCTION $F_{4}(\lambda, \theta)$

(HIGHEST ORDER TERM $\sin ^{4} x$ )

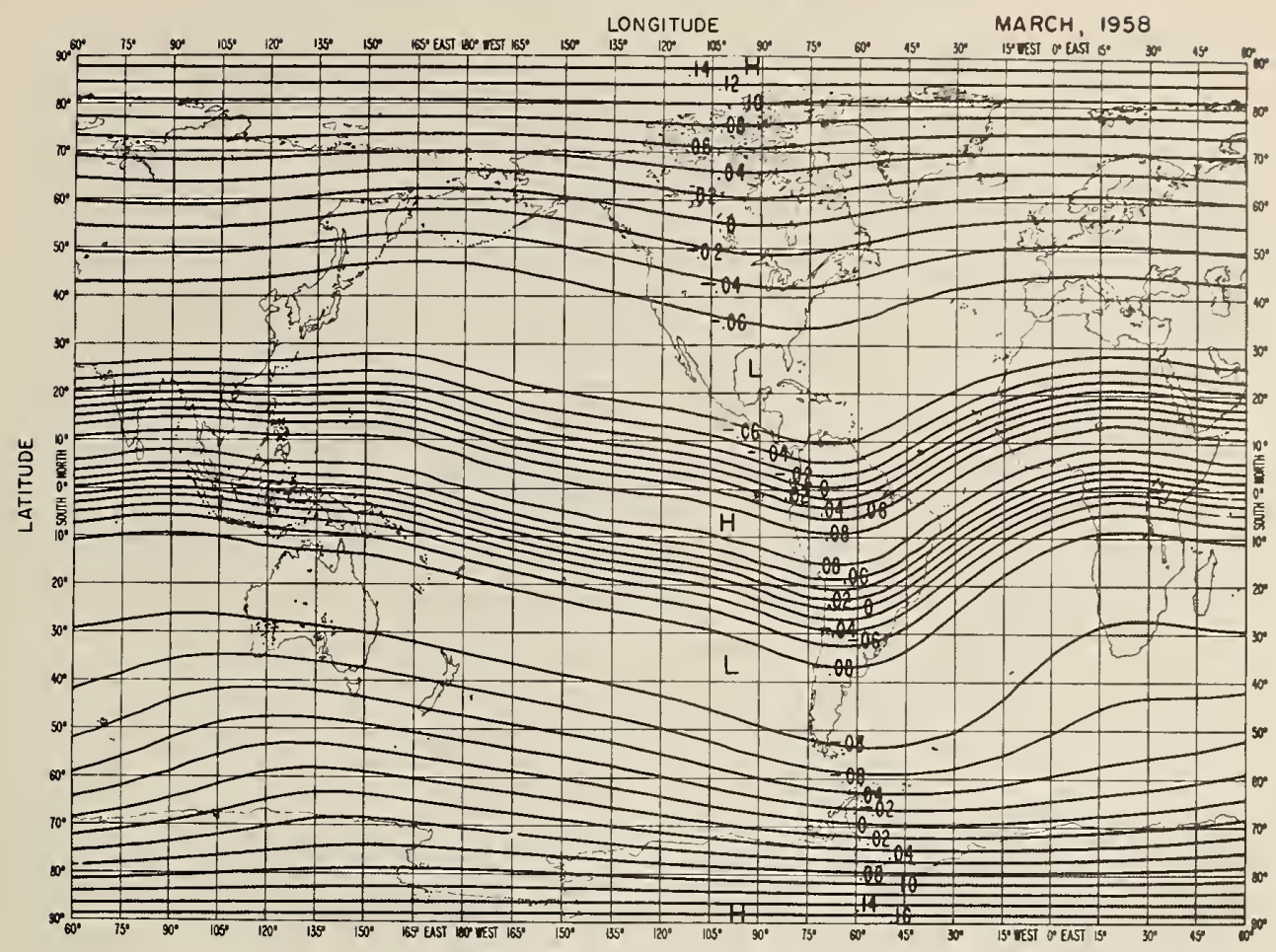

CONTOUR MAP OF ORTHONORMAL FUNCTION $F_{5}(\lambda, \theta)$ (HIGHEST ORDER TERM $\sin ^{5} x$ )

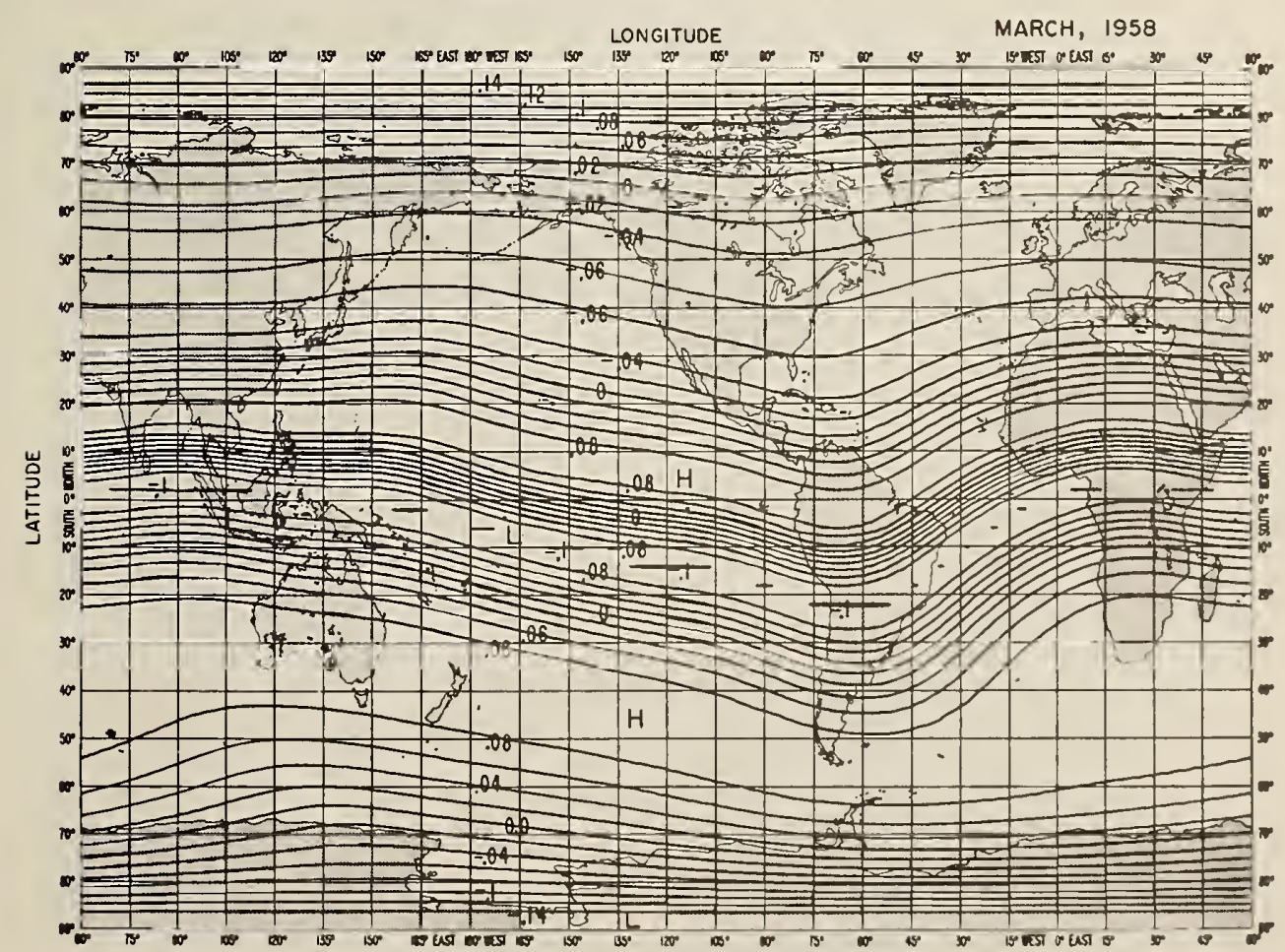


Figure B - 3

CONTOUR MAP OF ORTHONORMAL FUNCTION $F_{12}(\lambda, \theta)$

(HIGHEST ORDER TERM $\cos \lambda \cos \theta$ )

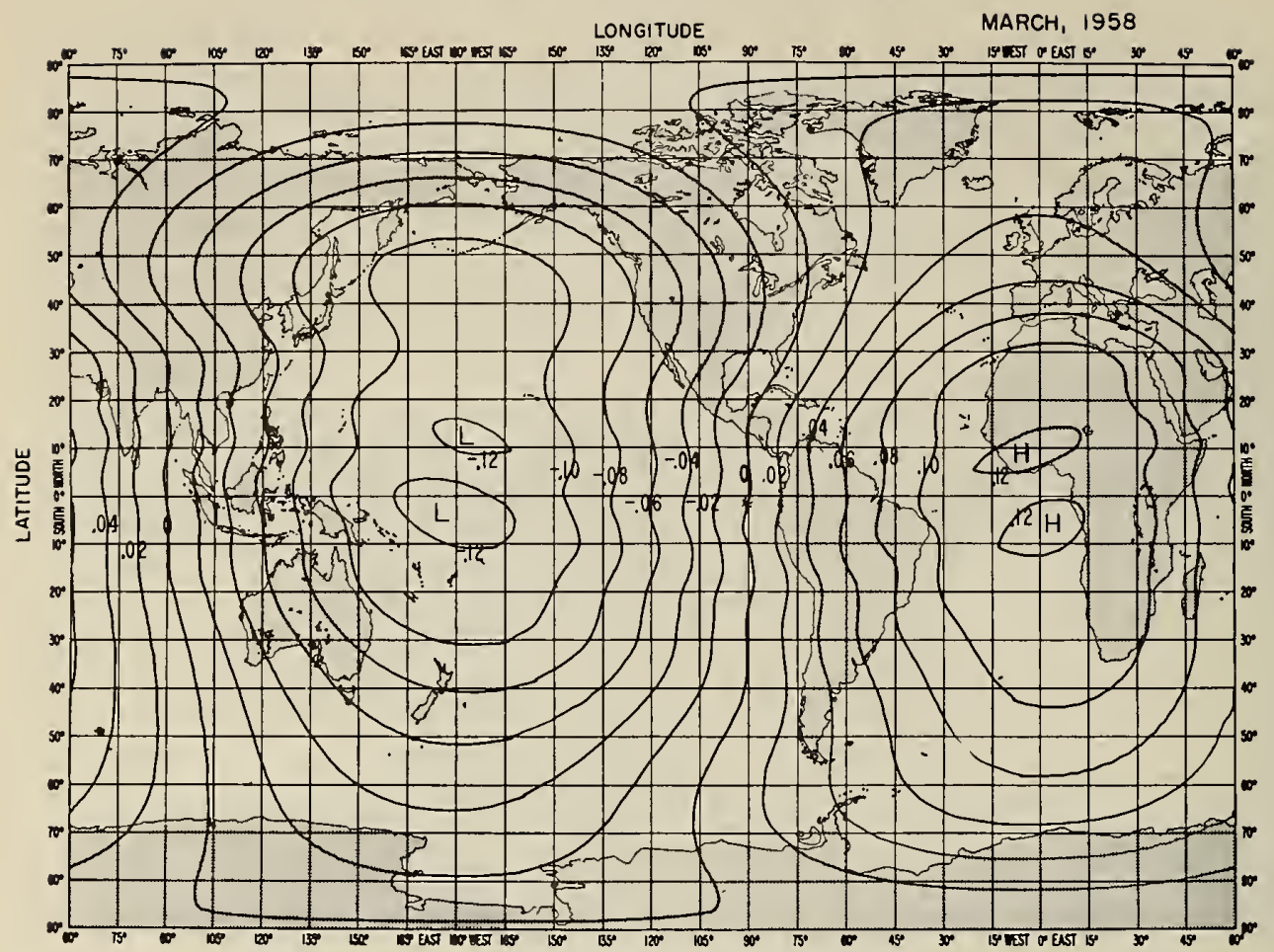

CONTOUR MAP OF ORTHONORMAL FUNCTION $F_{13}(\lambda, \theta)$

(HIGHEST ORDER TERM $\cos \lambda \sin \theta$ )

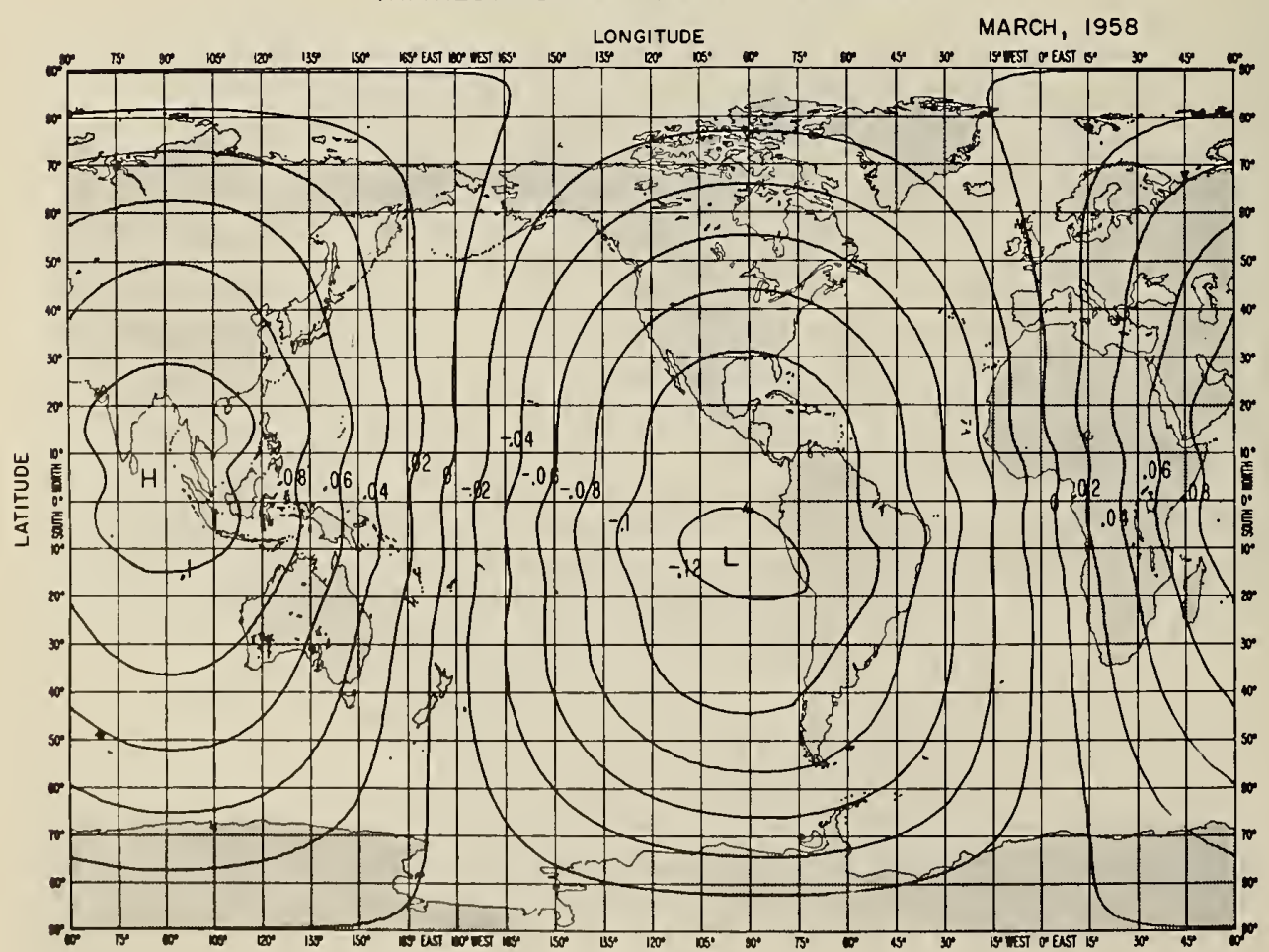


Figure $B-4$

CONTOUR MAP OF ORTHONORMAL FUNCTION $F_{24}(\lambda, \theta)$

(HIGHEST ORDER TERM $\sin ^{6} \times \cos \lambda \cos \theta$ )

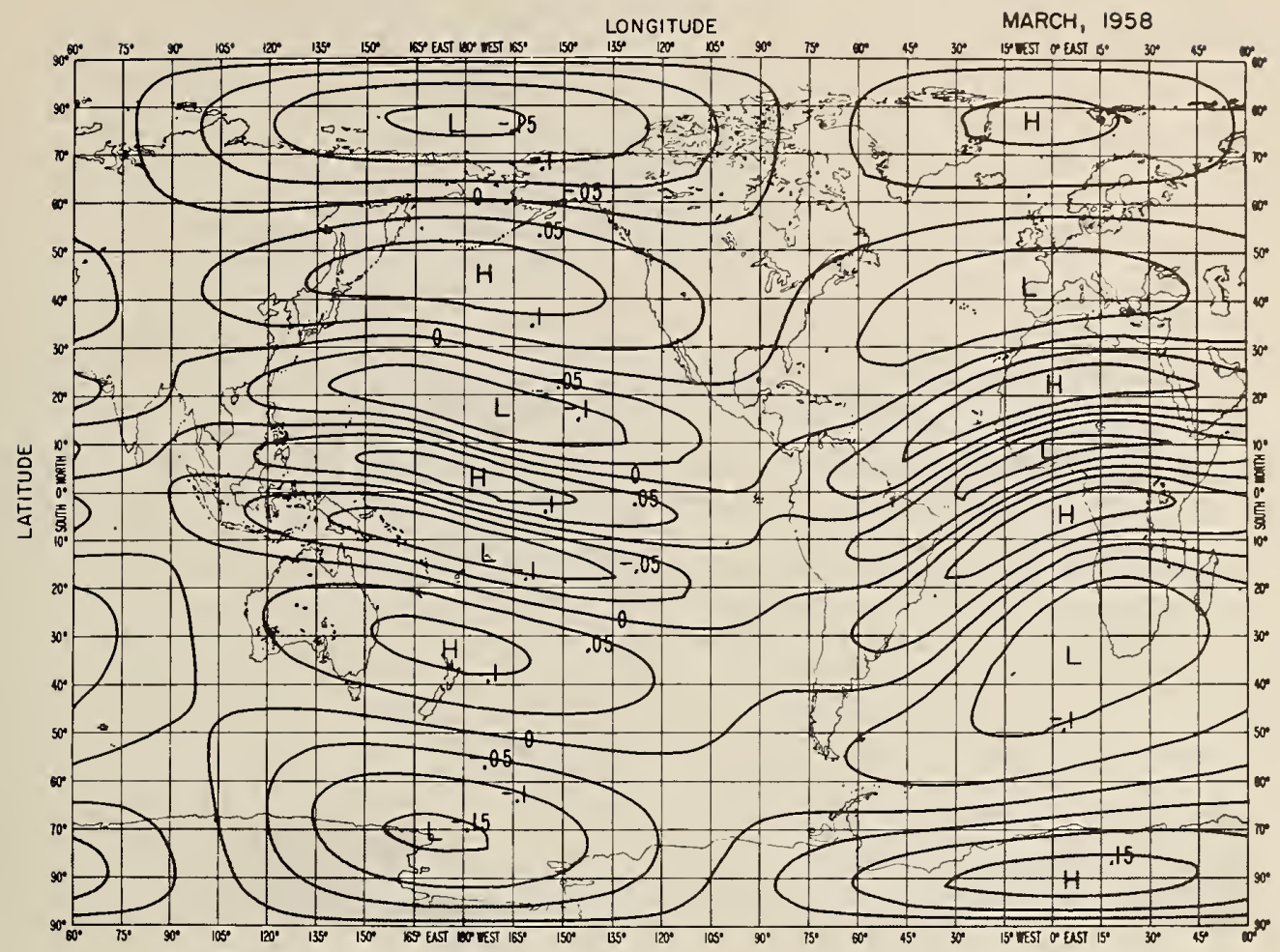

CONTOUR MAP OF ORTHONORMAL FUNCTION $F_{25}(\lambda, \theta)$

(HIGHEST ORDER TERM $\sin ^{6} \times \cos \lambda \sin \theta$ )

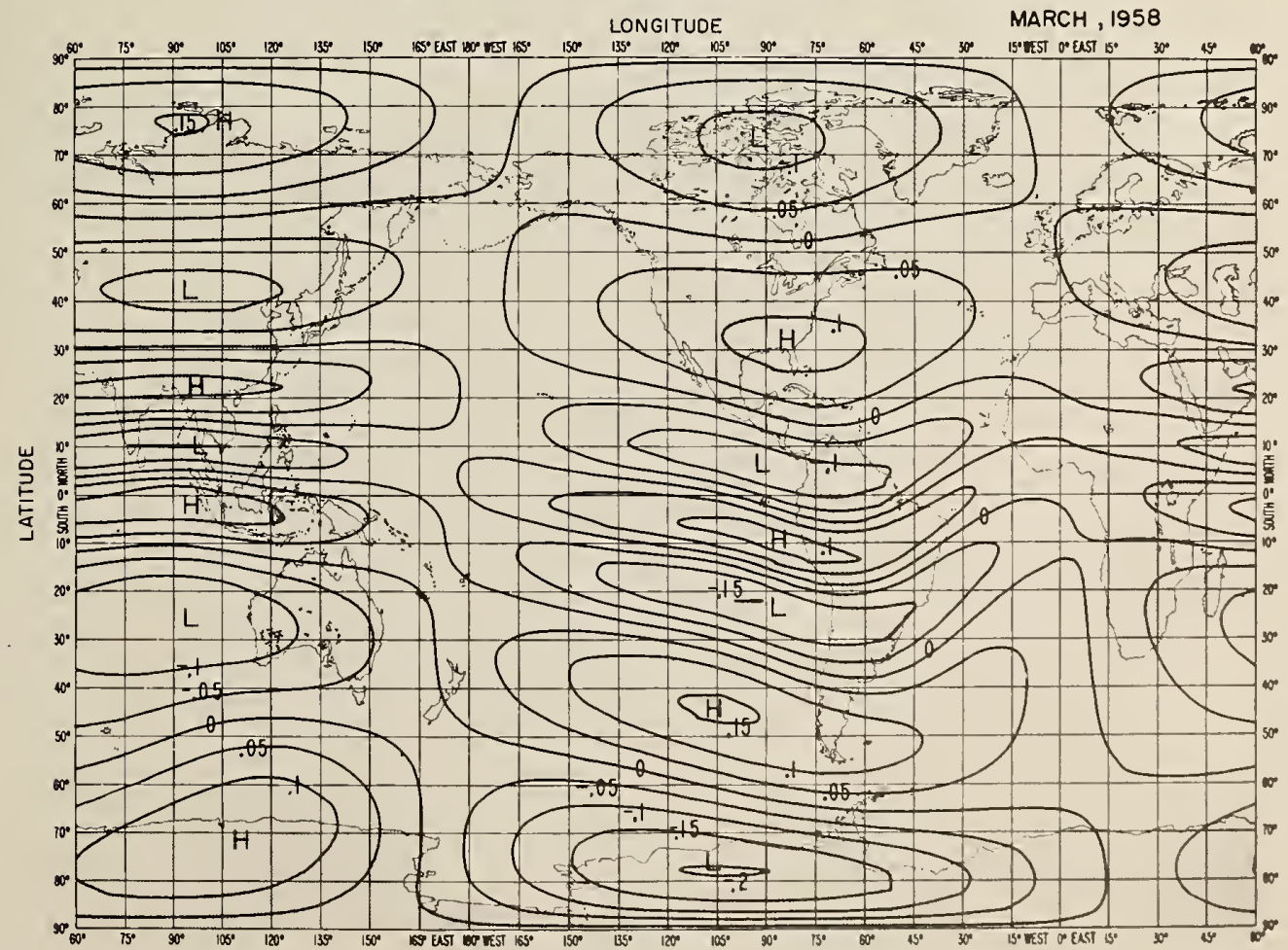

61 

Appendix C

Diurnal Variation

of

Orthonormal Coefficients $\mathrm{d}_{k}$ 
Figure C - I

DIURNAL VARIATION OF ORTHONORMAL COEFFICIENTS $d_{k}$
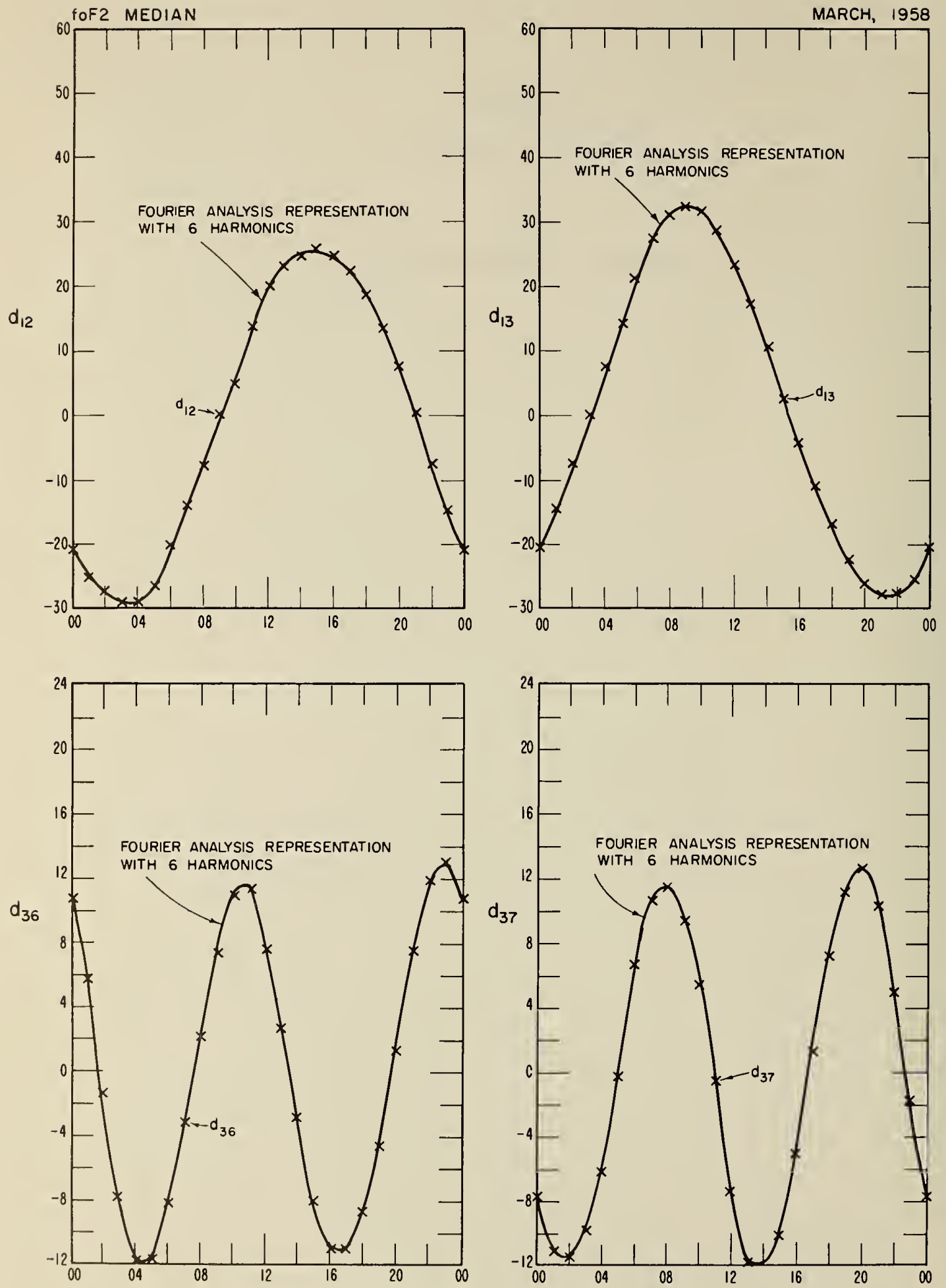

UNIVERSAL TIME 
Figure $\mathrm{C}-2$

DIURNAL VARIATION OF ORTHONORMAL COEFFICIENTS $d_{k}$
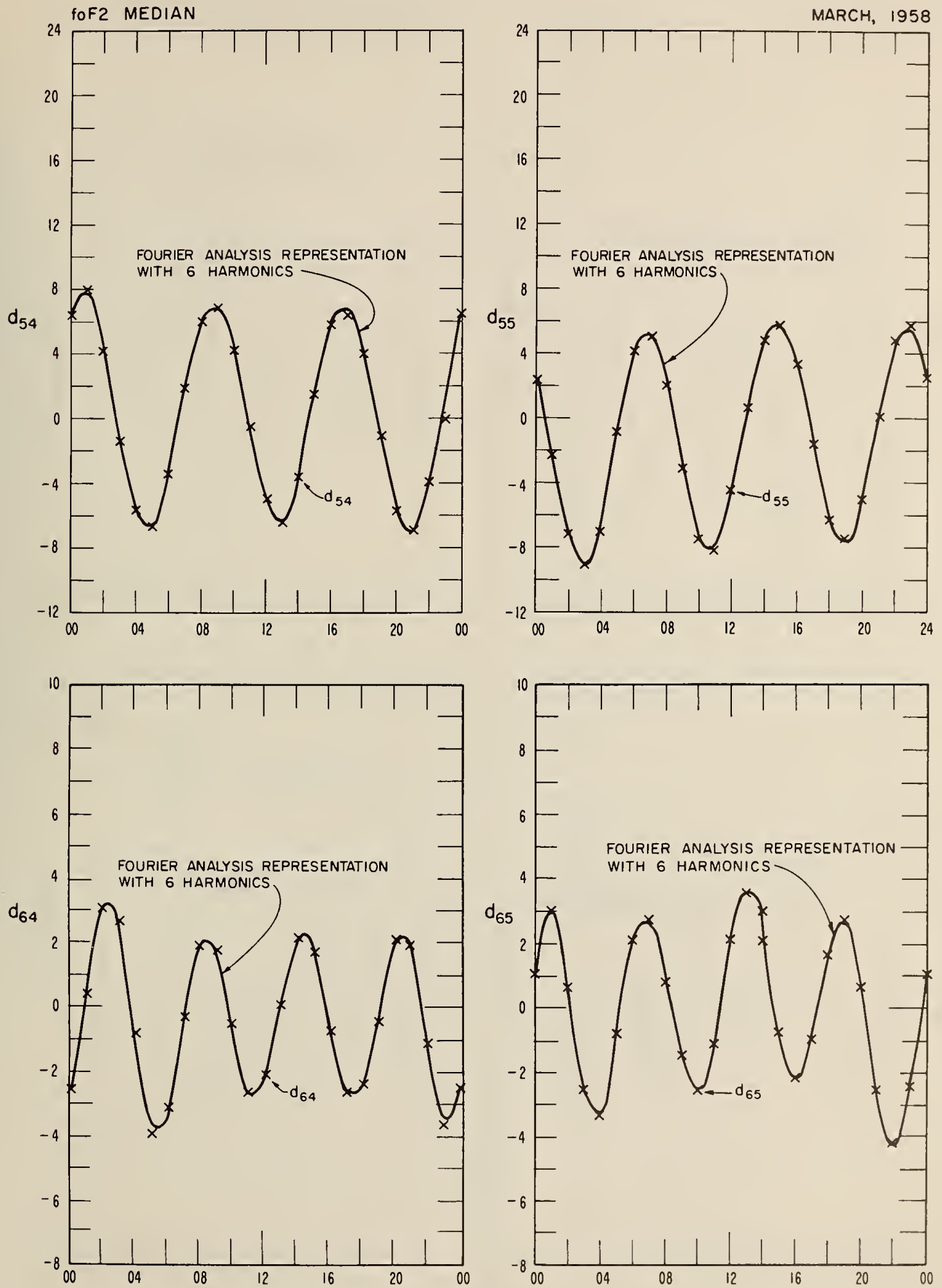

UNIVERSAL TIME 
Figure C - 3

DIURNAL VARIATION OF ORTHONORMAL COEFFICIENTS $d_{k}$

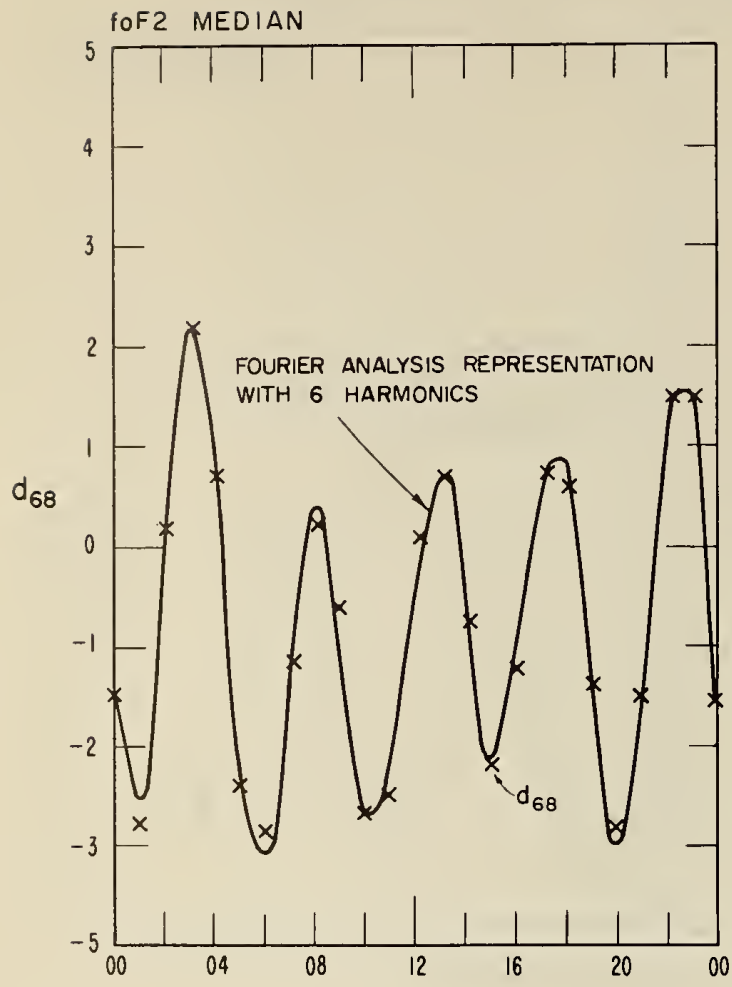

MARCH, 1958
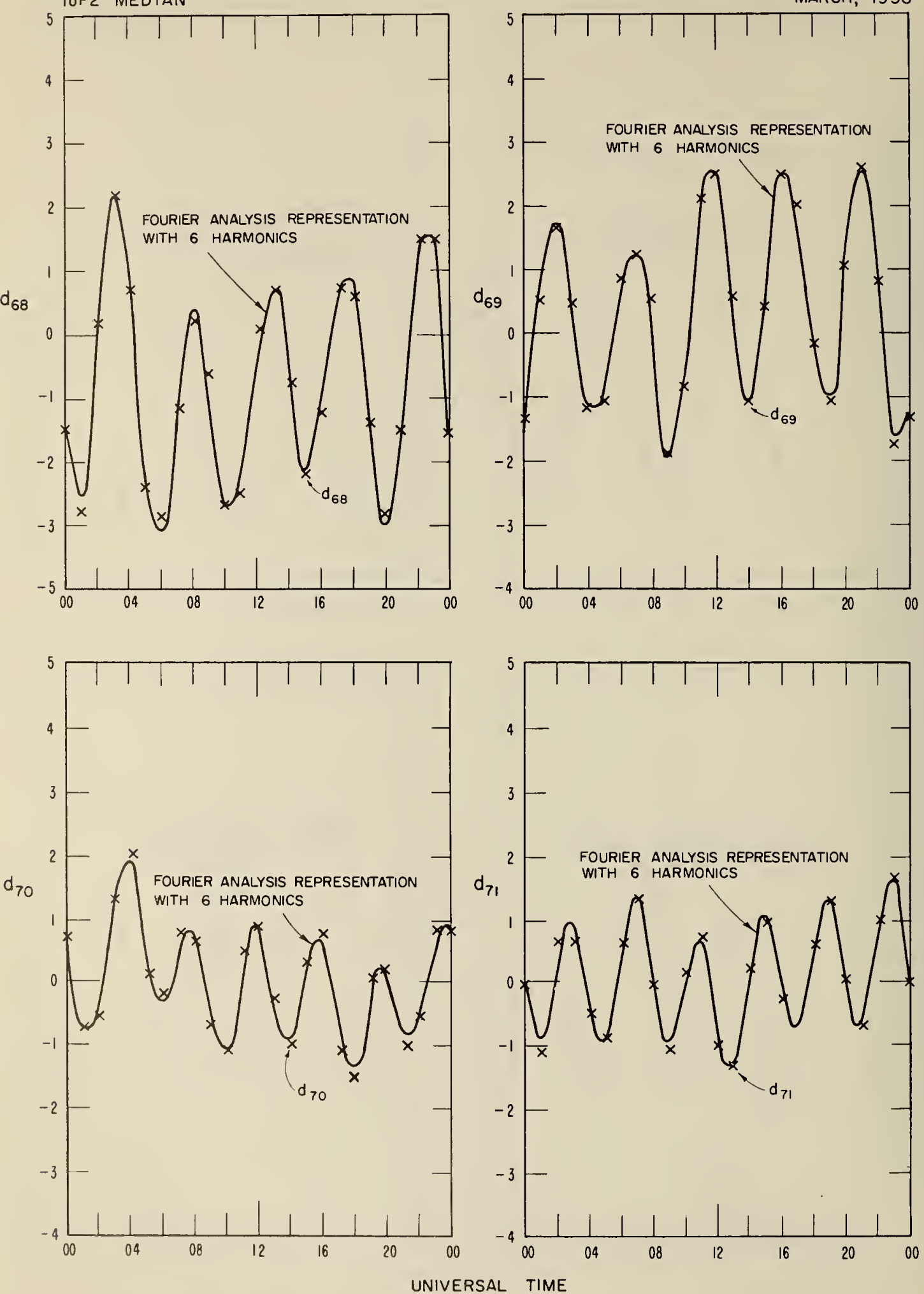
Figure C - 4

DIURNAL VARIATION OF ORTHONORMAL COEFFICIENTS $d_{k}$
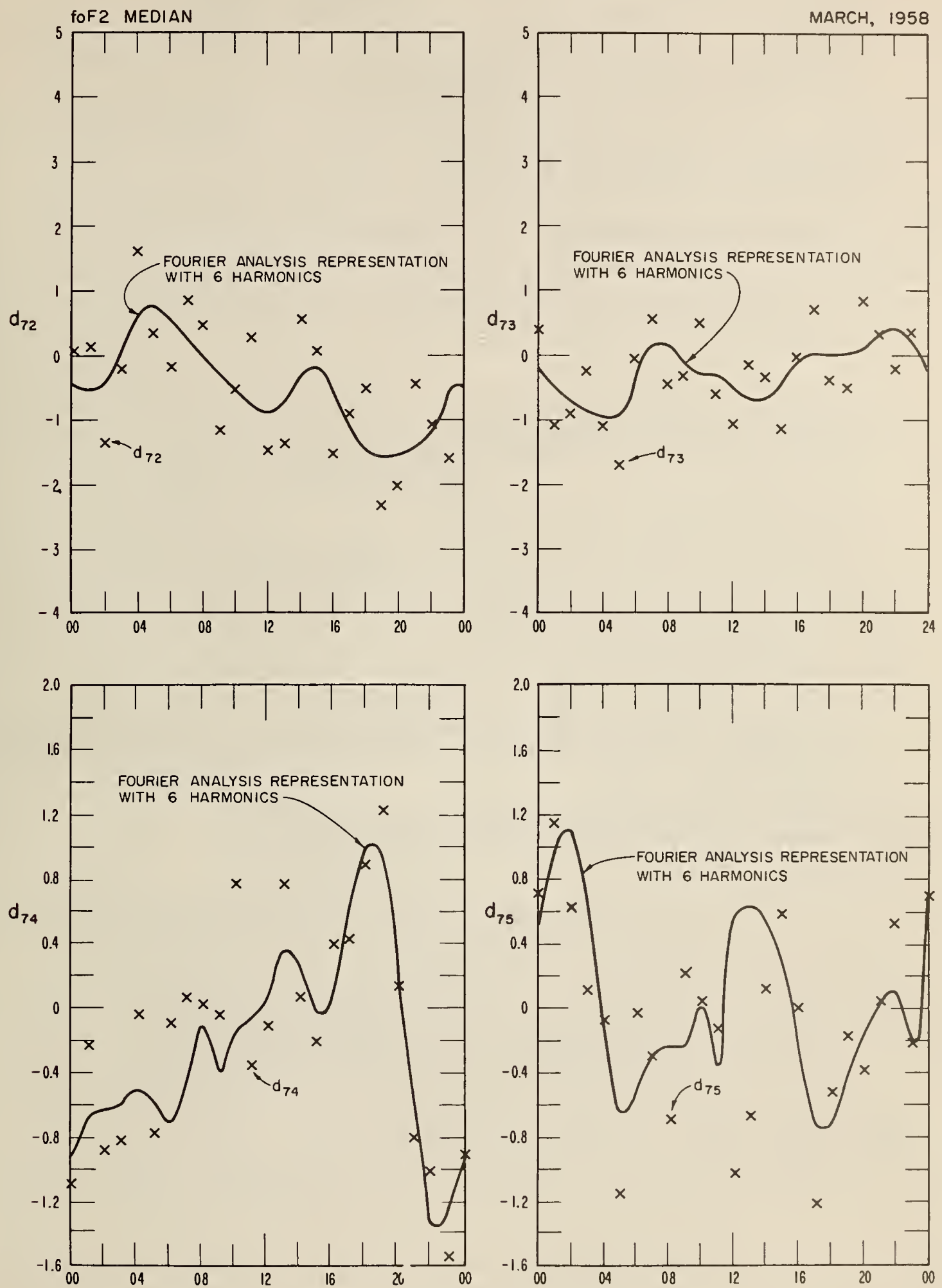

UNIVERSAL TIME 


\title{
Appendix D. SAMPLE Program Listing
}

\author{
PROGRAM SAMPLE \\ TYPE INTEGER CC1, CC2,CC3 \$ TYPE REAL M3000 \\ DIMENSION U(17,76), UM(17,76), FLON(100), FLAT(100),K(14),KM(14), \\ 1 COT $(8)$, SIT $(8), G(76), G M(76), P(3), C(3), \operatorname{COM}(3), A F(9), B F(9), A M(9)$, \\ $2 \operatorname{BM}(9), O M E G(24), T I M E(24), D F(76), D M(76)$ \\ $D A T A(P(3)=3 . E 5),(D R=.01745329),(R D=57.29578)$ \\ C \\ 10 READ $(60,1) C C 1, C C 2, C C 3, N P, N T, T I M E$ \$ IF (EOF,6ก)12,14 \\ 1 FORMAT $(3$ I $1,13,12,24 F 3.1)$ \\ C \\ 12 CALL EXIT \\ $14 \operatorname{READ}(60,2)$ (FLAT $(N), F L O N(N), N=1, N P)$ \\ 2 FORMAT $(20 F 4 \cdot 1)$ \\ C \\ CALL READ U(K,U) \$ NFF $=K(9)+1$ \$ GO TO $(15,16,18), C C 2$ \\ 15 I CODE $=K(12)$ \$ GO TO 20 \\ C \\ 16 I CODE $=4501 \$$ GO TO 20 \\ 18 CALL READ U(KM,UM) \$ NMF $=K M(9)+1$ \$ ICODE $=4508$ \\ 20 PRINT $3, C C 1, C C 2, C C 3, K(11)$, ICODE, K(13),K(14) \$ IF(CC1)200, InO \\ 3 FORMAT $(21$ HICARD COLIJMNS $1,2,3=3$ I $3,3 X, 4$ HDATEI $5,3 X, 14$ HCHARACTERIST I \\ ICI $5,3 X, 13$ HFUNCTION CODEI $4,3 X, 14$ HSUNSPOT NUMBERI $5 / 1 X$ ) \\ C \\ $10000199 N=1, N P$ \& $P=F L A T(N)$ \& $P(2)=F L O N(N)$ \& CALL MAGFIN(P,COM ) \\ $C C I=0$, COMPUTF DIURNAL C!JRVE,EACH PT • \\ $T M P=C O M(2) * C O M(2)+\operatorname{COM}(3) * \operatorname{COM}(3)$ \\ $C=R D * A T A N F(A T A N F(-C O M / S Q R T F(T M P)) / S Q R T F(\operatorname{COSF}(D R * P))) \quad E C(\Sigma)=F L O N(N)$ \\ $C(3)=P$ \& CALL GK(K,C,G) \$ GO TO(115,110,105),CC2 \\ 105 CALL GK(KM,C,GM) \$ CALL AJBJ(KM(10), NMF,UM,GM, AM,BM) \$ GO TO 115 \\ 110 GYF $=1.4 * S Q R T F(C O M * C O M+T M P)$ \\ 115 CALL AJBJ(K(10), NFF,U,G,AF,BF) \$ IF (CC3) 125,120 \\ $120 \mathrm{~T}=-180$. \$ GO TO 130 \\ $125 T=180 \cdot-F L O N(N)$ \\ 130 DO 179 I $=1,24$ \$ CALL SICOJT $(8, C O T, S I T, T)$ \\ CALL ABSICO(K(10), AF,BF,COT,SIT,OMEG(I))\$GO TO $(179,140,135), C C 2$ \\ 135 CALL ABSICC(KM(IO), AM,BM, COT,SIT,M30Oก)\$OMEG(I) =1.1*M3000*OMEG(I) \\ GO TO 170 \\ 140 OMEG (I ) =OMEG (I ) +GYF \\ $179 T=T+15$. \$ PR INT 4,P( 1$), P(2)$ \\ 4 FORMAT $(9 H$ LATITUDEF $5.1,3 \times$, 9HLONG ITUDEF 6.1$)$ \\ 199 PRINT 5,OMEG \$ GO TO 10 \\ 5 FORMAT $(3 X, 24 F 5.1)$ \\ CCI NOT=0, COMPUTE OMEGA FOR FIXED TIMES, VARYING POINTS \\ 200 DO $279 \mathrm{I}=1$, NT \$ T=15.*TIME(I)-180. \$ CALL SICOJT(8,COT,S!T,T) \\ CALL DKSICOINFF,K(10),U,SIT, COT,DF) \$ IF(ICZ.FQ.3)205,210 \\ 205 CALL DKSICO(NMF,KM(10),UM,SIT, COT, DII) \\ 210 DO $279 \quad N=1, N P$ \$ $P=F L A T(N) \$ P(2)=F L O N(N) \$ C A L L M A G F I N(P, C O M)$ \\ $T M P=\operatorname{COM}(2) * \operatorname{COM}(2)+C O M(3) * C O M(3) \$ C(2)=F \operatorname{LON}(N) \$ C(3)=P$ \\ $C=R D * A T A N F(A T A N F(-C O M / S Q R T F(T M P)) / S Q R T F(C O S F(D R * P)))$ \\ CALL GK $(K, C, G)$ \$CALL DKGK(NFF, G, DF, OMEGA) \$GO TO $(279,220,215), C C 2$ \\ 215 CALL GK(KM,C,GM) \$ CALL DKGK (NMF, GM, DM, M3000) \\ OMEGA $=1$. $1 * M 3000 * O M E G A$ \$ GO TO 279 \\ 220 OMEGA $=$ OMEGA+1.4*SQRTF $(C O M * C O M+T M P)$ \\ 279 PRINT 6,TIME(I),P(1),P(2), OMEGA \$ GO TO 10 \\ 6 FORMAT $\left(6 H U_{\bullet} T_{\bullet}=F 5.1,3 \times\right.$, 8HLATITUDEF5.1,3X, 24HEAST LONGITUDEF6.1, 3X
}


1,7 HOMEGA $=F 6.11$

END

C

SUBROUTINE MAGFIN(POS, UNE)

COMPUTE NASA MAGNETIC. FIELD COMPONENTS

DIMENSION $P(7,7), D P(7,7), C P(7), A O R(7), S P(7), P O S(3), U N E(3), C T(7,7)$, $1 \quad G(7,7), H(7,7)$

DATA $(P(1,1)=1),,(D P(1,1)=0 \cdot),(S P(1)=0),.(C P(1)=1),,(C T=2(0 \cdot)$,

$1.33333333, .26666667, .25714286, .25396825, .25252525,3(0 \bullet 1, .2$,

$2.22857142, .23809523, .24242424,4(0), .14285714, .19047619, .21212121$, $35(0), .11111111, .16161616,.6(0) \cdot), 009090909,14 ! 0.1 \%,(5=0 ., 0304112$,

$4.024035,-.031518,-.041794, .016256,-.019523,0 ., .021474,-.051253$,

$5.062130,-.045298,-.034407,-.004353,210.1,-.013381,-.024898$,

$6-.021795,-.019447, .003212,3(0.1,-.006496, .007008,-.000628, .021413$, $74(0.1,-.002044, .002775, .001051,5 ! 0.1, .000697, .000227,6 ! 0.1 .0001115$ $8),(H=8(0),-.057989, .033124,. .0 I 4870,-.011825,-.000796,-.075758$, $92(0.1,-.001579,-.004075, .010006,-.002,-.008735,310.1, .00021, .00043$ $13.004597,-.003406,4(0.1, .001385, .002421,-.000113,5(0 \bullet),-. n n 1228$, $2-.001116,6(0),-.000325.),(R D=57.2957795),(H C=6371200$ •)

$P 2=P O S(2) \$ P 1=P O S \$ I F(P 1-89.9) 2,4,1$

$1 \quad P 1=89.9 \$ P 2=0 \$ G O$ TO 4

2 I F $(P 1+89.9) 3,4,4$

3 P $1=-89.9 \$ P 2=0$

$4 \mathrm{PHI}=P 2 / R D \$ A R=H C /(H C+P O S(3)) \$ C=S I N F(\quad P I / R D) \$ S=S Q R T F(C P-C * C)$ $S P(2)=S I N F(P H I) \$ C P(2)=C O S F(P H I) \$ A O R=A R * A R \$ A O R(2)=A O R * A R \$ D O 5 \quad M=3,7$ $S P(M)=S P(2) * C P(M-1)+C P(2) * S P(M-1)$

$C P(M)=C P(2) * C P(M-1)-S P(2) * S P(M-1)$

$5 \quad A O R(M)=A R * A O R(M-1)$

$B V=0 . \$ B N=B V \$ B P H I=B V \$ D O \quad \& \quad N=2,7 \$ F N=N \$ S U M R=0 . \$ S U M T=S U M R R \$ S U M P=S U M T$ DO $7 M=1, N \$$ IF $(N-M) 8,9,8$

$9 P(N, N)=S * P(N-1, N-1) \$ D P(N, N)=S * D P(N-1, N-1)+C * P(N-1, N-1)$ S GO TO 10

$8 P(N, M)=C * P(N-1, M)-C T(N, M) * P(N)-2, M)$

$D P(N, M)=C * D P(N-1, M)-S * P(N-1, M)-C T(N, M) * D P(N-2, M)$

$10 F M=M-1 \$ T S=G(N, M) * C P(M)+H(N, M) * S P ! M) \$ S U M R=S U M R R+P(N, M) * T S$ SUMT $=S U M T+D P(N, M) * T S$

$B V=B V+A O R(N) * F N * S U M R$ क $B N=B N-A O R(N) * S U M T$

$6 \quad B P H I=B P H I-A O R(N) * S U M P S U N E(1)=-B V S U N E(2)=B N S ! U N E(3)=-B P H I / S$

RETURN \$ END

SUBROUTINE GK I K,C,G ,

C

COMPUTE COORDINATE FUNCTIONS,G(I),I $=1, \ldots, K+1$

C $C(1)=$ MODIFIED LATITUDE.C( 2$), C(3)=$ GEOG LAT . LONGITUDE, RESPECT IVELY DIMENSION $K(1), C(1), G(1)$

\section{DATA}

$(D R=.017453293),(N=8)$

$X=D R * C \quad \$ Y=C(2) * D R \$ Z=D R * C(3) \$ K O=K \$ S X=S I N F(X) \$ G(2)=5 \times \$ G=1$.

IF (KO.EQ.1) 12,4

4 DO $10 \quad I=2, K O$

$10 \mathrm{G}(\mathrm{I}+1)=S X * G(\mathrm{I})$

12 KDIF $=K(2)-K O \$$ IF (KDIF) 16,80

$16 \mathrm{~J}=1$ \$CXI=COSF $(Z)$ \& $C X=C X 1$ \$ $T=Y$

$18 K C=K(J)+4 \$ G(K C-2)=C X * \operatorname{COSF}(T) \$ G(K C-1)=C X * S I N F(T) \quad \$ I F(K D I F-2) 20,28$

$20 K N=K(J+1) \$ D O 22 I=K C, K N, 2 \Phi G(I)=S X * G(I-2)$

$22 \mathrm{G}(\mathrm{I}+1)=S X * \mathrm{G}(\mathrm{I}-1)$

28 IF (J.EQ.N) 80,30

$30 K D I F=K(J+2)-K N$

$\$ I F(K D I F) 32,80$ 
$32 C X=C X * C X 1 \Phi J=J+1$ \& $F J=J$ I $T=F J * Y$ \& $\quad$ GO TO 18

80 RETURN

END

SUBROUTINE READ U(K,U)

DIMENSION $K(1), U(17,1)$

READ $(60,1) K D,(K(I), I=1,10),(K(I), I=12,14)$, DATA,K(I), NCARDS

1 FORMAT (I I, 13 I5,6X,A I, I 4, I 3 )

$M X=K(9)+1$ \$DO $5 \mathrm{I}=1,17 \$ D O 5 \mathrm{~J}=1, M X$

$5 U(I, J)=0 \$ D O 25 \quad I=1, N C A R D S$

READ $(60,2)$ I I,MI,D1, I 2,M2,D2, I 3,M3,D3, I 4, M4,D4, DATUM,KDATE, ID

2 FORMAT(4) 2 I $2, E 14.7), A 1, I 4, I 3)$

$L 1=I 1+1 \quad \$ \quad L 2=I 2+1 \quad \$ \quad L 3=I 3+1 \quad \$ \quad L 4=I 4+1 \quad \$ M I=M I+1 \quad \$ \quad M 2=M 2+1$

$M 3=M 3+1 \$ M 4=M 4+1$ \$ IF $(K(11) \cdot E Q \cdot K U A T E) 10,30$

10 IF( DATA.EQ. DATUM) 15,30

15 IF (ID.EQ. I ) 16,30

$16 U(L I, M I)=D 1 \$ I F(I, L T \cdot N C A R D S) 18,20$

$18 U(L 2, M 2)=D 2 \$ U(L 3, M 3)=D 3 \$ G O$ TO 25

20 IF ( I 2$) 21,28$

$21 U(L 2, M 2)=D 2 \$$ IF (I 3$) 22,28$

$22 U(L 3, M 3)=D 3 \$$ IF $(I 4) 25,28$

$25 U(L 4, M 4)=D 4$

28 RETURN

30 PRINT 3, ID,K $(11), K(12)$

3 FORMAT (23HI ERROR IN CARD NUMBER I3,2 I 5 )

CALL EXIT

END

SUBROUT INE DKSICO (MX, LH, D, SITIME, COT IME, DK)

DIMENSION D $(17,1)$, COTIME (1), SITIME (1), DK (1)

DO $5 K=1, M X$

$D K(K)=D(1, K)$

DO $5 \mathrm{~L}=1, \mathrm{LH}$

$5 D K(K)=D K(K)+D(2 * L, K) * S I T I M E(L)+D(2 * L+1, K) * \operatorname{COTIME}(L)$ RETURN

END

SUBROUTINE DKGK (MX,G,DKSTAR, OMEGA) DIMENSION $G(1)$, DKSTAR $(1)$

OMEGA $=$ G*DKSTAR

DO $5 \quad K=2, M X$

5 OMEGA $=$ OMEGA+DKSTAR $(K) * G(K)$

RETURN

END

SUBROUT INE AJBJ (LH, MX,D, G, ASTAR, BSTAR)

DIMENSION D (17, 1), G( 1), ASTAR(1), BSTAR(1)

$N=L H+1$

DO $5 J=1, N$

$\operatorname{ASTAR}(J)=0$

DO $5 \mathrm{~K}=1, M X$

$5 \operatorname{ASTAR}(J)=\operatorname{ASTAR}(J)+D(2 * J-1, K) * G(K)$

DO $10 \mathrm{~J}=2, \mathrm{~N}$

$\operatorname{BSTAR}(J)=0$. 
DO $10 \mathrm{~K}=1, M X$

$10 \operatorname{BSTAR}(J)=B \operatorname{STAR}(J)+D(2 * J-2, K) * G(K)$

RETURN

END

C

SUBROUTINE ABSICO(LH, ASTAR, BSTAR, COTIME, SITIME, OMESA)

C COMPUTE OMEGA, SUMMING THE FOURIER SERIES

DIMENSION COTIME( 1 ), SITIME (1), ASTAR(1),BSTAR(1)

OMEGA = ASTAR

DO $5 \mathrm{~J}=1$, LH

$5 \operatorname{OMEGA}=\operatorname{OMEGA}+\operatorname{ASTAR}(J+1)$ \#COTIME $(J)+B S T A R(J+1) * \operatorname{SITIME}(J)$ RETURN

END

SUBROUTINE SICOJT (L,C,S,A)

C COMPUTE SIN $(J T), \operatorname{COS}(J T), J=1, \ldots, L$ FOR ANGLE A DIMENSION $C(1), 5(1)$

$T=.01745329 * A$ \& $C=\operatorname{COSF}(T) \quad \& \quad S=\operatorname{SINF}(T)$ \& DO $10 \quad \mathrm{I}=2, \mathrm{~L}$ $C(I)=C * C(I-1)-S * S(I-I)$

$10 S(I)=C * S(I-1)+S * C(I-I)$ \& RETURN

END 



TECHNICAL NOTE no. 338 - NOT ISSUED 
